\title{
Revision of the "euryglossiform" species of the Afrotropical bee genus Scrapter Lepeletier \& Serville, 1828 (Hymenoptera: Apoidea: Colletidae)
}

\author{
Michael KUHLMANN \\ Department of Life Sciences, Natural History Museum, Cromwell Road, London, SW7 5BD, UK. \\ E-mail: m.kuhlmann@nhm.ac.uk \\ urn:Isid:zoobank.org:author:B99AE0ED-FA89-4DFE-A658-1C8DF37F9FAB
}

\begin{abstract}
The South African endemic bees of the "euryglossiform" species of the genus Scrapter Lepeletier $\&$ Serville, 1828 are revised and illustrated. The species-group is defined for the first time and comprises 20 species, 16 of which are described here as new: Scrapter exiguus sp. nov. ㅇ, 0 , S. gessorum sp. nov.

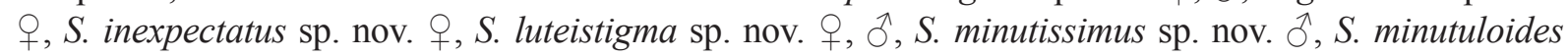
sp. nov. , S. minutus sp. nov. ㅇ, S. nanus sp. nov. ㅇ, o, S. nigerrimus sp. nov. ㅇ, S. nigritarsis sp. nov.

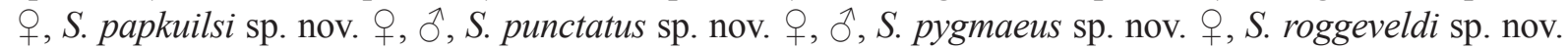

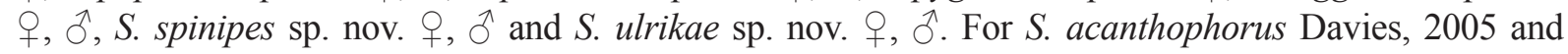
S. sittybon Davies, 2005 the female is here described for the first time. A key to all species is provided.
\end{abstract}

Key words. Scrapter, bees, South Africa, new species, taxonomy

Kuhlmann M. 2014. Revision of the "euryglossiform" species of the Afrotropical bee genus Scrapter Lepeletier \& Serville, 1828 (Hymenoptera: Apoidea: Colletidae). European Journal of Taxonomy 95: 1-69. http://dx.doi. org/10.5852/ejt.2014.95

\section{Introduction}

The bee genus Scrapter Lepeletier de Saint-Fargeau \& Audinet-Serville, 1828 currently comprises 43 described species (Eardley \& Urban 2010) and is largely restricted to southern Africa with a single record from Kenya (Davies et al. 2005). The centre of diversity and endemism of Scrapter is the Greater Cape Floristic Region (GCFR) in the winter rainfall area of western South Africa (Kuhlmann 2009). Alleged records from Uganda (Munyuli 2013 and previous publications) are based on fabricated data and have been retracted.

Many Scrapter species seem to be geographically restricted and specialized flower visitors, partly with short seasonal and daily flight periods, that are easily overlooked (Eardley 1996; Kuhlmann \& Eardley 2012). Intensive collecting in the past ten years has revealed an unexpectedly high number of undescribed species and new large samples of taxonomically difficult species complexes have become available (Kuhlmann, unpubl.). This freshly collected material now allows for a critical reevaluation of previous taxonomic decisions. Eventually, the number of Scrapter species will likely be $>100$, probably making it the most speciose bee genus in the GCFR and, thus, an ideal model for studying pollinator diversification. 
As a group Scrapter is easily identifiable as it is the only hairy colletid bee genus in Africa with two submarginal cells, but there is a huge intrageneric morphological diversity (Davies \& Brothers 2006; Michener 2007). Scrapter was first revised by Eardley (1996), who recognized 31 species, and later Davies et al. (2005) and Davies \& Brothers (2006) described an additional twelve species and documented in detail the diverse morphology of the genus. The morphological diversity of Scrapter is also a major obstacle for a better understanding of intrageneric relationships within the genus. Michener (2007: 171f) divided Scrapter in two groups and stated that some of the characters he used are (sub)generic characters in other bee groups. However, because some Scrapter species combine these characters this makes a clear definition of groups difficult. These problems can partly be remedied once more specimens and species become available that allow for a more comprehensive assessment of individual variation and characters, hopefully leading to a better definition and circumscription of species-groups than previously possible.

The "euryglossiform" Scrapter are a good example of taxonomic confusion caused by the lack of sufficient material and highlight the need for further collecting. Differences between species are often subtle and can only be recognized by comparing series of specimens. Consequently, the few available specimens of the species-group, although representing different taxa, were initially interpreted as a single species, $S$. albitarsis (Friese, 1909) and assigned to the heterogenous S. flavostictus Cockerell, 1934 species-group (Eardley 1996). Three more species of the group were described and relationships discussed by Davies et al. (2005) based on males only: S. acanthophorus Davies, 2005 (related to $S$. albitarsis $=$ S. flavostictus species-group of Eardley (1996)), S. glareus Davies, 2005 (relation unclear, but resembles $S$. niger Lepeletier \& Serville, $1828=S$. bicolor Lepeletier \& Serville, 1828 speciesgroup of Eardley (1996)) and S. sittybon Davies, 2005 (relation unclear but similar to $S$. calx Eardley, 1996 (= S. flavostictus species-group) and S. nitidus (Friese, 1909) (= S. nitidus species-group of Eardley (1996)).

The divergent assignment of the four species to species-groups illustrates the present state of Scrapter systematics and the need for a comprehensive taxonomic and phylogenetic study including the full extent of the (undescribed) diversity to identify intrageneric relationships and monophyletic groups. As a first step towards this goal and based on 954 specimens mainly collected in the last ten years, the species-group of "euryglossiform" Scrapter is here defined for the first time. Within this group 16 new species and the females of two other species are described for the first time.

\section{Material and methods}

Terminology for the description of species is based on Michener (2007) for general morphology and for surface sculpturing Harris (1979) is followed. Puncture density is expressed as the relationship between puncture diameter (d) and the space between them (i), such as $\mathrm{i}=1.5 \mathrm{~d}$ or $\mathrm{i}<\mathrm{d}$. The following abbreviations were used for morphological structures:

$$
\begin{aligned}
\mathrm{T} & =\text { metasomal tergum } \\
\mathrm{S} & =\text { metasomal sternum } \\
\mathrm{B} 1 & =\text { body length }
\end{aligned}
$$

Body length was measured from the vertex to the apex of the body.

Acronyms for collections where specimens are deposited, are as follows:

$$
\begin{aligned}
& \text { AMGS }=\text { Albany Museum, Grahamstown, South Africa } \\
& \text { CUIC }=\text { Cornell University Collection, Ithaca, USA } \\
& \text { EMUS }=\text { Entomological Museum, Utah State University, USA }
\end{aligned}
$$


PCYU = Laurence Packer collection of York University, Toronto, Canada

NHML $=$ Natural History Museum, London, UK

RCMK = research collection of Michael Kuhlmann, London, UK

$\mathrm{SANC}=$ South African National Collection of Insects, Pretoria, South Africa

ZMHB = Museum für Naturkunde der Humboldt-Universität, Berlin, Germany

Nomenclature of plant names follows Germishuizen \& Meyer (2003).

If not given on the labels, coordinates of collecting sites were identified using Microsoft Encarta ${ }^{\circledR}$ World Atlas (version 10, 2001). Distribution maps are not included in this paper because all species are only known from a few or even only a single locality.

Scanning electron microscopy (SEM) was carried out using a Leo 1455VP. The backscattered electron images were taken under low vacuum (variable pressure) of uncoated specimens. In this mode electronpoor organic material appears darker than electron-rich material (e.g., pins, soil dust particles) consisting of heavier chemical elements.

The following abbreviations are used for collectors:

$\mathrm{KT}=\mathrm{K}$. Timmermann

$\mathrm{MK}=\mathrm{M}$. Kuhlmann

\section{Results}

Class Hexapoda Blainville, 1816

Order Hymenoptera Linnaeus, 1758

Superfamily Apoidea Latreille, 1802

Epifamily Anthophila Latreille, 1804

Family Colletidae Lepeletier, 1841

Subfamily Scraptrinae Ascher \& Engel, 2005

Genus Scrapter Lepeletier \& Serville, 1828

Scrapter Lepeletier \& Serville, 1828: 403 (not Scrapter Lepeletier, 1841: 260). Type species: Scrapter bicolor Lepeletier and Serville, 1828, by subsequent designation in Vachal (1897: 63). (For later type designations and confusion with Scrapter Lepeletier, see Michener 1997.)

Polyglossa Friese, 1909: 123. Type species: Polyglossa capensis Friese, 1909, by subsequent designation in Cockerell (1921: 203). (For a later type designation by Sandhouse, see Michener 1997.)

Strandiella Friese, 1912: 181. Type species: Strandiella longula Friese, $1912=$ Scrapter niger Lepeletier \& Serville, 1828, by subsequent designation in Cockerell (1916: 430).

Polyglossa (Parapolyglossa) Brauns, 1929: 134. Type species: Polyglossa heterodoxa Cockerell, 1921, by subsequent designation in Sandhouse (1943: 584) (see Michener 1997).

Detailed diagnoses and descriptions of Scrapter were provided by Eardley (1996), Engel (2005), Davies \& Brothers (2006) and Michener (2007), so they are not repeated here. Regarding the availability of Scrapterini versus Scraptrinae see Ascher \& Engel (2006). Scrapter shows an unusual level of intrageneric diversity, described in detail by Davies \& Brothers (2006), so various authors suggested that after revision the genus could be split up into several (sub)genera (Engel 2005; Melo \& Gonçalves 2005; Michener 2007). The current system of species-groups suggested by Eardley (1996) does not convincingly reflect this diversity, as it partly contains morphologically heterogenous and presumably 
paraphyletic species-groups. The S. flavostictus-group is an example of such an inhomogeneous assemblage and includes the first described "euryglossiform" Scrapter, S. albitarsis. This species and its relatives are here transferred to a new species-group.

\section{The group of "euryglossiform" Scrapter}

The term "euryglossiform" Scrapter is introduced here for a group of morphologically monotonous species, including the smallest bees of the genus $(3.5-7.0 \mathrm{~mm})$, that are predominantly black, often with yellow markings on the legs. This species-group can also be referred to as the $S$. albitarsis-group, named after the first described species. In their body shape, sparse pilosity, surface sculpture and narrow groove-like facial fovea they superficially resemble andreniform Euryglossinae. These similarities might be convergent (Michener 2007: 171) but potentially reflect the presumed sister-group relationship of the Australian Euryglossinae and Scraptrinae (Almeida \& Danforth 2009).

The species of the "euryglossiform" Scrapter are characterized by a) a sulcus-like facial fovea with an invisible bottom as in Hylaeus (e.g., Fig. 1D), b) basitibial plate of female with simple marginal carinae, c) body small, without metasomal hair bands in females and most males, and d) membraneous apicolateral lobes on male S7 (e.g., Fig. 5D), sometimes reduced to small structures, in nine of the 14 species where the males are known. In other Scrapter species these lobes, that are a common feature in many colletid genera, are only known in a much more reduced form from some species of the $S$. nitidus-group. This group also shares the narrow facial fovea and the shape of male genitalia with the "euryglossiform" Scrapter and might be their closest relatives as Davies et al. (2005) already suggested in their description of $S$. acanthophorus.

As relationships of species within the "euryglossiform" Scrapter are not clear, they are listed in alphabetical order.

\section{Species of "euryglossiform" Scrapter}

\section{Scrapter acanthophorus Davies, 2005}

Figs 1-2

Scrapter acanthophorus Davies, 2005: 153-155, figs 4-8, holotype $\overparen{\partial}$ (type locality: Knersvlakte, 30 km north of Vanrhynsdorp, South Africa) (SANC).

\section{Diagnosis}

The female of $S$. acanthophorus is here described for the first time. It can be separated from other species of this group by the combination of the following characters: clypeus distinctly convex (Fig. 1C-D), foretibia dominantly blackish-brown, stigma brown, apical margins of metasomal terga broadly brownish translucent, terga between punctures smooth and shiny (Fig. 1B). The male is characterized by an unmodified antenna, hind tibia apically broadened inside forming a spine (Fig. 2E), coarsely but more sparsely punctate scutum and metasomal terga (Fig. 2C) and the form of S7 (Fig. 2D).

\section{Material examined (25 specimens)}

SOUTH AFRICA: 1 + W. Cape, Knersvlakte, Sukkulent Karoo, $40 \mathrm{~km} \mathrm{~N}$ of Vanrhynsdorp, Farm Kalkgat, 140 m, 31 ${ }^{\circ} 07^{\prime} 04^{\prime \prime}$ S, 18 $8^{\circ} 55^{\prime} 18^{\prime \prime}$ E, 10 Sep. 2003, KT (RCMK); 1 \&, W. Cape, Knersvlakte,

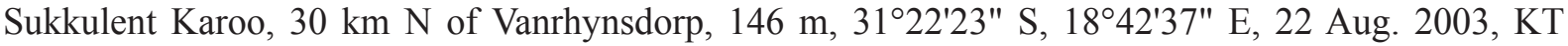

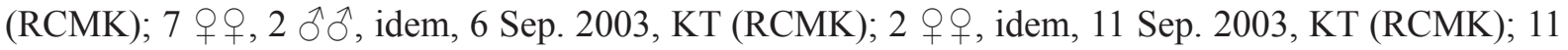

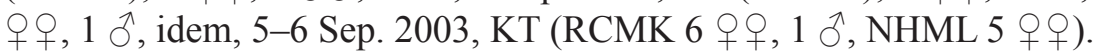




\section{Description}

\section{Female}

Body LENGTH. 6.0-6.5 mm.

HEAD. Head wider than long. Integument black except part of mandibles dark reddish-brown. Face sparsely covered with long, greyish, erect hair (Fig. 1C). Clypeus strongly convex with coarse punctation,
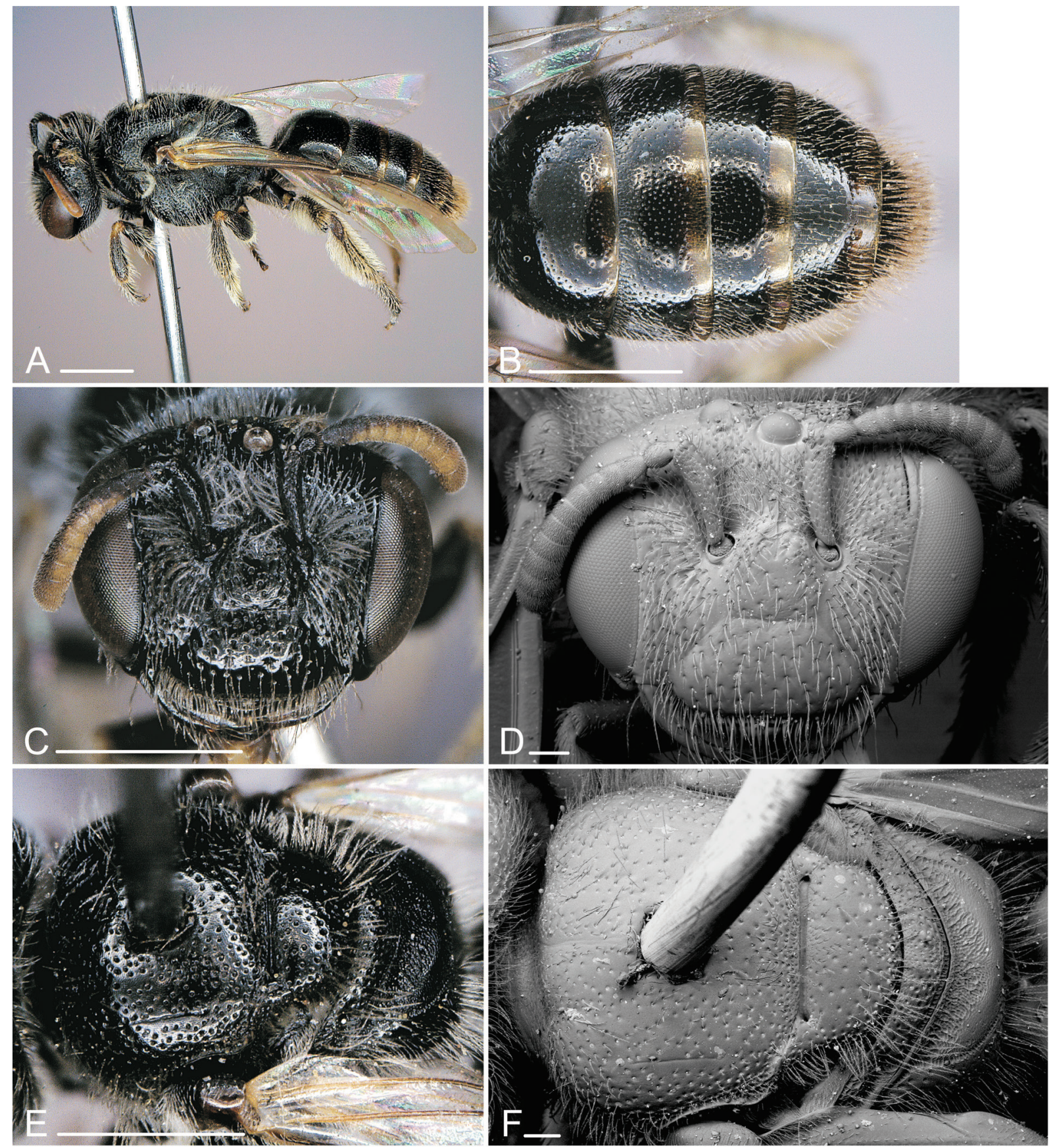

Fig. 1. Scrapter acanthophorus Davies, 2005, o. A. Lateral view. B. Metasoma (dorsal view). C. Head. D. Head (SEM). E. Thorax (dorsal view). F. Thorax (dorsal view, SEM). Scale bars: photos: $1 \mathrm{~mm}$, SEM: $0.1 \mathrm{~mm}$. 
apically sparse $(i=2-3 \mathrm{~d})$, basally dense $(i=0.5-1 \mathrm{~d})$; surface between punctures apically smooth and shiny, basally superficially shagreened and slightly matt (Fig. 1C-D). Malar area medially narrow, almost linear. Antenna dorsally blackish-brown, ventrally yellowish-brown.

Mesosoma. Integument black. Mesoscutal disc between punctures superficially shagreened but shiny; disc densely $(\mathrm{i}=0.5-1.0 \mathrm{~d})$ and coarsely punctate (Fig. 1E-F). Metanotum slightly shorter than basal area of propodeum, apically with narrow carinate depression (Fig. 1F). Propodeum basally finely but
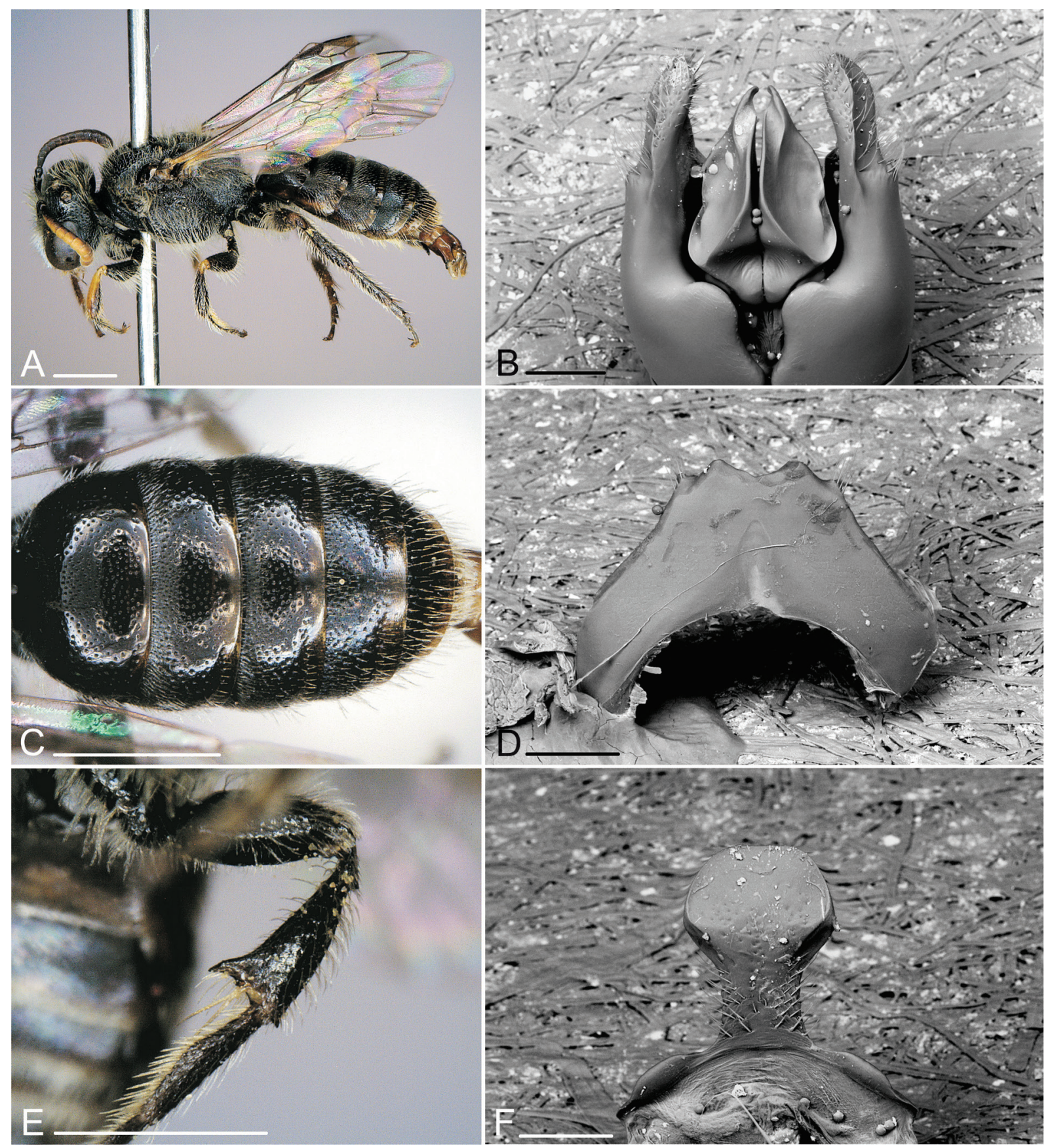

Fig. 2. Scrapter acanthophorus Davies, 2005, ô. A. Lateral view. B. Genitalia (dorsal view, SEM). C. Metasoma (dorsal view). D. S7 (dorsal view, SEM). E. Hind tibia. F. S8, apical end (SEM). Scale bars: photos: $1 \mathrm{~mm}$, SEM: $0.1 \mathrm{~mm}$. 
broadly carinate (Fig. 1F). Mesoscutum, scutellum, metanotum, mesepisternum and propodeum sparsely covered with short, greyish, erect hair (Fig. 1A).

WINGs. Slightly yellowish-brown; wing venation and stigma brown.

LEGs. Integument black to dark reddish-brown; fore and mid tibia basally with small yellowish spot. Vestiture greyish-white, scopa greyish-white.

Metasoma. Integument black, apical margins of terga broadly translucent yellowish to reddish-brown (Fig. 1B). Discs of T1 and T2 without hair, laterally sparsely covered with long erect greyish-white hair; following terga with increasingly more and longer hair; T3-T4 basally with a very narrow and sparse band of very fine, short, erect hair; apical tergal hair bands missing on all terga (Fig. 1B). Prepygidial and pygidial fimbriae greyish-brown. T1 densely $(i=1 \mathrm{~d})$ but finely punctate, between punctures polished and shiny; T2-T4 shiny, with dense, fine, superficial punctation; T2-T4 with polished broad apical tergal depression (Fig. 1B).

\section{Male}

Body LENGTH. 5.2-6.0 mm.

HEAD. Head slightly wider than long. Integument black, except mandible partly dark reddish-brown. Face densely covered with long, greyish-white, erect hair. Malar area medially narrow, almost linear. Antenna dorsally dark brown, ventrally yellowish-brown (Fig. 2A).

Mesosoma. Integument black. Mesoscutal disc between punctures superficially shagreened but shiny; disc densely $(\mathrm{i}=0.5-1.0 \mathrm{~d})$ and coarsely punctate. Mesoscutum, scutellum, metanotum, mesepisternum and propodeum covered with long, greyish, erect hair.

WINGS. Slightly yellowish-brown; wing venation and stigma brown.

LEGS. Integument black, fore tarsi and inner side of fore tibia yellow, base of mid tibia with small yellow spot (Fig. 2A). Hind tibia inside apically broadened, with a spine; hind basitarsus medially broadened (Fig. 2E). Vestiture greyish-white.

Metasoma. Integument black, apical margins of terga broadly translucent yellowish to reddish-brown (Fig. 2C). Discs of T1-T3 without hair, laterally sparsely covered with short, erect greyish-white hair; following terga with increasingly more and longer hair; T2-T4 basally with a very narrow and sparse band of very fine, short, erect hair; apical tergal hair bands missing on all terga (Fig. 2C). T1 and following terga densely ( $\mathrm{i}<0.5-1 \mathrm{~d}$ ) but finely punctate, between punctures polished or superficially sculptured, shiny to slightly matt; terga with broad, polished to superficially sculptured but shiny apical tergal depression (Fig. 2C). S3 and particularly S4-S5 with long apical hair fringes.

Terminalia. Genitalia (Fig. 2B), S7 (Fig. 2D) and terminal plate of S8 (Fig. 2F) as illustrated.

\section{Distribution}

The species is only known from the Knersvlakte, a semi-desert plane in southern Namaqualand.

\section{Floral hosts}

Unknown.

\section{Seasonal activity}

August-September. 
Scrapter albitarsis (Friese, 1909)

Figs 3-5

Polyglossa albitarsis Friese, 1909: 87, 124, holotype ổ (type locality: Steinkopf, South Africa) (ZMBH).

\section{Diagnosis}

The female of $S$. albitarsis can be separated from other species of this group by the combination of the following characters: facial fovea short (Fig. 4A), scutum sparsely punctate, looking almost impunctate and shiny (Figs 3C-D, 4C-D), mesepisternum strongly reticulate, stigma brown, apical margins of metasomal terga either black or just very slightly translucent (Fig. 3E-F). The male is characterized by an unmodified antenna, simple and black hind tibia, hind basitarsus yellowish (Fig. 5A), S7 with apicolateral lobes and apical emargination broad and shallow (Fig. 5D).

\section{Material examined (370 specimens)}

SOUTH AFRICA: 2 $ふ$,$~ N$. Cape, $2 \mathrm{~km} \mathrm{NW}$ of Nieuwoudtville, route to Grasberg, $742 \mathrm{~m}, 31^{\circ} 21^{\prime} 17^{\prime \prime} \mathrm{S}$, $19^{\circ} 05^{\prime} 49^{\prime \prime}$ E, 26 Aug. 2006, KT (RCMK); 1 , Nieuwoudtville, Flower Reserve East, 735 m, 31 $1^{\circ} 21^{\prime} 55^{\prime \prime}$

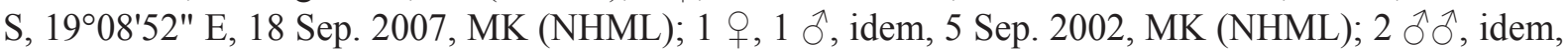

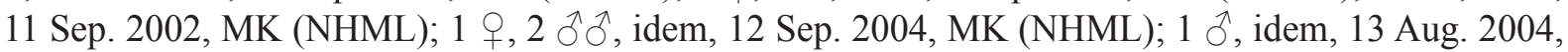

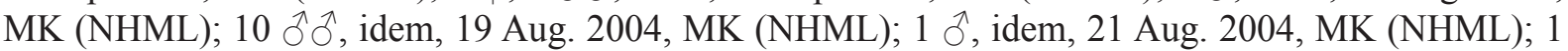

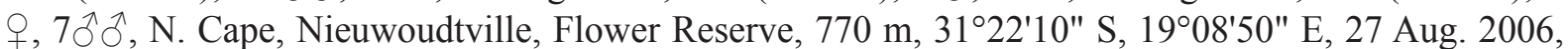

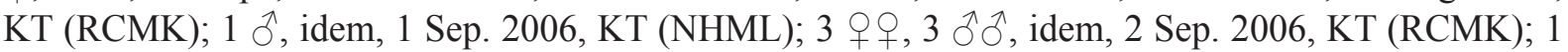

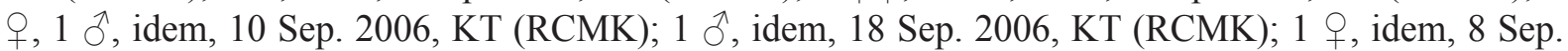

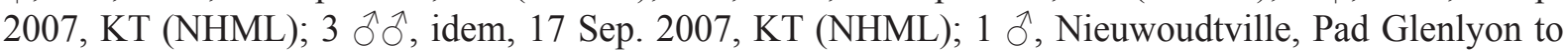
R27, 740 m, 31 ${ }^{\circ} 23^{\prime 2} 24^{\prime \prime ~ S, ~ 1909 ' 06 " ~ E, ~} 3$ Sep. 2007, on Ruschia sp., KT (NHML); 4 q , , Knersvlakte,

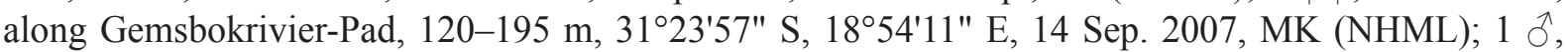
N. Cape, Nieuwoudtville, Glen Lyon, Renosterveld, 700 m, 31 ${ }^{\circ} 24^{\prime} 42^{\prime \prime}$ S, $19^{\circ} 09^{\prime} 00^{\prime \prime}$ E, 25 Aug. 2006, KT (RCMK); 2 우, 1 ơ, Gemsbokrivier-Pad, $4.5 \mathrm{~km} \mathrm{NE}$ of Grootdrif, road side, $170 \mathrm{~m}, 31^{\circ} 25^{\prime} 54^{\prime \prime} \mathrm{S}$,

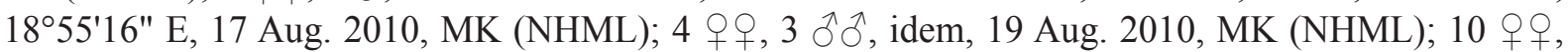

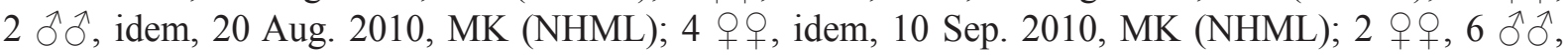

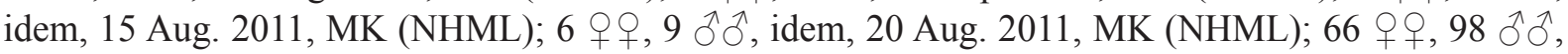

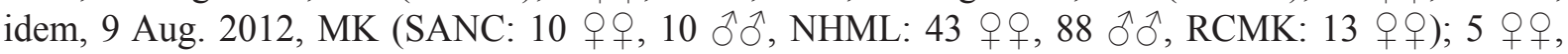

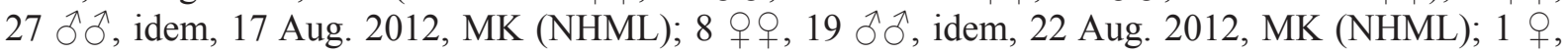
idem, 4 Sep. 2012, MK (RCMK); 4 우, Knersvlakte, path along Gemsbokrivier, 195 m, 31 ${ }^{\circ} 26^{\prime} 40^{\prime \prime}$ S, 1856'23" E, 14 Sep. 2007, KT (NHML); 9 우, idem, 21 Sep. 2007, KT, MK (NHML); 2 우, idem, 24 Aug. 2008, MK (NHML); 1 ภ, 15 km SE of Nieuwoudtville, Farm Grootfontein, dolerite hill, 790 m, $31^{\circ} 30^{\prime} 06^{\prime \prime} \mathrm{S}, 1^{\circ} 13^{\prime} 27^{\prime \prime} \mathrm{E}, 11$ Sep. 2009, MK (NHML); 1 , 1 ○े, $20 \mathrm{~km} \mathrm{~S}$ of Nieuwoudtville, Farm

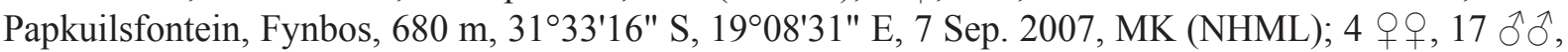
Farm Kanolfontein, $20 \mathrm{~km} \mathrm{~W}$ of Sutherland, road side, $1385 \mathrm{~m}, 32^{\circ} 24^{\prime} 43^{\prime \prime}$ S, 20²7'28" E, 7 Sep. 2012,

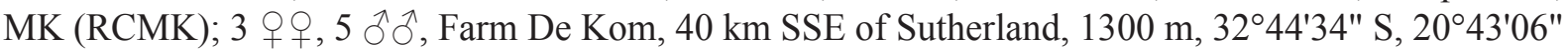
E, 8 Sep. 2012, MK (RCMK).

\section{Description}

\section{Female}

Body LENGTH. 4.5-4.8 mm.

HEAD. Head slightly wider than long. Integument black, except part of mandibles dark reddishbrown. Face sparsely covered with long, greyish, erect hair (Fig. 3B). Clypeus almost flat with sparse, shallow and inconspicuous punctation $(i=2-3 \mathrm{~d})$; surface between punctures apically smooth or only 
superficially sculptured, shiny, basally more heavily sculptured and matt (Figs 3B, 4A-B). Malar area medially narrow, almost linear. Antenna dorsally blackish-brown, ventrally yellowish-brown.

Mesosoma. Integument black. Mesoscutal disc between punctures with variable sculpture, from superficially reticulate and shiny to strongly reticulate and matt; disc very sparsely ( $i=3-5 \mathrm{~d})$, finely and
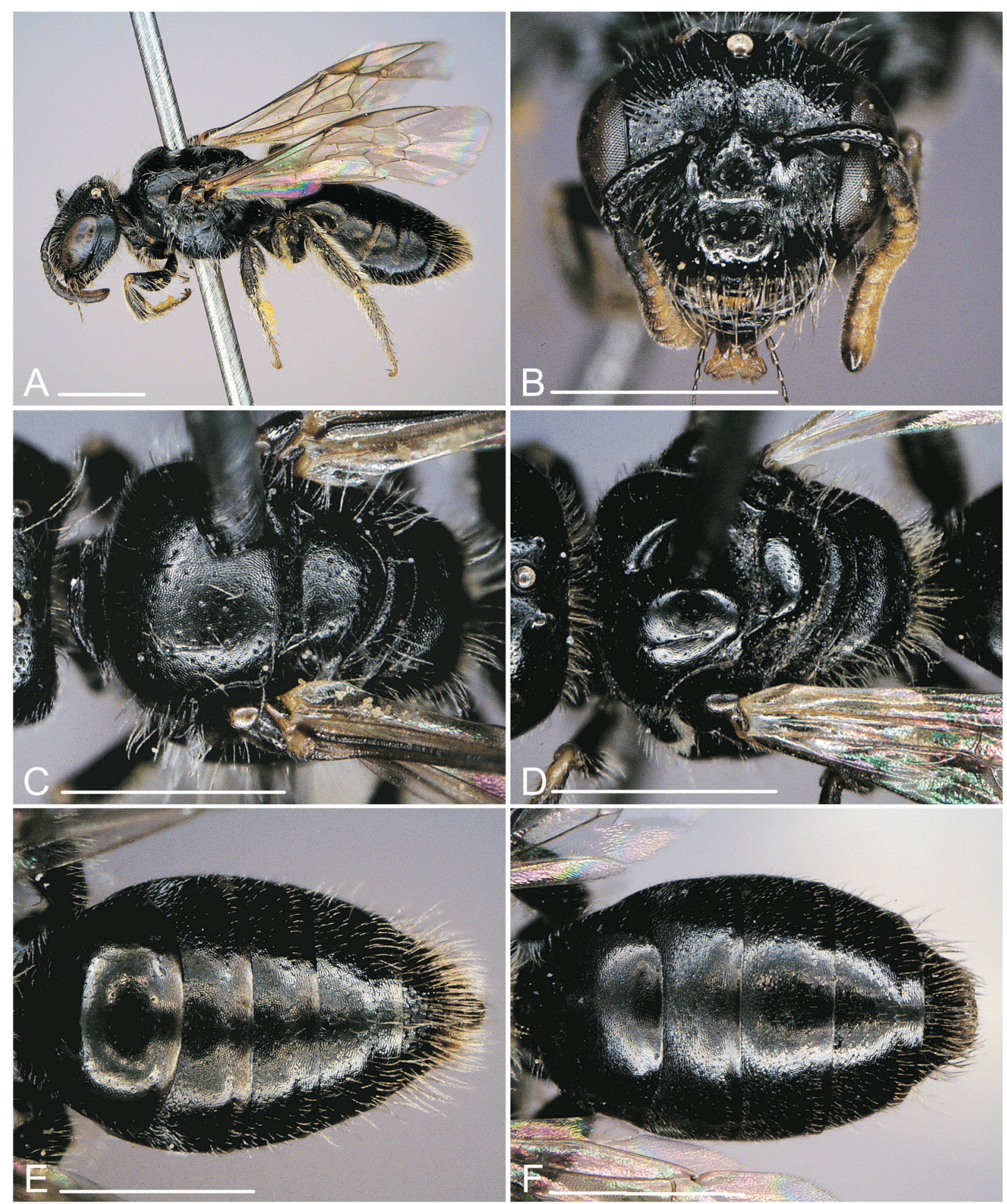

Fig. 3. Scrapter albitarsis (Friese, 1909), ․ A. Lateral view. B. Head. C. Thorax (dorsal view). D. Thorax (dorsal view). E. Metasoma (dorsal view). F. Metasoma (dorsal view). Scale bars: $1 \mathrm{~mm}$. 
shallowly punctate (Figs 3C-D, 4C-D). Metanotum half as long as basal area of propodeum, apically with indistinct narrow carinate depression (Fig. 4C-D). Propodeum basally without or with very weak carination (Fig. 4C-D). Mesoscutum, scutellum, metanotum, mesepisternum and propodeum sparsely covered with short greyish, erect hair (Fig. 3A).

WINGS. Yellowish-brown; wing venation and stigma brown.

LEGS. Integument black to dark reddish-brown; fore tibia anteriorly in the basal half with a yellowishbrown spot. Vestiture greyish-white, scopa greyish-white, often dorsally blackish-brown.

Metasoma. Integument black, apical margins of terga sometimes narrowly translucent dark reddishbrown (Fig. 3E-F). Discs of T1 and T2 without hair; following terga with increasingly more and longer hair; apical tergal hair bands missing on all terga (Fig. 3E-F). Prepygidial and pygidial fimbriae sparse, greyish-brown. T1 impunctate, \pm densely sculptured and matt; following terga usually with stronger sculpture, sometimes with very fine, dispersed and superficial punctation; T2-T4 with matt, relatively broad apical tergal depression (Fig. 3E-F).

\section{Male}

Body LeNGTH. $3.8-4.7 \mathrm{~mm}$.

HEAD. Head slightly wider than long. Integument black, except mandible partly dark reddish-brown. Face densely covered with long, greyish-white, erect hair. Malar area medially narrow, almost linear.
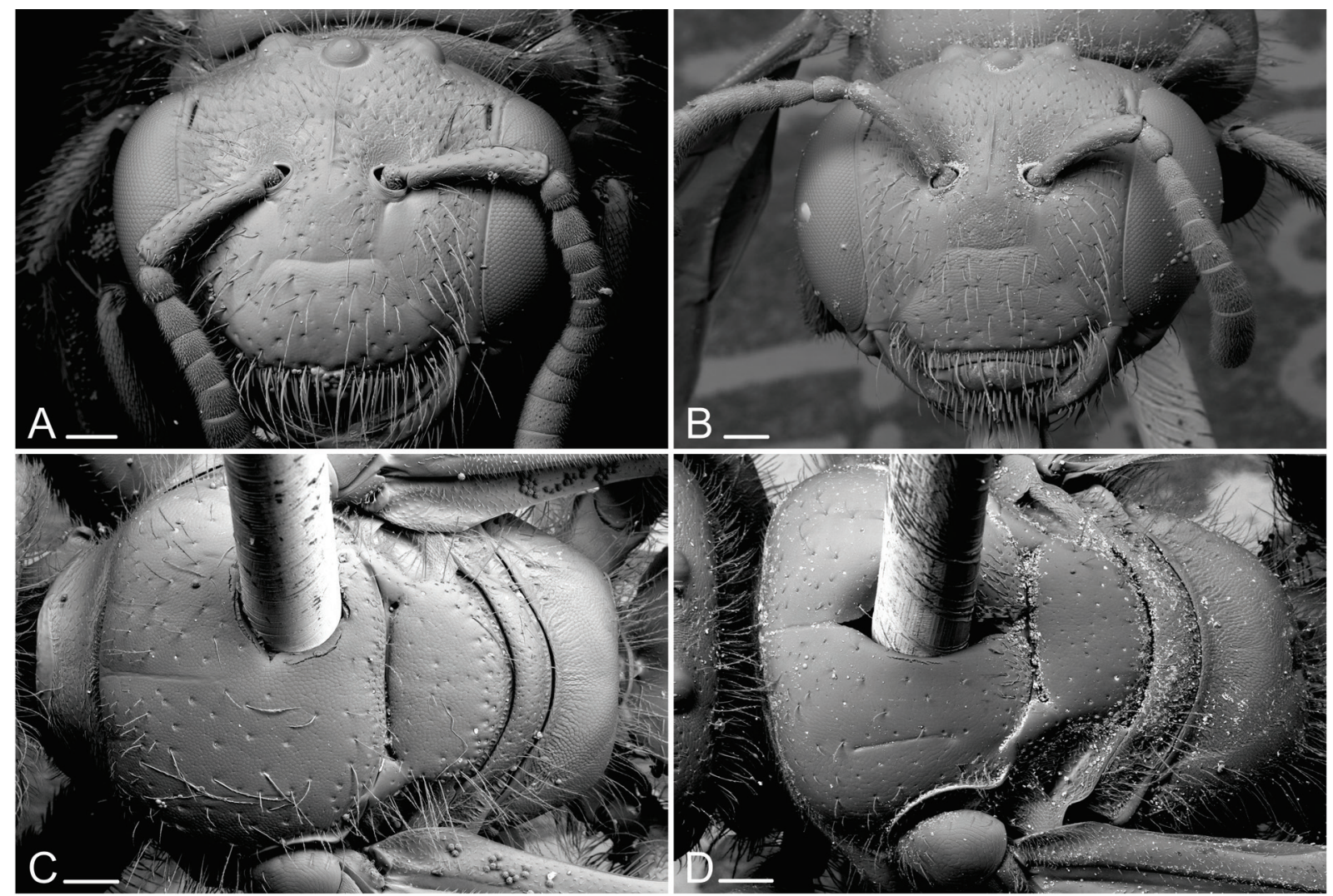

Fig. 4. Scrapter albitarsis (Friese, 1909), $q$, all SEM. A. Head. B. Head. C. Thorax (dorsal view). D. Thorax (dorsal view). Scale bars: $0.1 \mathrm{~mm}$. 
,ntenna dorsally dark brown, ventrally yellowish-brown except last three flagellar segments completely brown (Fig. 5A).

Mesosoma. Integument black. Mesoscutal disc almost impunctate, strongly reticulate and matt. Mesoscutum, scutellum, metanotum, mesepisternum and propodeum sparsely covered with long, greyish, erect hair (Fig. 5A).

WINGS. Yellowish-brown; wing venation and stigma brown.

LEGS. Integument black, tarsi, fore tibia anteriorly, mid tibia basally and apically and hind tibia apically, sometimes basally yellow to yellowish-brown (Fig. 5A). Hind tibia unmodified. Vestiture greyish-white.
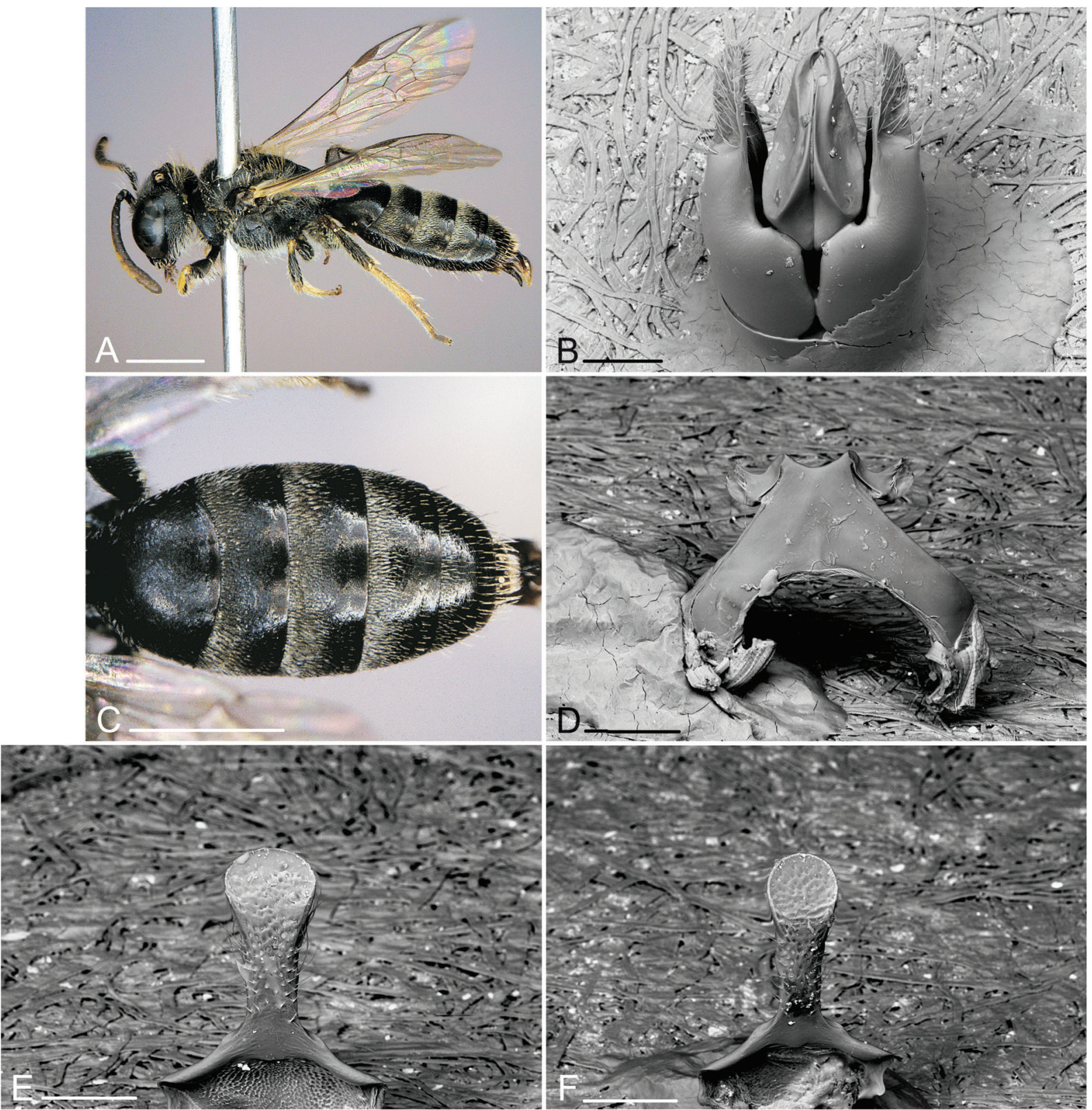

Fig. 5. Scrapter albitarsis (Friese, 1909), O. A. Lateral view. B. Genitalia (dorsal view, SEM). C. Metasoma (dorsal view). D. S7 (dorsal view, SEM). E. S8, apical end (SEM). F. S8, apical end (SEM). Scale bars: photos: $1 \mathrm{~mm}$, SEM: $0.1 \mathrm{~mm}$. 
Metasoma. Integument black, apical margins of terga partly translucent dark reddish-brown (Fig. 5C). Disc of T1 without hair; T2-T4 basally with a broad and dense band of very fine, short, erect, silverish hair covering about half of the terga; apical tergal hair bands missing on all terga (Fig. 5C). Terga impunctate, heavily sculptured and matt; terga with broad and sculptured apical tergal depression (Fig. 5C). S3-S5 with sparse apical hair fringes.

Terminalia. Genitalia (Fig. 5B), S7 (Fig. 5D) and terminal plate of S8 (Fig. 5E-F) as illustrated.

\title{
Distribution
}

The species is apparently widespread in the South African winter rainfall region from low lying areas to the mountains.

\section{Floral hosts}

Aizoaceae: Galenia sarcophylla, Galenia sp., Ruschia sp.

\section{Seasonal activity}

August-September.

\author{
Scrapter exiguus sp. nov. \\ urn:1sid:zoobank.org:act:ADCF3C72-3BCC-4B21-98FC-7594D0298BCA
}

Figs $6-7$

\section{Diagnosis}

The female of $S$. exiguus sp. nov. can be separated from other species of this group by the combination of the following characters: supraclypeal area, clypeus (Fig. 6C-D) and mesepisternum shiny, only partly and superficially reticulate, scutum sparsely punctate, looking almost impunctate and shiny (Fig. 6E-F), stigma brown, apical margins of metasomal terga black (Fig. 6B). The male is characterized by an unmodified antenna, simple and black hind tibia, hind basitarsus yellowish (Fig. 7A), S7 with apicolateral lobes and apical emargination narrow and deep (Fig. 7D).

\section{Etymology}

The name "exiguus" (lat. small) refers to the small size and the inconspicuous appearance of the species. Scrapter exiguus sp. nov. was named by the winners of the competition "Build and observe" organized by the German Federal Ministry of Education and Research as part of the Science Year 2012 "Project Earth: Our Future". The first prize was awarded to the most original wild bee "hotel" (artifical nesting site), built by the study group "Tierpark AG" at the grammar school in Nordhorn (NW Germany) and involved (in alphabetical order) Melina Hages, Anna Hensen, Theresa Honikel, Marleen Kleinert and Anna-Lena Steußloff.

\section{Type material (44 specimens)}

\section{Holotype}

SOUTH AFRICA: + , W. Cape, Knersvlakte, Sukkulent Karoo, $30 \mathrm{~km}$ N of Vanrhynsdorp, $146 \mathrm{~m}$, 31 $22^{\circ} 23^{\prime \prime}$ S, 1842'37" E, 5-6 Sep. 2003, K. Timmermann (SANC).

\section{Paratypes}

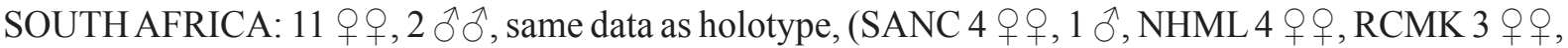

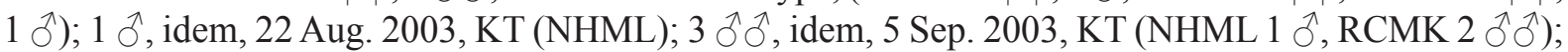

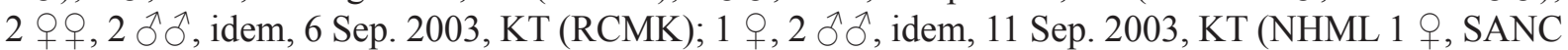

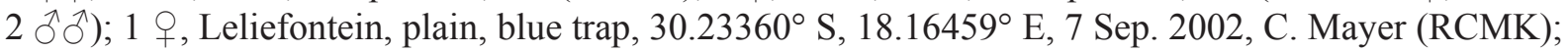


1 ㅇ, Remhoogte, plain, white trap, 30.23530 S, $18.16568^{\circ}$ E, 23 Sep. 2003, C. Mayer (RCMK); 2 우의, W. Cape, Knersvlakte, Sukkulent Karoo, 40 km N of Vanrhynsdorp, Farm Kalkgat, 140 m, 31 $1^{\circ} 07^{\prime} 04^{\prime \prime}$

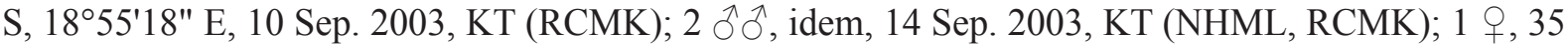
km W of Springbok, 29³7' S, 17³1' E, 28 Sep. 1997, MK (RCMK); 1 q, N. Cape, S of Kliphoogte, 466 m, 29 03' S, 17²4' E, 14 Sep. 2011, L. Packer (PCYU); 1 +, N. Cape, 21.6 km E of Springbok, 1006 m, 29³4' S, 1804' E, 26 Sep. 2011, L. Packer (PCYU); 1 ㅇ, Knersvlakte, along GemsbokrivierPad, 120-195 m, 31²3'57" S, 1854'11" E, 14 Sep. 2007, MK (RCMK); 1 + , Gemsbokrivier-Pad, 4.5 km NE of Grootdrif, road side, 170 m, 31 ${ }^{\circ} 25^{\prime} 54^{\prime \prime}$ E, 1855'16" E, 15 Aug. 2011, MK (RCMK); 3 우,
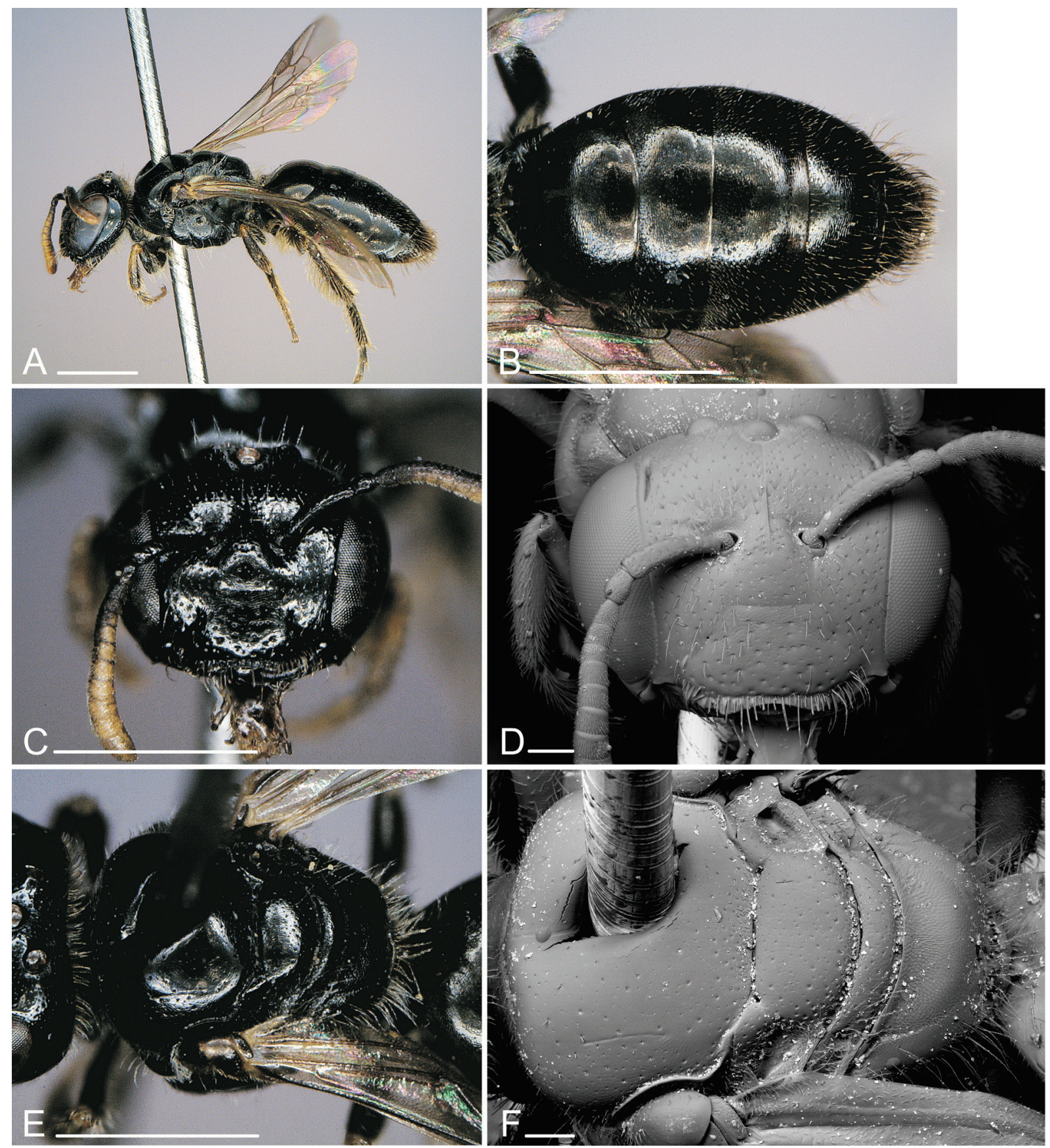

Fig. 6. Scrapter exiguus sp. nov., ㅇ. A. Lateral view. B. Metasoma (dorsal view). C. Head. D. Head (SEM). E. Thorax (dorsal view). F. Thorax (dorsal view, SEM). Scale bars: photos: $1 \mathrm{~mm}$, SEM: 0.1 $\mathrm{mm}$. 
idem, 20 Aug. 2011, MK (RCMK); 1 क, W. Cape, Farm Kaaps SE of Drif, Knersvlakte, 31 ${ }^{\circ} 26^{\prime} 01^{\prime \prime}$ S, 1847'34" E, 22 Sep. 1999, MK (RCMK); 1 +, Knersvlakte, path along Gemsbokrivier, 195 m, $31^{\circ} 26^{\prime} 40^{\prime \prime}$ S, 18 $16^{\circ} 23^{\prime \prime}$ E, 14 Sep. 2007, KT (RCMK); 3 우, idem, 21 Sep. 2007, KT (RCMK).

\section{Description}

\section{Female}

BoDY LENGTH. 4.4-4.8 mm.
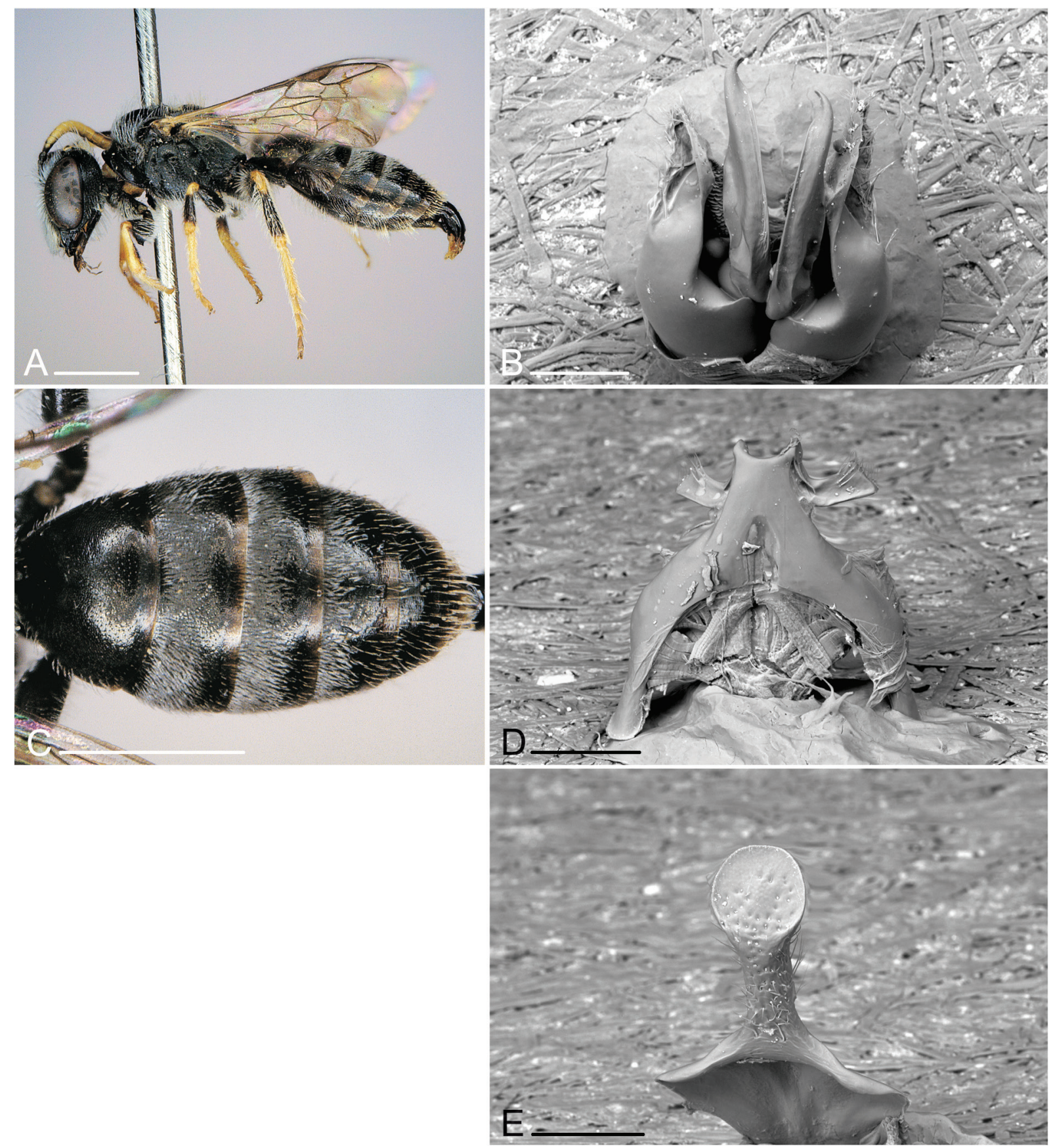

Fig. 7. Scrapter exiguus sp. nov., đ̊. A. Lateral view. B. Genitalia (dorsal view, SEM). C. Metasoma (dorsal view). D. S7 (dorsal view, SEM). E. S8, apical end (SEM). Scale bars: photos: $1 \mathrm{~mm}$, SEM: $0.1 \mathrm{~mm}$. 
HEAD. Head slightly wider than long. Integument black, except part of mandibles dark reddish-brown. Face sparsely covered with long, greyish, erect hair (Fig. 6C). Clypeus almost flat with dispersed large, shallow punctation ( $i=1-2 \mathrm{~d}$ ); surface between punctures apically smooth or only superficially sculptured, shiny, basally more heavily sculptured and matt (Fig. 6C-D). Malar area medially narrow, almost linear. Antenna dorsally blackish-brown, ventrally yellowish-brown.

Mesosoma. Integument black. Mesoscutal disc between punctures smooth or with superficial sculpture, shiny; disc very sparsely ( $\mathrm{i}=3-5 \mathrm{~d}$ ), finely and shallowly punctate (Fig. 6E-F). Metanotum about $3 / 4$ as long as basal area of propodeum, apically with distinct narrow carinate depression (Fig. 6F). Propodeum basally without carination (Fig. 6F). Mesoscutum, scutellum, metanotum, mesepisternum and propodeum sparsely covered with short, greyish, erect hair (Fig. 6A).

WiNGS. Yellowish-brown; wing venation and stigma brown.

LEGS. Integument black to dark reddish-brown; fore tibia anteriorly dominantly yellowish-brown. Vestiture greyish-white, scopa greyish-white, dorsally blackish-brown.

Metasoma. Integument black, apical margins of terga sometimes narrowly translucent dark reddishbrown (Fig. 6B). Discs of T1 and T2 without hair; following terga with increasingly more and longer hair; apical tergal hair bands missing on all terga (Fig. 6B). Prepygidial and pygidial fimbriae sparse, yellowish-brown. $\mathrm{T} 1$ impunctate, superficially to \pm densely sculptured and mostly shiny; following terga usually with stronger sculpture, sometimes with very fine, dispersed and superficial punctation; T2-T4 with finely sculptured, relatively broad apical tergal depression (Fig. 6B).

\section{Male}

Body LeNGTH. 4.3-4.8 mm.

HEAD. Head slightly wider than long. Integument black, except mandible partly dark reddish-brown. Face densely covered with long, greyish-white, erect hair. Malar area medially narrow, almost linear. Antenna dorsally dark brown, ventrally yellowish-brown except last three flagellar segments completely or largely brown (Fig. 7A).

Mesosoma. Integument black. Mesoscutal disc almost impunctate, strongly reticulate and matt. Mesoscutum, scutellum, metanotum, mesepisternum and propodeum sparsely covered with long, greyish, erect hair (Fig. 7A).

WINGs. Slightly yellowish-brown; wing venation and stigma brown.

LEGS. Integument black, tarsi, fore tibia anteriorly (posteriorly brown), mid and hind tibia basally and apically yellow to yellowish-brown (Fig. 7A). Hind tibia unmodified. Vestiture greyish-white.

Metasoma. Integument black, apical margins of terga partly translucent dark reddish-brown (Fig. 7C). Disc of T1 without hair; T2-T4 basally with a broad and dense band of very fine, short, erect, silverish hair covering about half of the terga; apical tergal hair bands missing on all terga (Fig. 7C). Terga impunctate, sculptured and slightly matt; terga with broad and slightly sculptured apical tergal depression (Fig. 7C). S3-S5 with sparse apical hair fringes.

Terminalia. Genitalia (Fig. 7B), S7 (Fig. 7D) and terminal plate of S8 (Fig. 7E) as illustrated.

\section{Distribution}

The species is known from a few places across Namaqualand. 


\section{Floral hosts}

Aizoaceae: Galenia sarcophylla.

\section{Seasonal activity}

August-September.

\section{Scrapter gessorum sp. nov. \\ urn:1sid:zoobank.org:act:03602B44-A91A-431C-A1B2-4277EA13643D}

Fig. 8

\section{Diagnosis}

The female of $S$. gessorum sp. nov. can be separated from other species of this group by the combination of the following characters: facial fovea long (Fig. 8D), scutum sparsely punctate, looking almost impunctate and shiny (Fig. 8E-F), mesepisternum strongly reticulate, stigma brown, apical margins of metasomal terga black (Fig. 8B). The male is unknown.

\section{Etymology}

Named after Friedrich $\uparrow$ and Sarah Gess from the Albany Museum in Grahamstown who have done pioneering research on the bees and aculeate wasps of southern Africa. Their support of my taxonomic studies on southern African bees is much appreciated.

Type material (2 specimens)

\section{Holotype}

SOUTH AFRICA: , Cape Province, Willowmore / 000368, 33ํ17' S, $23^{\circ} 28^{\prime}$ E, 7 Oct. 1971, C. JacotGuillarmod (identified as Scrapter albitarsis (Friese), det. C.D. Eardley 1995) (AMGS).

\section{Paratype}

SOUTH AFRICA: 1 क, Nieuwoudtville, path to farm Glenlyon, $740 \mathrm{~m}, 31^{\circ} 23^{\prime} 24^{\prime \prime} \mathrm{S}, 19^{\circ} 09^{\prime} 06^{\prime \prime} \mathrm{E}, 7 \mathrm{Sep}$. 2007, on Ruschia unca, KT (RCMK).

\section{Description}

\section{Female}

BODY LENGTH. $4.8 \mathrm{~mm}$.

HEAD. Head slightly wider than long. Integument black, except part of mandibles dark reddish-brown. Face sparsely covered with long, greyish, erect hair (Fig. 8C). Clypeus almost flat with dense large, shallow punctation $(i=1.5-2.0 \mathrm{~d})$; surface between punctures apically smooth or only superficially sculptured, shiny, basally more heavily sculptured and matt (Fig. 8C-D). Malar area medially narrow, almost linear. Antenna dorsally blackish-brown, ventrally yellowish-brown.

Mesosoma. Integument black. Mesoscutal disc between punctures with superficial sculpture, shiny; disc very sparsely ( $i=3-5 \mathrm{~d}$ ), finely and shallowly punctate (Fig. 8E-F). Metanotum about 3/4 as long as basal area of propodeum, apically with indistinct, narrow, carinate depression (Fig. 8F). Propodeum basilaterally with shallow carination (Fig. 8F). Mesoscutum, scutellum, metanotum, mesepisternum and propodeum sparsely covered with short, greyish, erect hair (Fig. 8A).

WINGS. Yellowish-brown; wing venation and stigma brown. 
LEGS. Integument black to dark reddish-brown; fore tibia anteriorly dominantly yellowish-brown, mid tibia basally with small yellow spot (Fig. 8A). Vestiture greyish-white, scopa greyish-white, dorsally blackish-brown.

METASOMA. Integument black, apical margins of terga sometimes narrowly translucent dark reddishbrown (Fig. 8B). Disc of T1 without hair; following terga with increasingly more and longer hair; apical tergal hair bands missing on all terga (Fig. 8B). Prepygidial and pygidial fimbriae sparse, greyish-brown. T1 impunctate, superficially sculptured and shiny; following terga with stronger sculpture, partly with
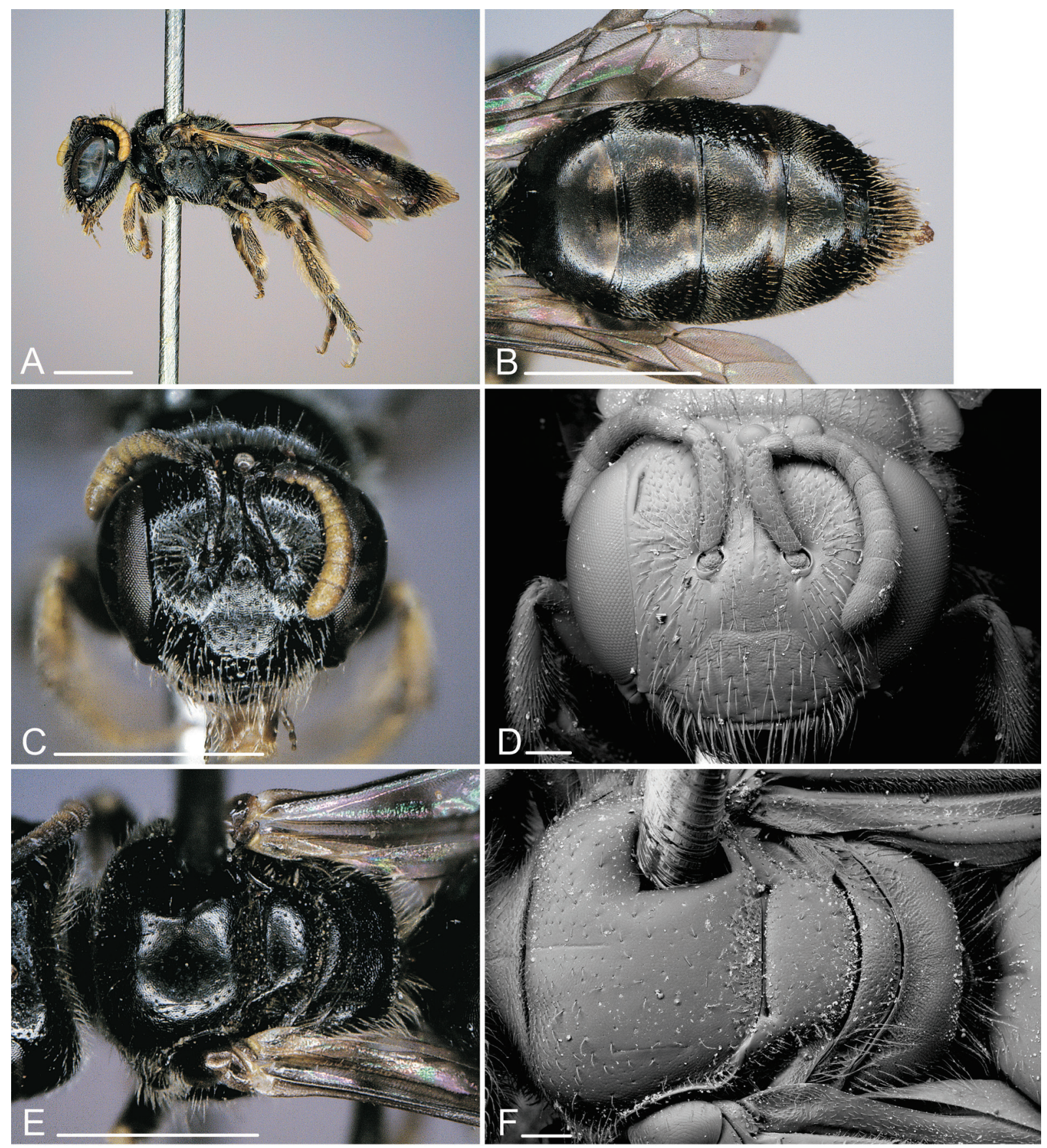

Fig. 8. Scrapter gessorum sp. nov., q. A. Lateral view. B. Metasoma (dorsal view). C. Head. D. Head (SEM). E. Thorax (dorsal view). F. Thorax (dorsal view, SEM). Scale bars: photos: $1 \mathrm{~mm}$, SEM: $0.1 \mathrm{~mm}$. 
very fine, dispersed and superficial punctation; T2-T4 with finely sculptured, relatively broad apical tergal depression (Fig. 8B).

\section{Male}

Unknown.

\section{Distribution}

The species is just known from two localities that are about $450 \mathrm{~km}$ apart in the Northern Cape and Eastern Cape provinces.

\section{Floral hosts}

Aizoaceae: Ruschia unca.

\section{Seasonal activity}

September-October.

Scrapter glareus Davies, 2005

Fig. 9

Scrapter glareus Davies, 2005: 166-168, figs 27-30, holotype $\overbrace{}^{\Uparrow}$ (type locality: Knersvlakte, $30 \mathrm{~km} \mathrm{~N}$ of Vanrhynsdorp, South Africa) (SANC).

\section{Diagnosis}

The male of $S$. glareus can be separated from other species of this group by the combination of the following characters: antenna unmodified, hind tibia simple and yellow with a brown spot on the back side, hind basitarsus yellowish (Fig. 9A), form of S7 (Fig. 9D). The female is unknown.

\section{Material examined}

No additional material examined.

\section{Description}

\section{Male}

BoDY LENGTH. 5.6-5.8 mm.

HEAD. Head slightly wider than long. Integument black, except mandible partly dark reddish-brown. Face densely covered with long, greyish-white, erect hair. Malar area medially narrow, almost linear. Antenna dorsally dark brown, ventrally yellowish-brown except last two to three flagellar segments completely or largely brown.

Mesosoma. Integument black. Mesoscutal disc densely but shallowly punctate ( $\mathrm{i}=1.0-1.5 \mathrm{~d}$ ), strongly reticulate and matt. Mesoscutum, scutellum, metanotum, mesepisternum and propodeum sparsely covered with long, greyish, erect hair (Fig. 9A).

WINGS. Slightly yellowish-brown; wing venation and stigma yellowish-brown.

LEGS. Integument black, tarsi, tibiae and femora apically yellow, tibia posteriorly with large brown spot (Fig. 9A). Hind tibia unmodified. Vestiture greyish-white.

Metasoma. Integument black, apical margins of terga partly translucent dark yellowish to reddish-brown (Fig. 9C). Disc of T1 without hair; T2-T4 basally with a broad and dense band of very fine, short, erect, 
silverish hair covering about $2 / 3$ of the terga; apical tergal hair bands missing on all terga (Fig. 9C). Terga impunctate, sculptured and slightly matt; terga with broad and superficially sculptured, shiny apical tergal depression (Fig. 9C). S3-S5 without distinct apical hair fringes.

Terminalia. Genitalia (Fig. 9B), S7 (Fig. 9D) and terminal plate of S8 (Fig. 9E) as illustrated.

\section{Female}

Unknown.
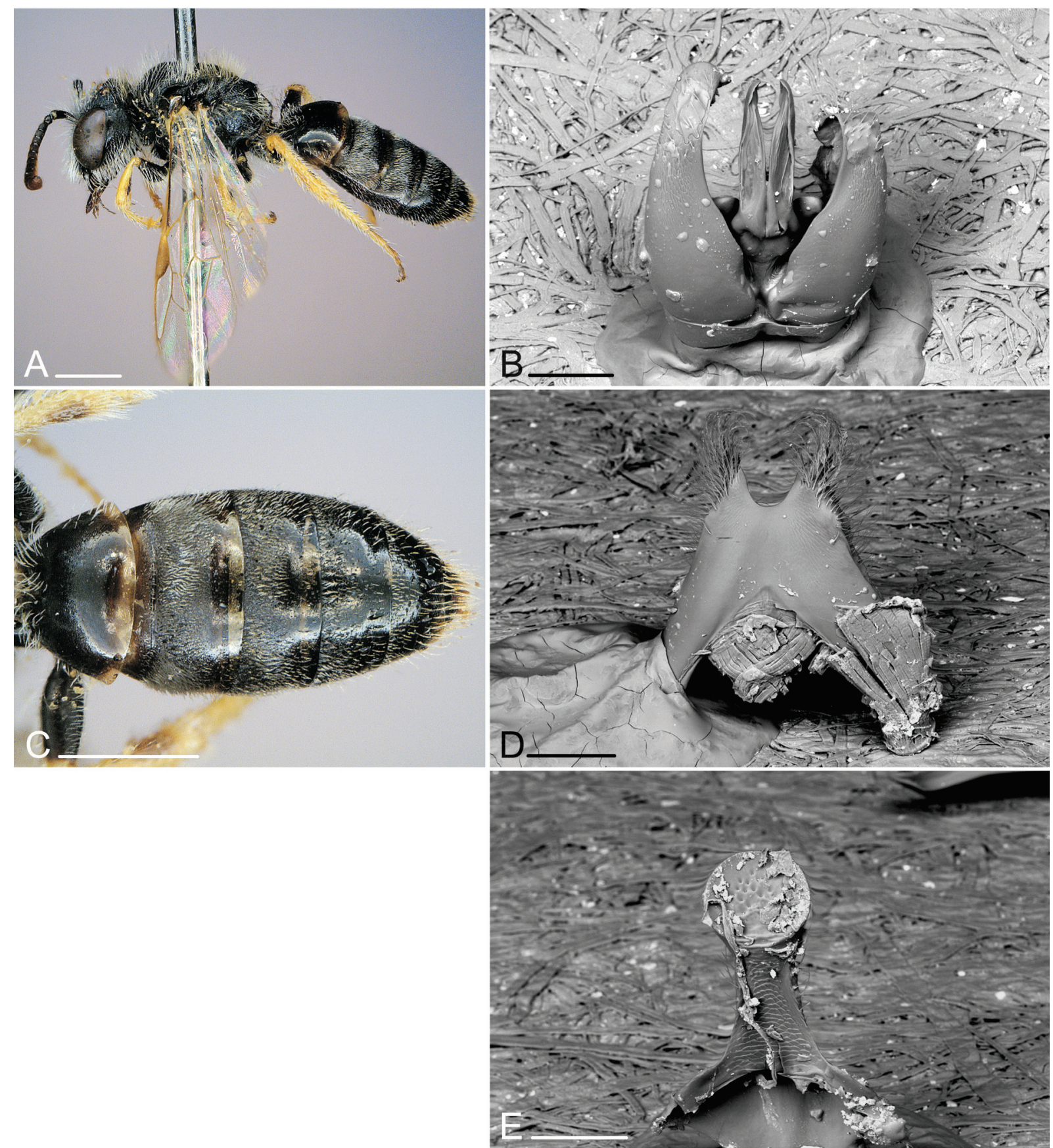

Fig. 9. Scrapter glareus Davies, O. A. Lateral view. B. Genitalia (dorsal view, SEM). C. Metasoma (dorsal view). D. S7 (dorsal view, SEM). E. S8, apical end (SEM). Scale bars: photos: $1 \mathrm{~mm}$, SEM: $0.1 \mathrm{~mm}$. 


\section{Distribution}

The species is only known from the Knersvlakte, a semi-desert plane in southern Namaqualand.

\section{Floral hosts}

Unknown.

\section{Seasonal activity}

September.

$$
\begin{gathered}
\text { Scrapter inexpectatus sp. nov. } \\
\text { urn:1sid:zoobank.org:act:30988A75-52DA-4F05-BD24-6AB536CB9C4A }
\end{gathered}
$$

Fig. 10

\section{Diagnosis}

The female of $S$. inexpectatus sp. nov. can be separated from other species of this group by the combination of the following characters: supraclypeal area and clypeus very sparsely and finely punctate, strongly reticulate and matt (Fig. 10C-D), scutum densely and coarsely punctate (Fig. 10E-F), stigma brown, apical margins of metasomal terga black (Fig. 10B). The male is unknown.

\section{Etymology}

The discovery of such an unusual species was unexpected, which is reflected in its name.

Type material (2 specimens)

\section{Holotype}

SOUTH AFRICA: ㅇ, $21 \mathrm{~km}$ E of Lambert's Bay, $122 \mathrm{~m}, 32^{\circ} 08^{\prime} 02^{\prime \prime} \mathrm{S}, 18^{\circ} 30^{\prime} 01^{\prime \prime} \mathrm{E}, 22$ Sep. 2001 (identified as $S$. albitarsis (Friese), det. 2005 GBP Davies) (CUIC).

\section{Paratype}

SOUTH AFRICA: 1 q, Sauer, 3250' S, 18³4' E, 21 Oct. 2008, T.L. Griswold (RCMK).

\section{Description}

Female

BODY LENGTH. $4.6 \mathrm{~mm}$.

HEAD. Head longer than wide. Integument black, except part of mandibles dark reddish-brown. Face sparsely covered with long, greyish, erect hair (Fig. 10C). Clypeus slightly convex with sparse, fine and shallow punctation ( $i=2-3 \mathrm{~d})$; surface between punctures densely sculptured and matt (Fig. 10C-D). Malar area medially narrow, almost linear. Antenna dorsally blackish-brown, ventrally yellowish-brown.

Mesosoma. Integument black. Mesoscutal disc between punctures densely reticulate and matt; disc densely ( $\mathrm{i}=0.5-1.0 \mathrm{~d}$ ) and finely punctate (Fig. 10E-F). Metanotum about $2 / 3$ as long as basal area of propodeum, apically with narrow carinate depression (Fig. 10F). Propodeum basally finely carinate (Fig. 10F). Mesoscutum, scutellum, metanotum, mesepisternum and propodeum sparsely covered with short, greyish, erect hair (Fig. 10A).

WINGS. Yellowish-brown; wing venation and stigma brown.

LEGS. Integument black. Vestiture greyish-white, scopa greyish-brown. 
Metasoma. Integument black. Discs of T1 and T2 without hair, following terga with very few and short hairs; apical tergal hair bands missing on all terga (Fig. 10B). Prepygidial and pygidial fimbriae blackish-brown. T1 densely ( $\mathrm{i}=1 \mathrm{~d}$ ) but very finely punctate, apically a bit coarser, between punctures superficially sculptured and slightly matt; on following terga punctation slightly larger and stronger sculpture; T2-T4 with superficially sculptured and shiny, narrow apical tergal depression (Fig. 10B).

Male

Unknown.
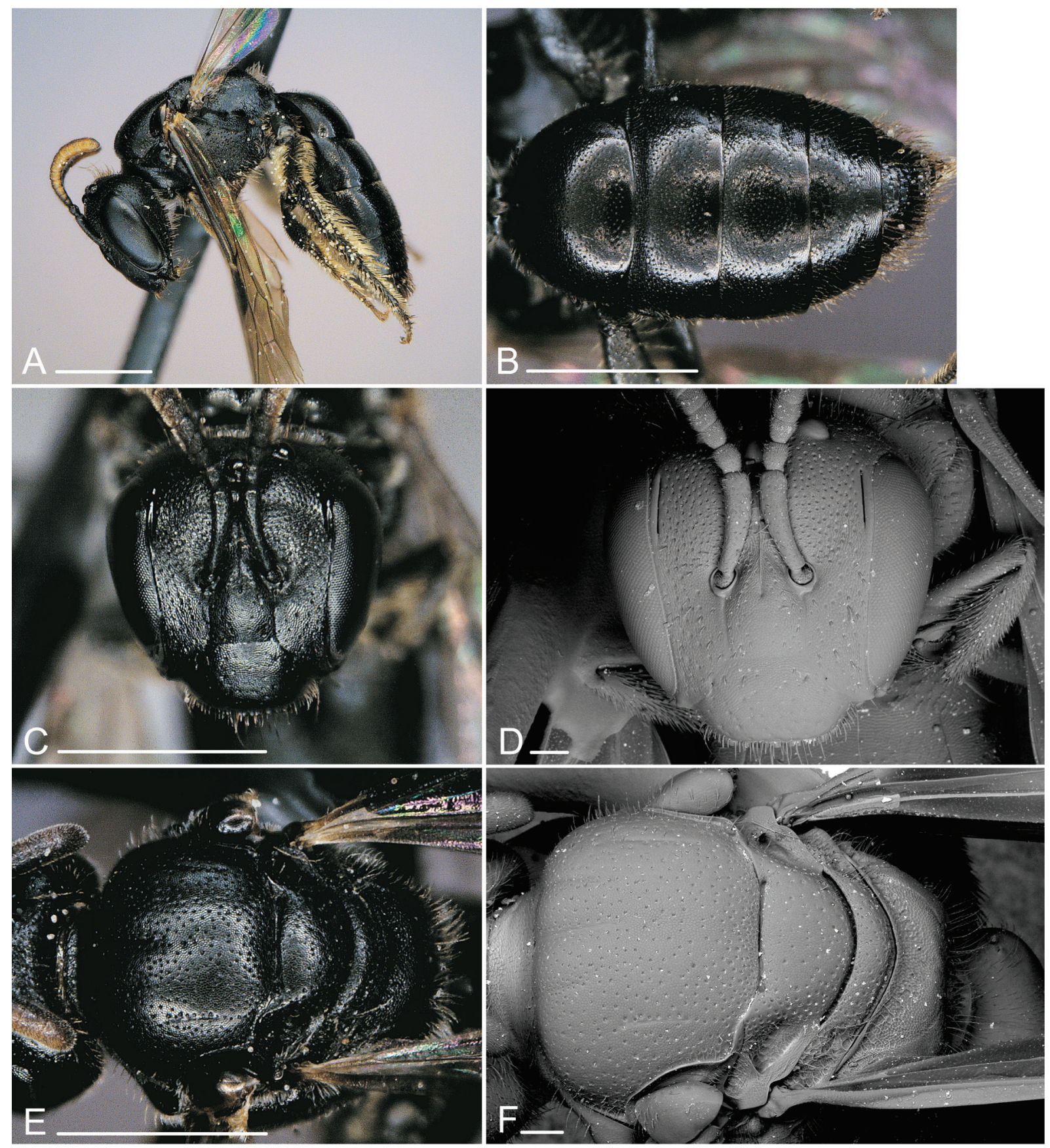

Fig. 10. Scrapter inexpectatus sp. nov.,, . A. Lateral view. B. Metasoma (dorsal view). C. Head. D. Head (SEM). E. Thorax (dorsal view). F. Thorax (dorsal view, SEM). Scale bars: photos: $1 \mathrm{~mm}$, SEM: $0.1 \mathrm{~mm}$. 


\section{Distribution}

The species is just known from two sites in the western part of the Western Cape Province.

\section{Floral hosts}

Unknown.

\section{Seasonal activity}

September-October.

Scrapter luteistigma sp. nov. urn:1sid:zoobank.org:act:6CECCB95-325C-4E9D-9A17-55FEED5B269F

Figs 11-12

\section{Diagnosis}

Both the female and male of $S$. luteistigma sp. nov. can be separated from all other species of this group by the bright yellowish stigma (Figs 11A, 12A).

\section{Etymology}

Named after the unique bright yellow stigma in the forewing of both males and females.

Type material (77 specimens)

\section{Holotype}

SOUTH AFRICA: + , Gemsbokrivier-Pad, $4.5 \mathrm{~km}$ NE of Grootdrif, road side, $170 \mathrm{~m}, 31^{\circ} 25^{\prime} 54^{\prime \prime} \mathrm{S}$, 185'ㄷ' E, 22 Aug. 2012, MK (SANC).

\section{Paratypes}

SOUTH AFRICA: 43 우, same data as holotype (SANC 5 우, NHML 25 우, RCMK 13 우); 1

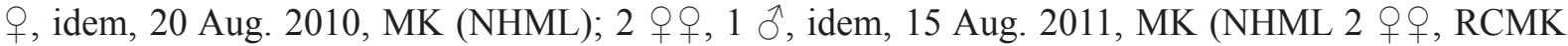

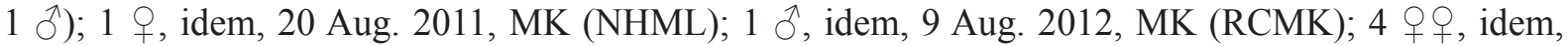
17 Aug. 2012, MK (RCMK); 15 우어, idem, 4 Sep. 2012, MK (NHML 12 우으, RCMK 3 웅); 6 우우,

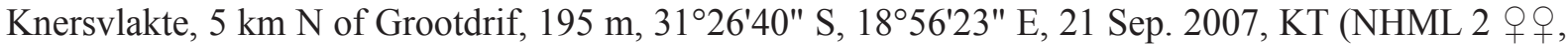
RCMK 4 웅); 2 우, idem, 24 Aug. 2008, MK (NHML, RCMK).

\section{Description}

\section{Female}

BODY LENGTH. 4.5-5.2 mm.

HEAD. Head slightly wider than long. Integument black, except part of mandibles dark reddish-brown. Face sparsely covered with long, greyish, erect hair (Fig. 11C). Clypeus slightly convex with sparse fine and shallow punctation ( $i=2-3 \mathrm{~d}$ ); surface between punctures apically superficial and shiny, basally distinctly reticulate and matt (Fig. 11C-D). Malar area medially narrow, almost linear. Antenna dorsally light brown, ventrally yellowish-brown (Fig. 11C).

Mesosoma. Integument black. Mesoscutal disc between punctures densely reticulate, matt; disc sparsely ( $\mathrm{i}=3-5 \mathrm{~d})$ and shallowly punctate (Fig. 11E-F). Metanotum slightly shorter than basal area of propodeum, apically with narrow carinate depression (Fig. 11F). Propodeum broadly but finely carinate (Fig. 11F). Mesoscutum, scutellum, metanotum, mesepisternum and propodeum sparsely covered with short, greyish, erect hair (Fig. 11A). 
Wings. Yellowish-brown; wing venation yellowish-brown, stigma bright yellowish (Fig. 11A).

LEGS. Integument black to dark reddish-brown; fore and mid tibia basally with small yellowish spot. Vestiture greyish-white, scopa greyish-white.

Metasoma. Integument black, apical margins of terga narrowly translucent yellowish to reddish-brown (Fig. 11B). Discs of T1-T4 without hair; apical tergal hair bands missing on all terga (Fig. 11B).
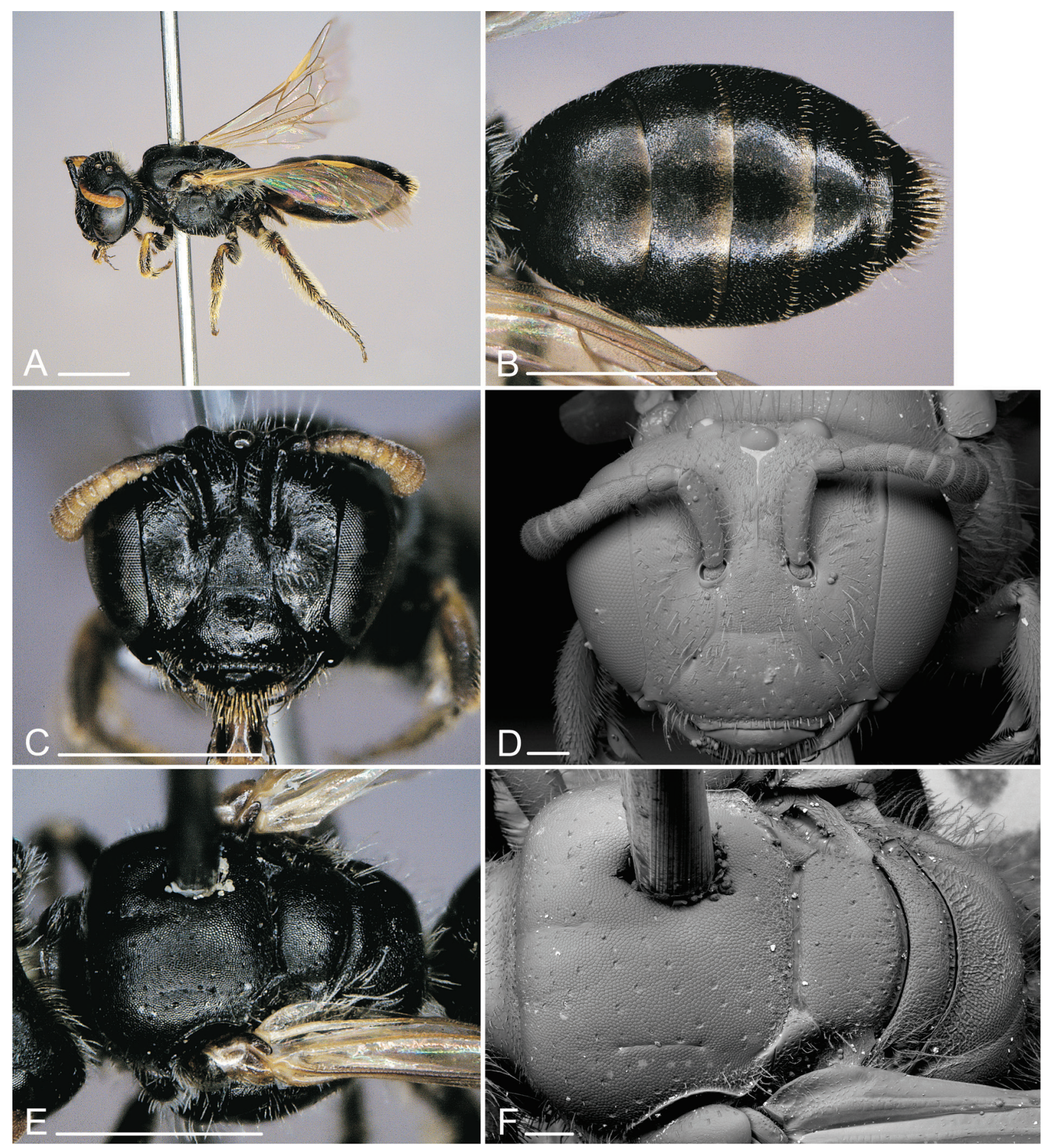

Fig. 11. Scrapter luteistigma sp. nov., +. A. Lateral view. B. Metasoma (dorsal view). C. Head. D. Head (SEM). E. Thorax (dorsal view). F. Thorax (dorsal view, SEM). Scale bars: photos: $1 \mathrm{~mm}$, SEM: $0.1 \mathrm{~mm}$. 
Prepygidial and pygidial fimbriae yellowish-brown. Terga impunctate, densely sculptured and matt; T2-T4 with indistinct, narrow apical tergal depression (Fig. 11B).

\section{Male}

BODY LENGTH. 4.4-4.7 mm.
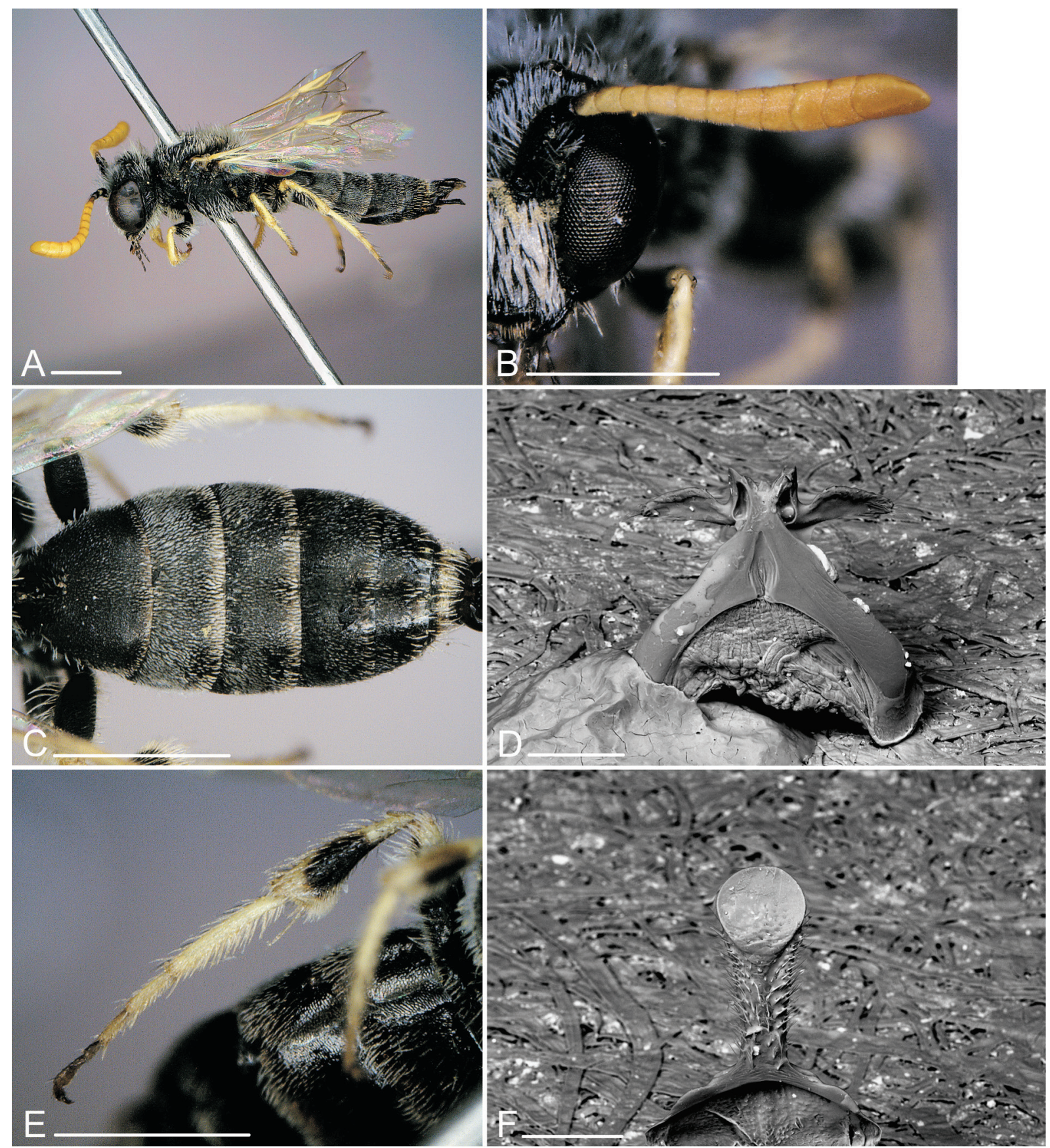

Fig. 12. Scrapter luteistigma sp. nov., đ̊. A. Lateral view. B. Antenna. C. Metasoma (dorsal view). D. S7 (dorsal view, SEM). E. Hind tibia. F. S8, apical end (SEM). Scale bars: photos: $1 \mathrm{~mm}$, SEM: $0.1 \mathrm{~mm}$. 
HEAD. Head slightly wider than long. Integument black, except mandible partly dark reddish-brown. Face densely covered with long, greyish-white, erect hair. Malar area medially narrow, almost linear. Antennal flagellum bright yellowish-orange, medioapically broadened (Fig. 12B).

Mesosoma. Integument black. Mesoscutal disc impunctate, strongly and densely sculptured, completely matt. Mesoscutum, scutellum, metanotum, mesepisternum and propodeum covered with long, greyish, erect hair (Fig. 12A).

Wings. Slightly yellowish-brown; wing venation yellowish-brown, stigma bright yellow (Fig. 12A).

LeGs. Integument black, tarsi, tibiae and femora apically yellow, tibia on both sides with darker spots of variable size (Fig. 12A, E). Hind tibia basally slightly curved, apically broadened and with a dense tuft of short, white hair on the inside (Fig. 12E). Vestiture greyish-white.

METASOMA. Integument black, apical margins of terga narrowly translucent yellowish-brown (Fig. 12C). T1 medially, T2 densely and following terga successively less covered with short, appressed scale-like hair; apical tergal hair bands missing on all terga (Fig. 12C). Terga impunctate, densely sculptured and matt; terga with narrow apical tergal depression (Fig. 12C). S3-S5 without conspicuous apical hair fringes.

Terminalia. S7 (Fig. 12D) and terminal plate of S8 (Fig. 12F) as illustrated.

\section{Distribution}

The species is only known from the type locality in the Knersvlakte, a semi-desert plane in southern Namaqualand.

\section{Floral hosts}

Aizoaceae: Galenia sarcophylla.

\section{Seasonal activity}

August-September.

Scrapter minutissimus sp. nov. urn:lsid:zoobank.org:act:6361FA10-BC8E-4EE6-AD60-3EB7169B380E

Fig. 13

\section{Diagnosis}

The male of S. minutissimus sp. nov. can be separated from other species of this group by the combination of the following characters: antenna unmodified, hind tibia simple and black, hind basitarsus yellowish (Fig. 13A) and S7 without apicolateral lobes (Fig. 13D). The female is unknown.

\section{Etymology}

Named for the very small body size of the species.

Type material ( 3 specimens)

\section{Holotype}

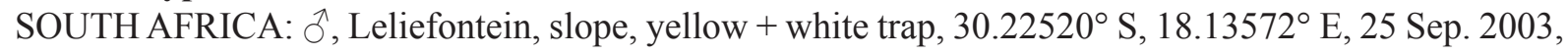
C. Mayer (SANC). 


\section{Paratypes}

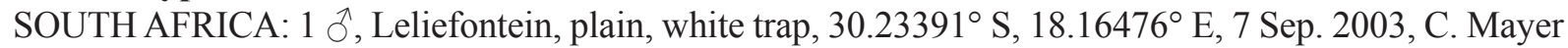
(RCMK); 1 今, Remhoogte, plain, white trap, $30.23453^{\circ} \mathrm{S}, 18.16499^{\circ} \mathrm{E}, 11 \mathrm{Sep} .2003$, C. Mayer (RCMK).

\section{Description}

\section{Male}

BODY LENGTH. 3.5-4.3 mm.
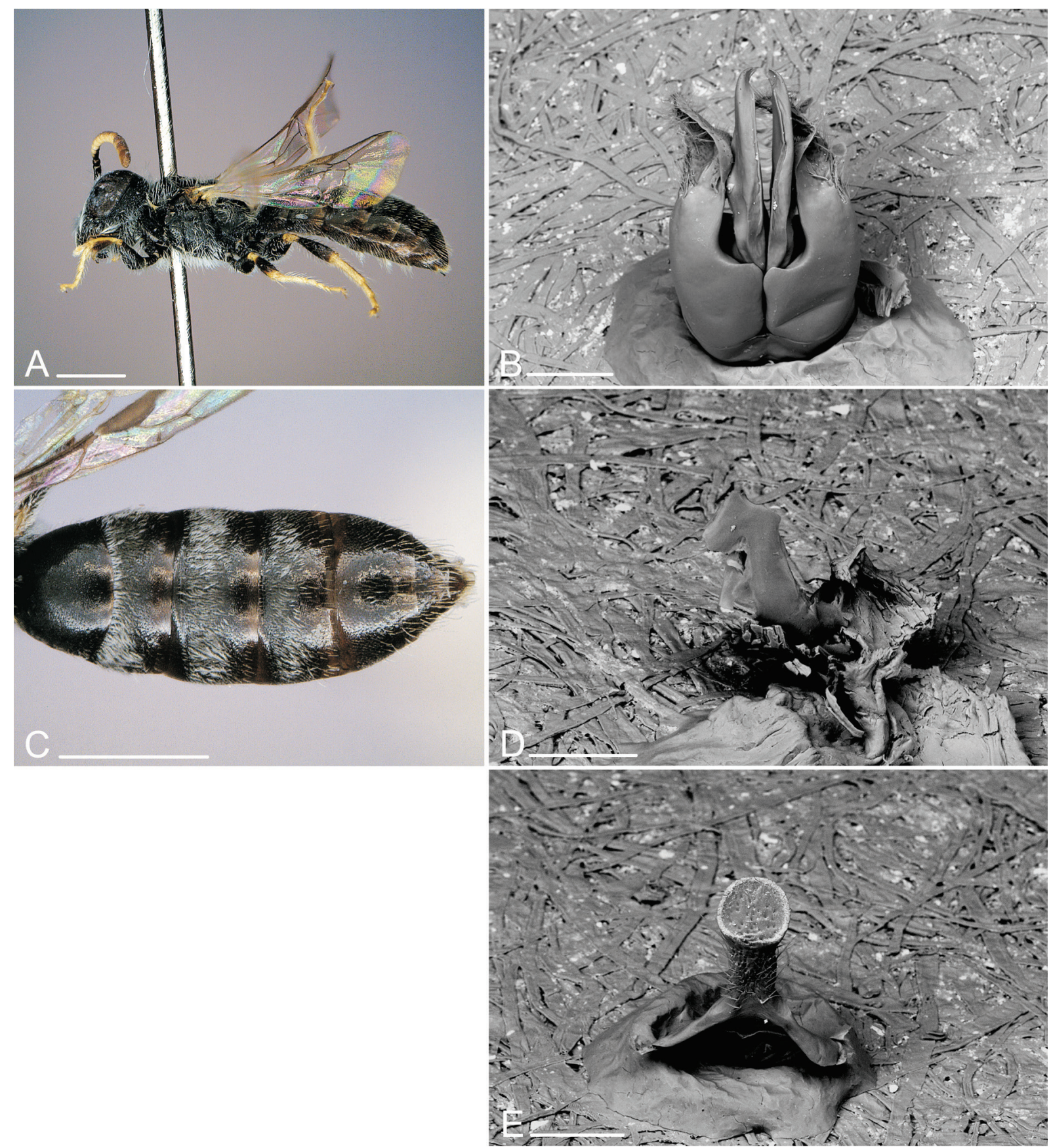

Fig. 13. Scrapter minutissimus sp. nov., Ô. A. Lateral view. B. Genitalia (dorsal view, SEM). C. Metasoma (dorsal view). D. S7 (dorsal view), left half missing (SEM). E. S8, apical end (SEM). Scale bars: photos: $1 \mathrm{~mm}$, SEM: $0.1 \mathrm{~mm}$. 
HEAD. Head slightly wider than long. Integument black, except mandible partly dark reddish-brown. Face densely covered with long, greyish-white, erect hair. Malar area medially narrow, almost linear. Antenna dorsally dark brown, ventrally yellowish-brown except last two to three flagellar segments completely or largely brown (Fig. 13A).

Mesosoma. Integument black. Mesoscutal disc impunctate, strongly sculptured and matt. Mesoscutum, scutellum, metanotum, mesepisternum and propodeum sparsely covered with long, greyish, erect hair (Fig. 13A).

WINGS. Slightly yellowish-brown; wing venation and stigma brown.

LEGS. Integument black, tarsi, fore tibia anteriorly (posteriorly brown), mid and hind tibia basally and apically yellow to yellowish-brown (Fig. 13A). Hind tibia unmodified. Vestiture greyish-white.

Metasoma. Integument black, apical margins of terga partly translucent dark reddish-brown (Fig. 13C). Disc of T1 without hair; T2-T4 basally with a broad and dense band of very fine, short, erect, silverish hair covering about half of the terga; apical tergal hair bands missing on all terga (Fig. 13C). Terga impunctate, sculptured and matt; terga with narrow and slightly sculptured, shiny apical tergal depression (Fig. 13C). S3-S5 without distinct apical hair fringes.

Terminalia. Genitalia (Fig. 13B), S7 (Fig. 13D) and terminal plate of S8 (Fig. 13E) as illustrated.

Female

Unknown.

\section{Distribution}

The species is only known from the Kamiesberg Mountains.

\section{Floral hosts}

Unknown.

\section{Seasonal activity}

September.

Scrapter minutuloides sp. nov. urn:Isid:zoobank.org:act:7C66995E-944D-4A1B-8262-A9071EB85C19

Fig. 14

\section{Diagnosis}

The female of S. minutuloides sp. nov. can be separated from other species of this group by the combination of the following characters: head distinctly broader than long, supraclypeal area and clypeus densely and distinctly punctate, only partly superficially sculptured and matt (Fig. 14C-D), scutum densely but relatively finely punctate (Fig. 14E-F), stigma brown, apical margins of metasomal terga black, terga densely and coarsely punctate (Fig. 14B). The male is unknown.

\section{Etymology}

Named for the small body size of the species. 
Type material (1 specimen)

\section{Holotype}

SOUTH AFRICA: ㅇ, W. Cape, Kamiesbergpass, 1077 m, 30¹1' S, 1759' E, 26 Sep. 2011, L. Packer (RCMK).
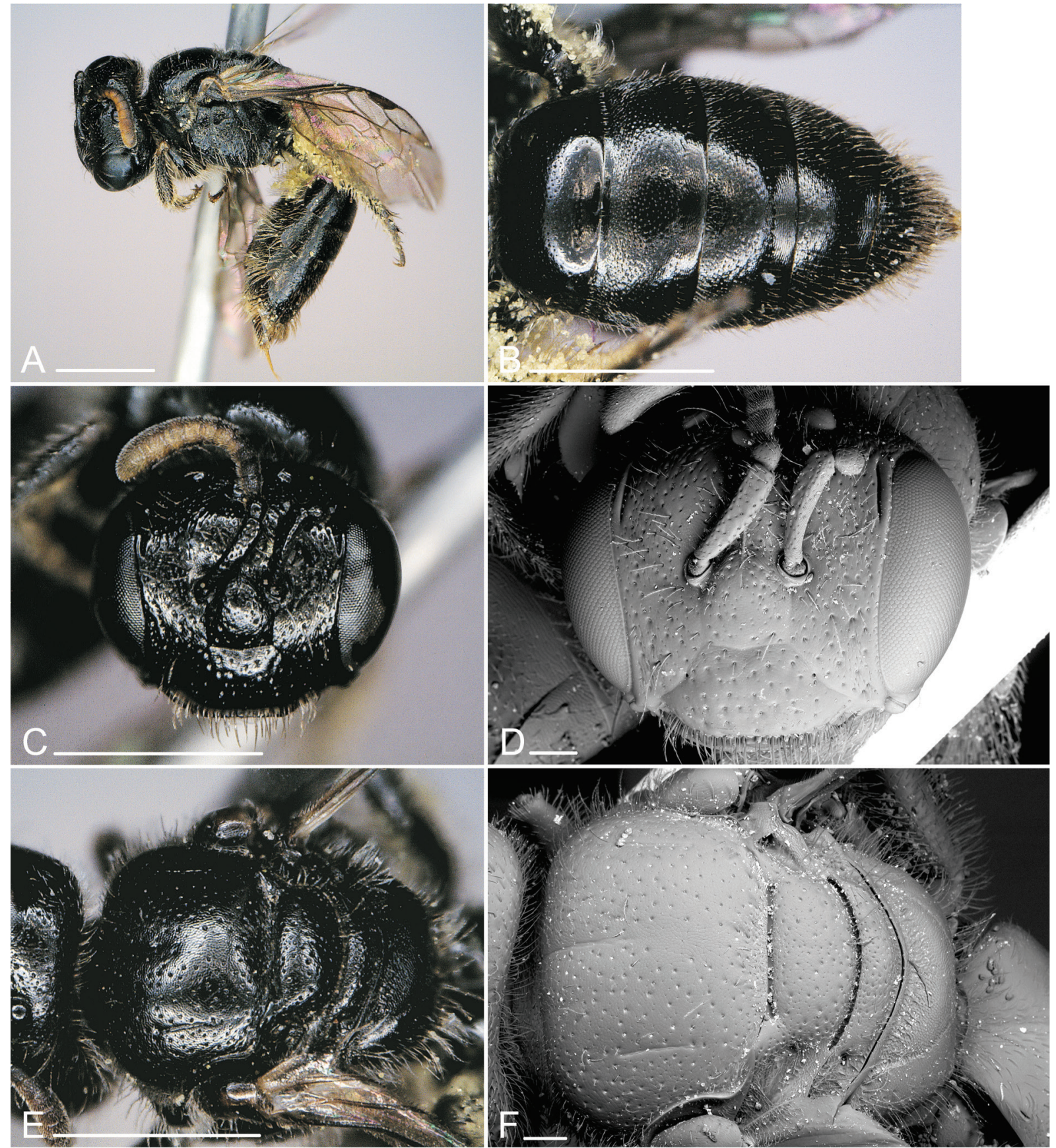

Fig. 14. Scrapter minutuloides sp. nov., ${ }^{\circ}$. A. Lateral view. B. Metasoma (dorsal view). C. Head. D. Head (SEM). E. Thorax (dorsal view). F. Thorax (dorsal view, SEM). Scale bars: photos: $1 \mathrm{~mm}$, SEM: $0.1 \mathrm{~mm}$. 


\section{Description}

\section{Female}

BODY LENGTH. $4.7 \mathrm{~mm}$.

HEAD. Head wider than long. Integument black, except part of mandibles dark reddish-brown. Face sparsely covered with long, greyish-brown, erect hair (Fig. 14C). Clypeus strongly convex with coarse and dense punctation $(\mathrm{i}=1.0-1.5 \mathrm{~d})$; surface between punctures mostly smooth and shiny, basally partly superficially sculptured and less shiny (Fig. 14C-D). Malar area medially narrow, almost linear. Antenna dorsally blackish-brown, ventrally yellowish-brown (Fig. 14C).

Mesosoma. Integument black. Mesoscutal disc between punctures superficially reticulate, slightly matt; disc sparsely $(\mathrm{i}=3-5 \mathrm{~d})$ and finely punctate (Fig. 14E-F). Metanotum slightly shorter than basal area of propodeum, apically with indistinct, narrow carinate depression (Fig. 14F). Propodeum basally finely but broadly carinate (Fig. 14F). Mesoscutum, scutellum, metanotum, mesepisternum and propodeum sparsely covered with short, greyish, erect hair (Fig. 14A).

WiNGS. Brownish; wing venation and stigma brown.

LEGS. Integument black. Vestiture greyish-white, scopa greyish-white, dorsally blackish-brown.

METASOMA. Integument black, apical margins of terga partly narrowly translucent dark reddish-brown (Fig. 14B). Discs of T1 and T2 without hair, following terga with very short but increasingly more and longer hair; apical tergal hair bands missing on all terga (Fig. 14B). Prepygidial and pygidial fimbriae blackish-brown. $\mathrm{T} 1$ densely $(\mathrm{i}=1 \mathrm{~d})$ but very finely punctate, between punctures polished and shiny; T2-T4 basally superficially sculptured, apically smooth and shiny, with dense ( $\mathrm{i}=0.5-1.0 \mathrm{~d}$ ), fine, superficial punctation; T2-T4 with superficially sculptured, broad apical tergal depression (Fig. 14B).

\section{Male}

Unknown.

\section{Distribution}

The species is only known from the Kamiesberg Mountains.

\section{Floral hosts}

Unknown.

\section{Seasonal activity}

September.

$$
\begin{aligned}
& \text { Scrapter minutus sp. nov. } \\
& \text { urn:1sid:zoobank.org:act:28AFECA3-0EC5-449D-B850-EEFB3AC29BEA }
\end{aligned}
$$

Fig. 15

\section{Diagnosis}

The female of $S$. minutus sp. nov. can be separated from other species of this group by the combination of the following characters: head about as long as broad, supraclypeal area and clypeus densely and distinctly punctate, only partly superficially sculptured and matt (Fig. 15B), scutum densely but relatively finely punctate, metanotum apicaly without distinct carinate depression (Fig. 15C-D), fore tibia anteriorly largely yellowish-brown, stigma brown, apical margins of metasomal terga black, terga densely and coarsely punctate (Fig. 15E). The male is unknown. 


\section{Etymology}

Named for the small body size of the species.

\section{Type material ( 2 specimens)}

\section{Holotype}

SOUTH AFRICA: + , Hantam Mountains, $30 \mathrm{~km} \mathrm{~N}$ of Calvinia, $880 \mathrm{~m}, 31^{\circ} 12^{\prime} 09^{\prime \prime} \mathrm{S}, 19^{\circ} 50^{\prime} 04^{\prime \prime} \mathrm{E}, 16$ Sep. 2007, K. Timmermann (SANC).

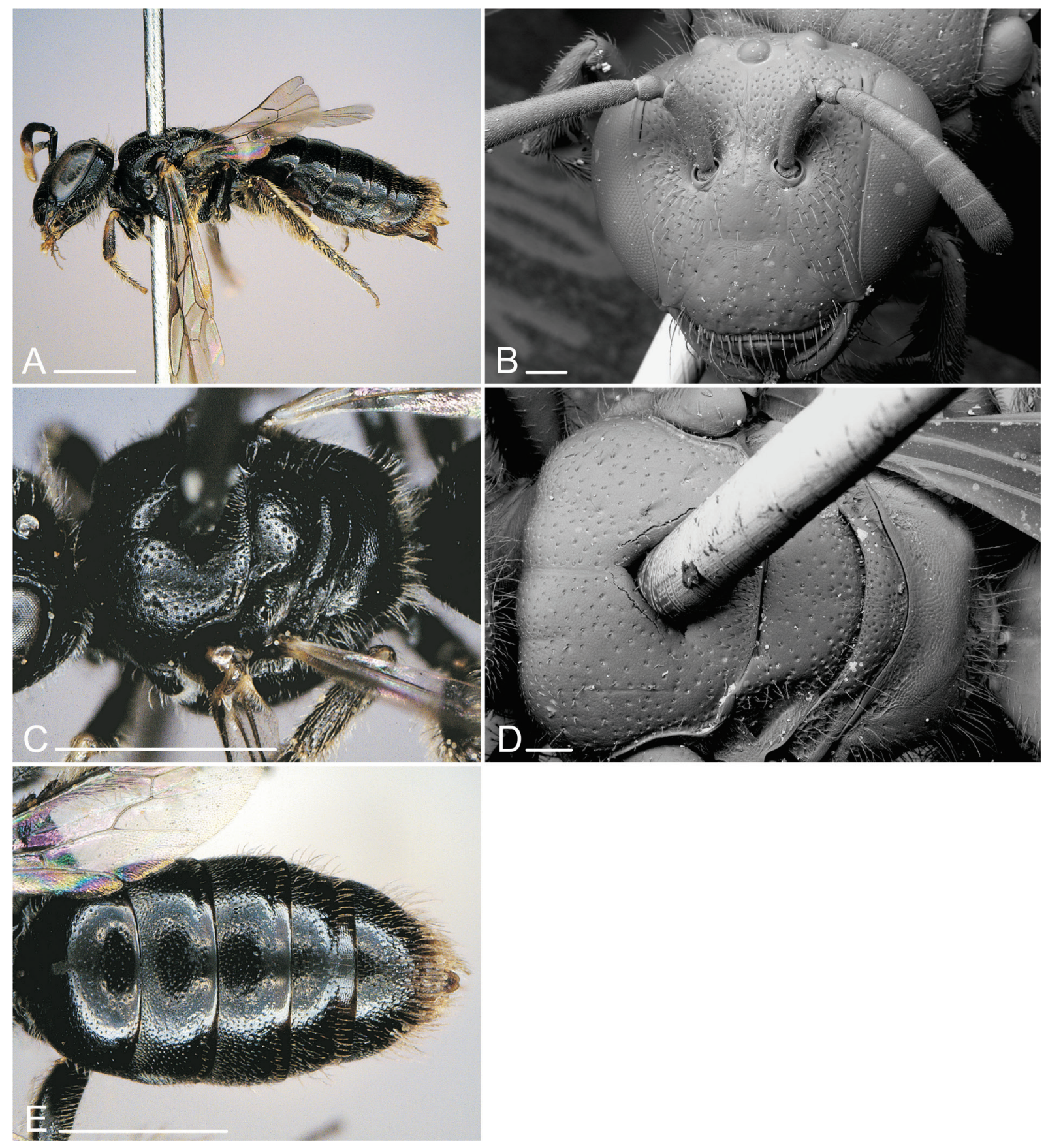

Fig. 15. Scrapter minutus sp. nov., + . A. Lateral view. B. Head (SEM). C. Thorax (dorsal view). D. Thorax (dorsal view, SEM). E. Metasoma (dorsal view). Scale bars: photos: $1 \mathrm{~mm}$, SEM: $0.1 \mathrm{~mm}$. 


\section{Paratype}

SOUTH AFRICA: 1 , same data as holotype (RCMK).

\section{Description}

\section{Female}

BODY LENGTH. $4.9 \mathrm{~mm}$.

HEAD. Head about as broad as long. Integument black, except part of mandibles dark reddish-brown. Face sparsely covered with long, greyish, erect hair (Fig. 15A). Clypeus convex with coarse and dense punctation ( $\mathrm{i}=1-2 \mathrm{~d})$; surface between punctures apically smooth and shiny, basally superficially sculptured and less shiny (Fig. 15B). Malar area medially narrow, almost linear. Antenna dorsally blackish-brown, ventrally yellowish-brown.

Mesosoma. Integument black. Mesoscutal disc between punctures superficially reticulate but shiny; disc densely $(\mathrm{i}=1.0-1.5 \mathrm{~d})$ and finely punctate (Fig. 15C-D). Metanotum slightly shorter than basal area of propodeum, apically with indistinct narrow carinate depression (Fig. 15D). Propodeum basally only laterally finely carinate (Fig. 15D). Mesoscutum, scutellum, metanotum, mesepisternum and propodeum sparsely covered with short, greyish, erect hair (Fig. 15A).

Wings. Yellowish-brown; wing venation and stigma brown.

LEGS. Integument black to dark reddish-brown; fore tibia basally with large yellowish spot (Fig. 15A). Vestiture greyish-white, scopa greyish-brown.

Metasoma. Integument black, apical margins of terga partly narrowly translucent dark reddish-brown (Fig. 15E). Discs of $\mathrm{T} 1$ and $\mathrm{T} 2$ without hair, following terga with very short but increasingly more and longer hair; apical tergal hair bands missing on all terga (Fig. 15E). Prepygidial and pygidial fimbriae greyish-brown. T1 densely $(i=1.0-1.5 \mathrm{~d})$ but very finely punctate, between punctures basally superficially sculptured, apically polished and shiny; T2-T4 basally superficially sculptured, apically smooth and shiny, with dense ( $\mathrm{i}=1.0-1.5 \mathrm{~d}$ ), fine, superficial punctation; T2-T4 with smooth and shiny, broad apical tergal depression (Fig. 15E).

\section{Male}

Unknown.

\section{Distribution}

The species is only known from the Hantam Mountains.

\section{Floral hosts}

Unknown.

\section{Seasonal activity}

September. 


\section{Scrapter nanus sp. nov. urn:1sid:zoobank.org:act:9C2CAC47-4239-49B3-B7B1-DB8D2A0B780C}

Figs 16-17

\section{Diagnosis}

The female of $S$. nanus sp. nov. can be separated from other species of this group by the combination of the following characters: head distinctly broader than long, supraclypeal area and clypeus densely and distinctly punctate, mostly finely sculptured and matt (Fig. 16C-D), scutum densely but relatively finely punctate, metanotum apicaly without distinct carinate depression (Fig. 15C-D), stigma brown, apical margins of metasomal terga black, terga densely and coarsely punctate (Fig. 16B). The male is characterized by an unmodified antenna, simple and black hind tibia and hind basitarsus (Fig. 17A), almost hairless, punctured and between punctures strongly sculptured abdominal terga (Fig. 17C, E) and form of S7 (Fig. 17D).

\section{Etymology}

Named for the small body size of the species.

Type material (172 specimens)

\section{Holotype}

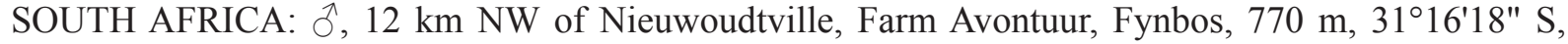
$19^{\circ} 02^{\prime} 55^{\prime \prime}$ E, 16 Aug. 2011, M. Kuhlmann (SANC).

\section{Paratypes}

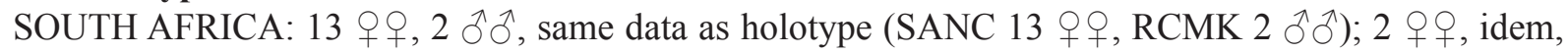

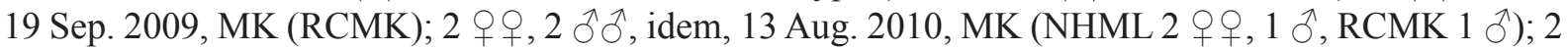

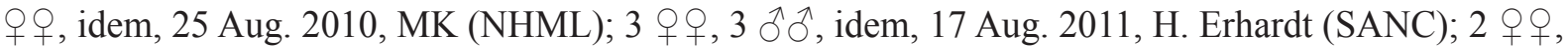

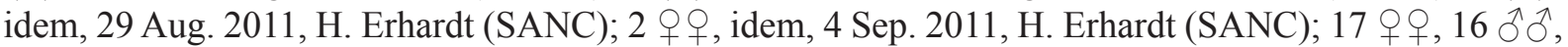

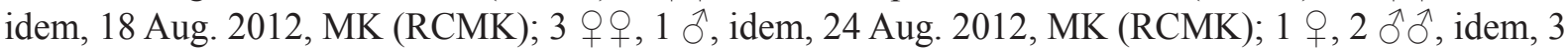
Sep. 2012, MK (RCMK); 3 qq , idem, 5 Sep. 2012, H. Erhardt (RCMK); 4 qq , 1 ô, N. Cape, Fynbos, $15 \mathrm{~km}$ NW of Nieuwoudtville, near Farm Engelsepunt, 843 m, 31 ${ }^{\circ} 14^{\prime} 08^{\prime \prime} \mathrm{S}, 18^{\circ} 58^{\prime} 23^{\prime \prime}$ E, 13 Sep. 2003, KT (NHML); 4 우, idem, 23 Sep. 2003, KT (NHML); 1 ㅇ, 1 $\curvearrowright$, N. Cape, Fynbos, 15 km NW of Nieuwoudtville, Farm Engelsepunt, 830 m, 31¹4'31" S, 1859'08" E, 22 Jul. 2003, KT (NHML); 2

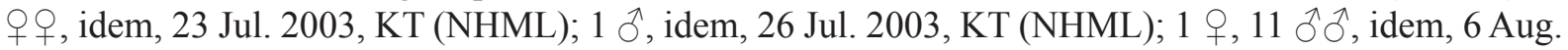

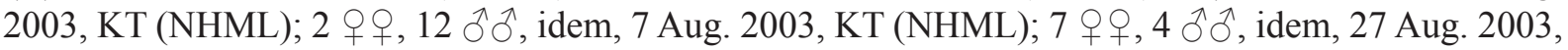
KT (NHML); 5 우, idem, 28 Aug. 2003, KT (NHML); 1 ㅇ, idem, 24 Sep. 2003, KT (NHML); 3 우, 2

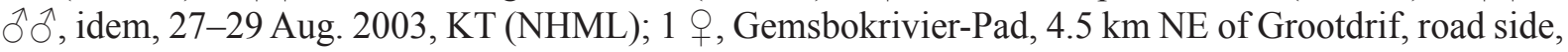
170 m, 31 25'54" S, 18 55'16" E, 17 Aug. 2012, MK (RCMK); 1 ô, 20 km S of Nieuwoudtville, Farm

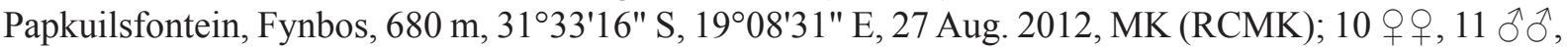

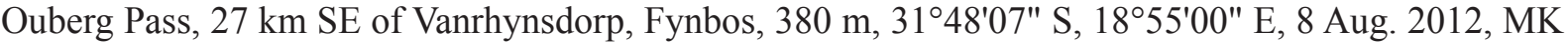

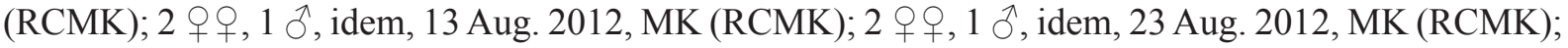
4 우, idem, 30 Aug. 2012, MK (RCMK).

\section{Description}

\section{Female}

BODY LENGTH. 4.5-4.8 mm.

HEAD. Head slightly wider than long. Integument black, except part of mandibles dark reddish-brown. Face sparsely covered with long, greyish, erect hair (Fig. 16C). Clypeus convex with coarse and dense punctation ( $\mathrm{i}=1-2 \mathrm{~d})$; surface between punctures apically superficially sculptured and shiny, basally 
denser and slightly matt (Fig. 16C-D). Malar area medially narrow, almost linear. Antenna dorsally blackish-brown, ventrally yellowish-brown.

Mesosoma. Integument black. Mesoscutal disc between punctures superficially reticulate and slightly matt; disc densely ( $\mathrm{i}=1.5-2.0 \mathrm{~d}$ ) and finely punctate (Fig. 16E-F). Metanotum slightly shorter than basal area of propodeum, apically with broad carinate depression (Fig. 16F). Propodeum basally distinctly and broadly carinate (Fig. 16F). Mesoscutum, scutellum, metanotum, mesepisternum and propodeum sparsely covered with short, greyish, erect hair (Fig. 16A).
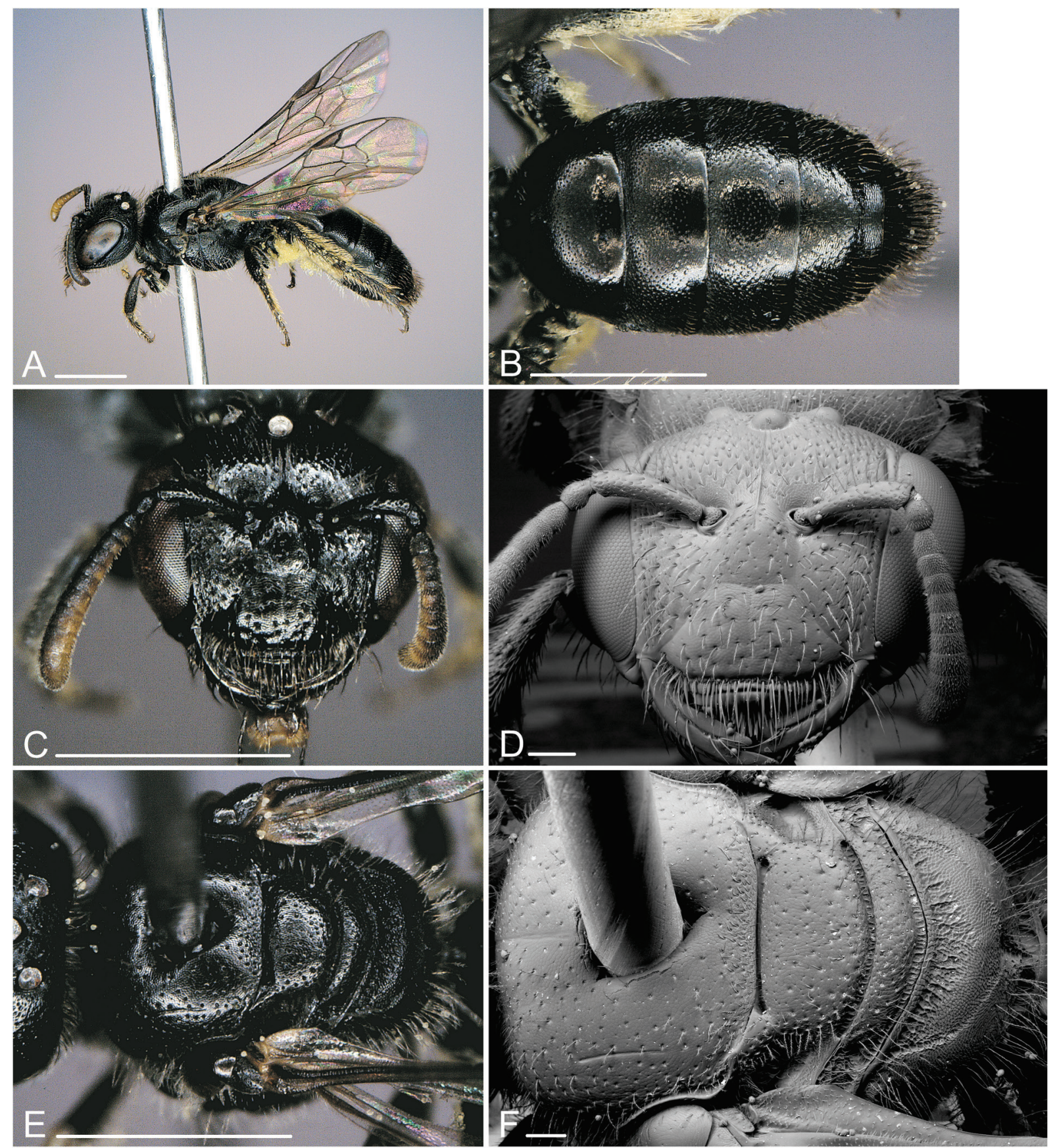

Fig. 16. Scrapter nanus sp. nov., ․ A. Lateral view. B. Metasoma (dorsal view). C. Head. D. Head (SEM). E. Thorax (dorsal view). F. Thorax (dorsal view, SEM). Scale bars: photos: $1 \mathrm{~mm}$, SEM: $0.1 \mathrm{~mm}$. 
WINGS. Slightly brownish; wing venation and stigma brown.

LEGS. Integument black to dark reddish-brown; fore tibia basally with small yellowish spot. Vestiture greyish-white, scopa greyish-white, dorsally blackish-brown.

Metasoma. Integument black, apical margins of terga partly narrowly translucent dark reddish-brown (Fig. 16B). Discs of T1 and T2 without hair, following terga with very short but increasingly more and

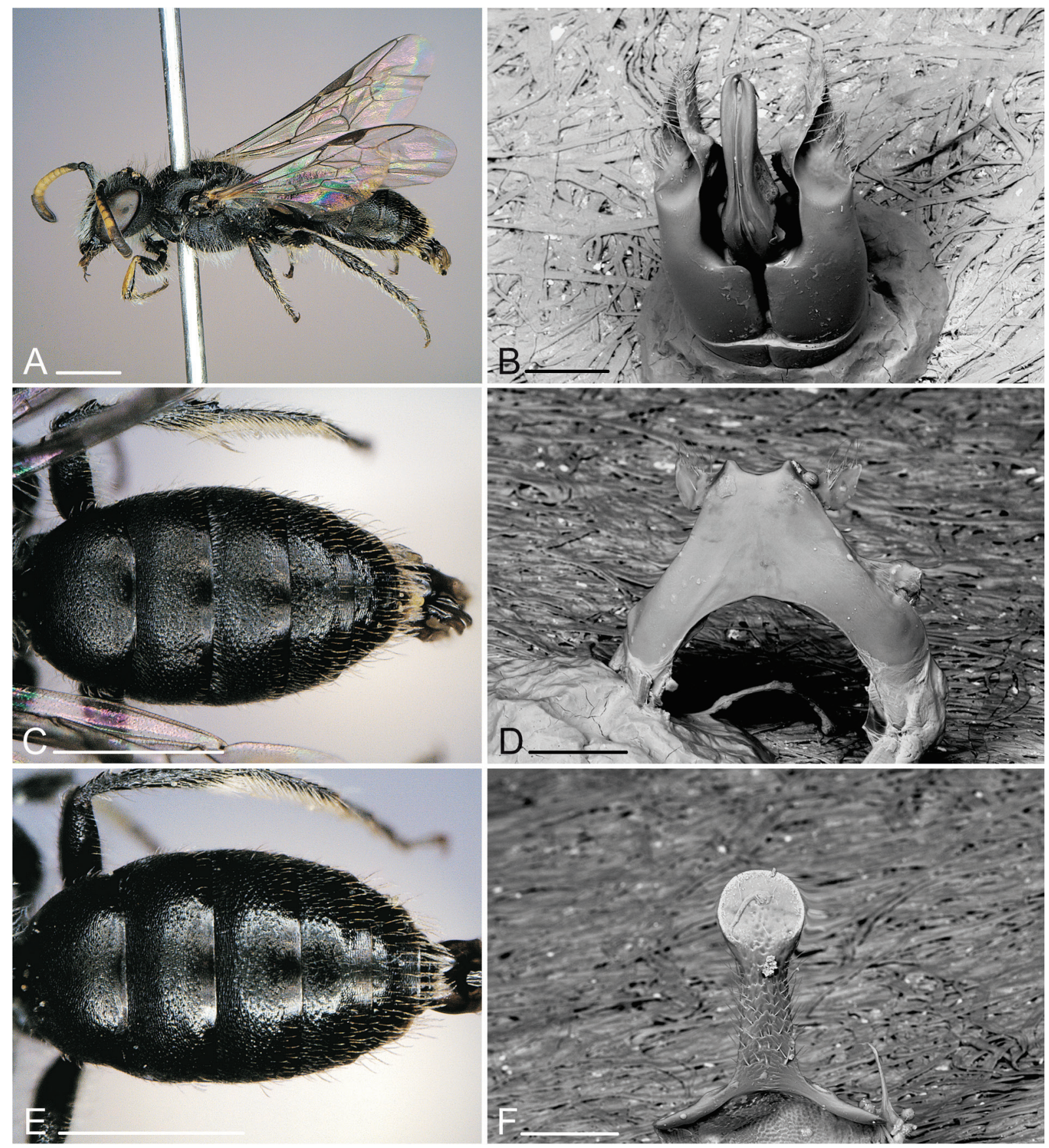

Fig. 17. Scrapter nanus sp. nov., Ô. A. Lateral view. B. Genitalia (dorsal view, SEM). C. Metasoma (dorsal view). D. S7 (dorsal view, SEM). E. Metasoma (dorsal view). F. S8, apical end (SEM). Scale bars: photos: $1 \mathrm{~mm}$, SEM: $0.1 \mathrm{~mm}$. 
longer hair; apical tergal hair bands missing on all terga (Fig. 16B). Prepygidial and pygidial fimbriae blackish-brown. T1 densely ( $i=0.5-1.0 \mathrm{~d}$ ) but very finely punctate, between punctures superficially sculptured but shiny; T2-T4 superficially sculptured, with dense $(i=0.5-1.0 \mathrm{~d})$ but slightly coarser, superficial punctation; T2-T4 with superficially sculptured but shiny, broad apical tergal depression (Fig. 16B).

Male

Body LENGTH. 4.3-4.7 mm.

HEAD. Head slightly wider than long. Integument black, except mandible partly dark reddish-brown. Face densely covered with long, greyish-white, erect hair. Malar area medially narrow, almost linear. Antenna dorsally dark brown, ventrally yellowish-brown except last three flagellar segments completely brown (Fig. 17A).

Mesosoma. Integument black. Mesoscutal disc between punctures densely reticulate and matt; disc sparsely $(\mathrm{i}=2-3 \mathrm{~d})$ and finely punctate. Mesoscutum, scutellum, metanotum, mesepisternum and propodeum covered with long, greyish, erect hair (Fig. 17A).

WINGs. Slightly yellowish-brown; wing venation and stigma brown.

LEGS. Integument black, fore tibia anteriorly yellow, base of mid tibia with small yellow spot (Fig. 17A). Hind tibia apicomedially slightly swollen (Fig. 17A). Vestiture greyish-white.

METASOMA. Integument black, apical margins of terga partly narrowly translucent dark reddish-brown (Fig. 17C, E). Discs of T1-T3 without hair, following terga with sparse and short but successively more and longer hair; apical tergal hair bands missing on all terga (Fig. 17C, E). T1 and following terga densely $(\mathrm{i}<0.5-1 \mathrm{~d})$, coarsely and irregularly punctate and strongly sculptured, matt; $\mathrm{T} 2-\mathrm{T} 4$ with broad, superficially sculptured but shiny apical tergal depression (Fig. 17C, E). S3 and particularly S4-S5 with long apical hair fringes.

Terminalia. Genitalia (Fig. 17B), S7 (Fig. 17D) and terminal plate of S8 (Fig. 17F) as illustrated.

\section{Distribution}

With one exception the species has only been found on sandy soils in Fynbos of the wider Nieuwoudtville area.

\section{Floral hosts}

Brassicaceae: white and blue Heliophila spp.

\section{Seasonal activity}

July-September.

\section{Scrapter nigerrimus sp. nov. urn:1sid:zoobank.org:act:55572B21-F7E9-48A1-AFBF-36EE912E1D1F}

Fig. 18

\section{Diagnosis}

The female of S. nigerrimus sp. nov. can be separated from other species of this group by the combination of the following characters: supraclypeal area and clypeus densely and distinctly punctate, mostly smooth 
and shiny (Fig. 18C-D), scutum densely and coarsely punctate (Fig. 18E-F), stigma brown, apical margins of metasomal terga black, terga finely and densely punctate (Fig. 18B). The male is unknown.

\section{Etymology}

Named for the completely black body of the species.
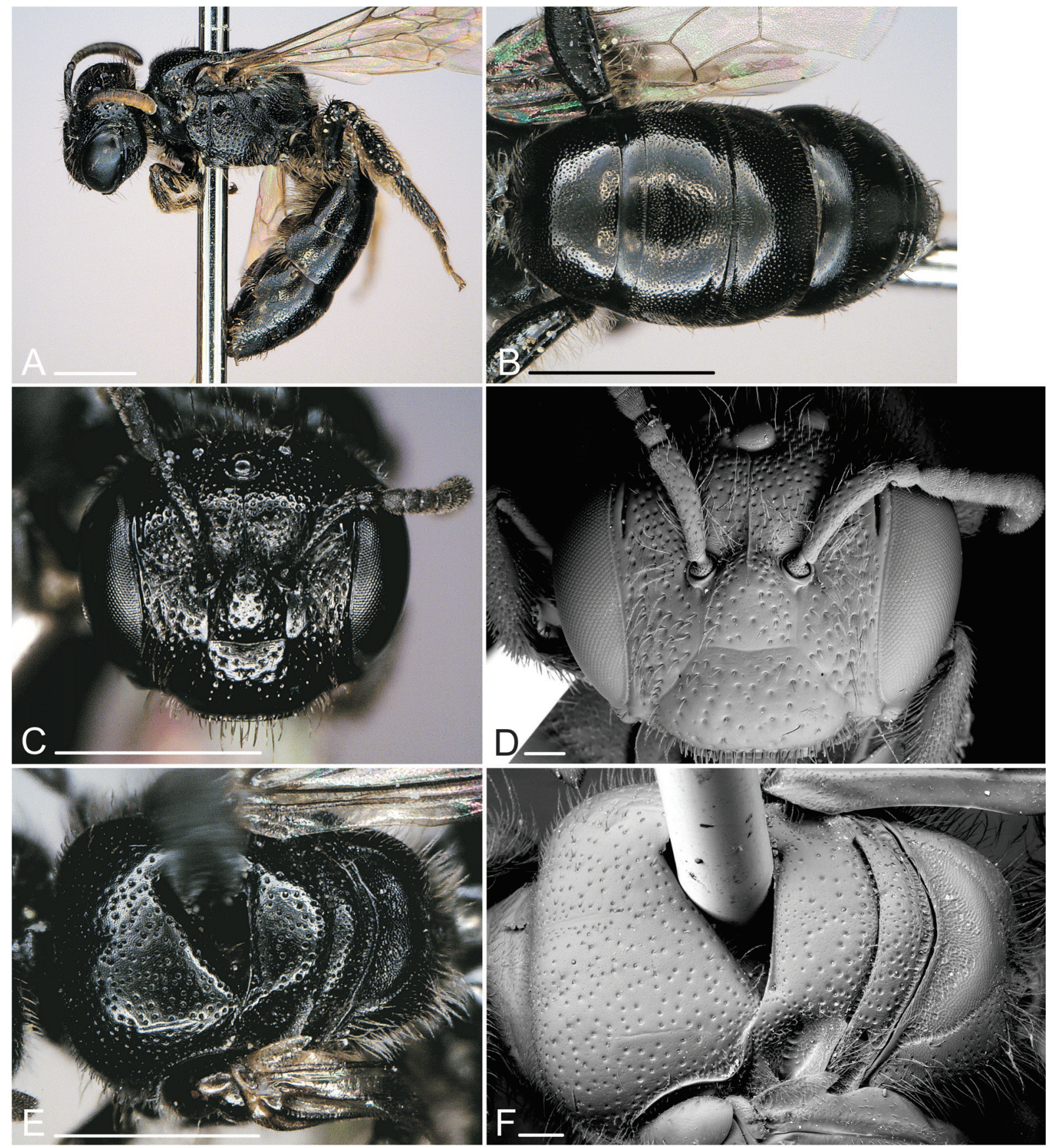

Fig. 18. Scrapter nigerrimus sp. nov.,, . A. Lateral view. B. Metasoma (dorsal view). C. Head. D. Head (SEM). E. Thorax (dorsal view). F. Thorax (dorsal view, SEM). Scale bars: photos: $1 \mathrm{~mm}$, SEM: $0.1 \mathrm{~mm}$. 
Type material ( 1 specimen examined)

\section{Holotype}

SOUTH AFRICA: + , W. Cape, Woodlot, nearby, 193 m, 3356' S, 18²4' E, 20 Sep. 2011, L. Packer (RCMK).

\section{Description}

\section{Female}

BODY LENGTH. $5.5 \mathrm{~mm}$.

HEAD. Head wider than long. Integument black, except part of mandibles dark reddish-brown. Face sparsely covered with long, greyish to blackish, erect hair (Fig. 18C). Clypeus strongly convex with coarse and dense punctation ( $\mathrm{i}=1-2 \mathrm{~d}$ ); surface between punctures smooth and shiny (Fig. 18C-D). Malar area medially narrow, almost linear. Antenna dorsally blackish-brown, ventrally yellowish-brown.

Mesosoma. Integument black. Mesoscutal disc between punctures superficially reticulate but shiny; disc densely ( $\mathrm{i}=0.5-1.0 \mathrm{~d}$ ) and finely punctate (Fig. 18E-F). Metanotum about as long as basal area of propodeum, apically with broad carinate depression (Fig. 18F). Propodeum basally shallowly but broadly carinate (Fig. 18F). Mesoscutum, scutellum, metanotum, mesepisternum and propodeum sparsely covered with short, greyish to blackish, erect hair (Fig. 18A).

WINGS. Brownish; wing venation and stigma brown.

LEGS. Integument black. Vestiture greyish to blackish, scopa blackish-brown.

Metasoma. Integument black (Fig. 18B). Discs of T1-T3 without hair, following terga with sparse and very short but increasingly more and longer hair; apical tergal hair bands missing on all terga (Fig. 18B). Prepygidial and pygidial fimbriae missing (rubbed off?). Terga densely $(\mathrm{i}=0.5-1 \mathrm{~d}$ ) but finely punctate, between punctures polished and shiny; apical tergal margins hardly depressed and punctate-like discs (Fig. 18B).

\section{Male \\ Unknown.}

\section{Distribution}

The species is known from the type locality on the Cape Peninsula near Cape Town.

\section{Floral hosts}

Unknown.

\section{Seasonal activity}

September.

Scrapter nigritarsis sp. nov. urn:1sid:zoobank.org:act:683368CE-FDA0-4A33-9BF9-3667D13AAF54

Figs 19-20

\section{Diagnosis}

The female of S. nigritarsis sp. nov. can be separated from other species of this group by the combination of the following characters: supraclypeal area and clypeus sparsely but distinctly punctate, mostly finely sculptured and slightly matt (Fig. 19C-D), scutum sparsely but relatively coarsely punctate, basal area 
of propodeum basally largely carinate (Fig. 19B), stigma brown, apical margins of metasomal terga black or only slightly brownish translucent, terga impunctate (Fig. 19E). The male is characterized by an unmodified antenna, simple and black hind tibia and hind basitarsus (Fig. 20A), almost hairless and impunctate abdominal terga (Fig. 20C) and form of S7 (Fig. 20D).

\section{Etymology}

Named for the black tarsi of the females.
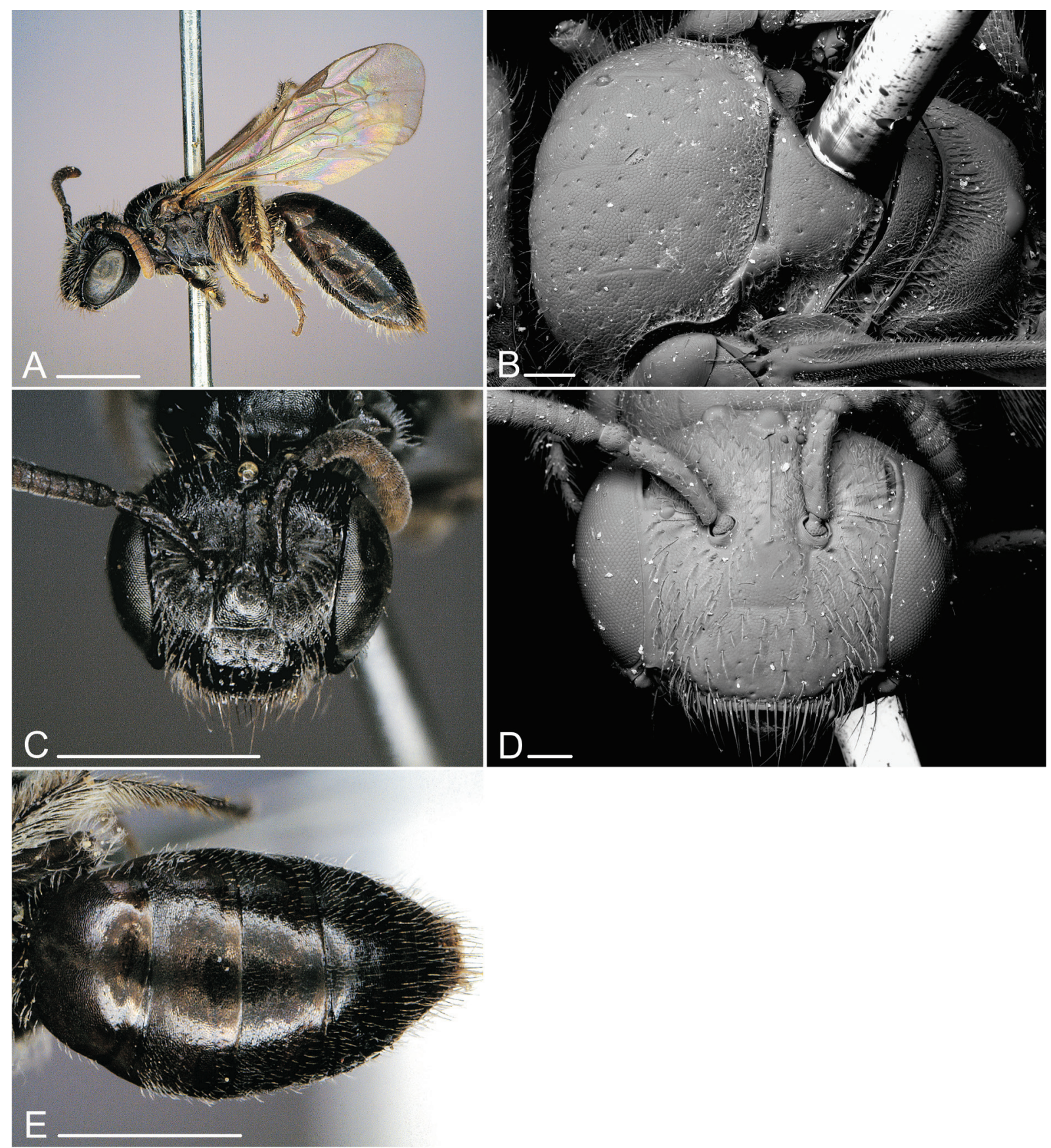

Fig. 19. Scrapter nigritarsis sp. nov., $q$. A. Lateral view. B. Thorax (dorsal view, SEM). C. Head. D. Head (SEM). E. Metasoma (dorsal view). Scale bars: photos: $1 \mathrm{~mm}$, SEM: $0.1 \mathrm{~mm}$. 
Type material ( 2 specimens examined)

\section{Holotype}

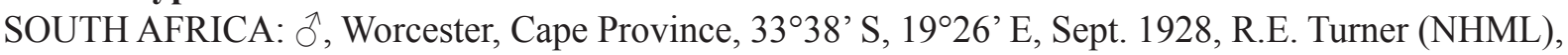
(identified as Scrapter albitarsis (Friese), C.D. Eardley det. 1995).

\section{Paratype}

SOUTH AFRICA: 1 , , same data as holotype (NHML) (identified as Scrapter albitarsis (Friese), C.D. Eardley det. 1995).

\section{Description}

\section{Female}

BODY LENGTH. $4.5 \mathrm{~mm}$.

HEAD. Head slightly wider than long. Integument black, except part of mandibles dark reddish-brown. Face sparsely covered with long, greyish, erect hair (Fig. 19C). Clypeus almost flat with dispersed large, shallow punctation ( $i=1-2 \mathrm{~d}$ ); surface between punctures apically smooth or only superficially sculptured, shiny, basally more heavily sculptured and matt (Fig. 19C-D). Malar area medially narrow, almost linear. Antenna dorsally blackish-brown, ventrally yellowish-brown.

Mesosoma. Integument black. Mesoscutal disc between punctures strongly reticulate, matt; disc sparsely $(\mathrm{i}=2-3 \mathrm{~d}$ ), finely and shallowly punctate (Fig. 19B). Metanotum about half as long as basal area of propodeum, apically with distinct, narrow carinate depression (Fig. 19B). Propodeum with distinct carination covering more than half of the basal area (Fig. 19B). Mesoscutum, scutellum, metanotum, mesepisternum and propodeum sparsely covered with short, greyish, erect hair (Fig. 19A).

WINGS. Yellowish-brown; wing venation and stigma brown.

LEGS. Integument black to dark reddish-brown; fore tibia basally with small yellow spot. Vestiture greyish-white, scopa greyish-white, dorsally blackish-brown.

Metasoma. Integument black, apical margins of terga sometimes narrowly translucent dark reddishbrown (Fig. 19E). Discs of T1 and T2 without hair; following terga with sparse and short but increasingly more and longer hair; apical tergal hair bands missing on all terga (Fig. 19E). Prepygidial and pygidial fimbriae very sparse, brownish. Terga impunctate, superficially and \pm densely sculptured, mostly shiny; T2-T4 with finely sculptured, narrow and indistinct apical tergal depression (Fig. 19E).

\section{Male}

BODY LENGTH. $4.4 \mathrm{~mm}$.

HEAD. Head slightly wider than long. Integument black, except mandible partly dark reddish-brown. Face densely covered with long, greyish-white, erect hair. Malar area medially narrow, almost linear. Antenna dorsally dark brown, ventrally dark orange-brown (Fig. 20A).

Mesosoma. Integument black. Mesoscutal disc impunctate, strongly sculptured and matt. Mesoscutum, scutellum, metanotum, mesepisternum and propodeum sparsely covered with long, greyish, erect hair (Fig. 20A).

WINGS. Slightly yellowish-brown; wing venation and stigma brown.

LEGS. Integument black to dark reddish-brown; fore tibia anteriorly dominantly yellow to yellowishbrown (Fig. 20A). Hind tibia unmodified. Vestiture greyish-white. 
Metasoma. Integument black, apical margins of terga partly translucent yellowish to dark reddishbrown (Fig. 20C). Disc of T1 without hair; apical tergal hair bands missing on all terga (Fig. 20C). Terga impunctate, sculptured and slightly matt; terga with broad and superficially sculptured, more shiny apical tergal depression (Fig. 20C). S3-S5 without distinct apical hair fringes.

Terminalia. Genitalia (Fig. 20B), S7 (Fig. 20D) and terminal plate of S8 (Fig. 20E) as illustrated.
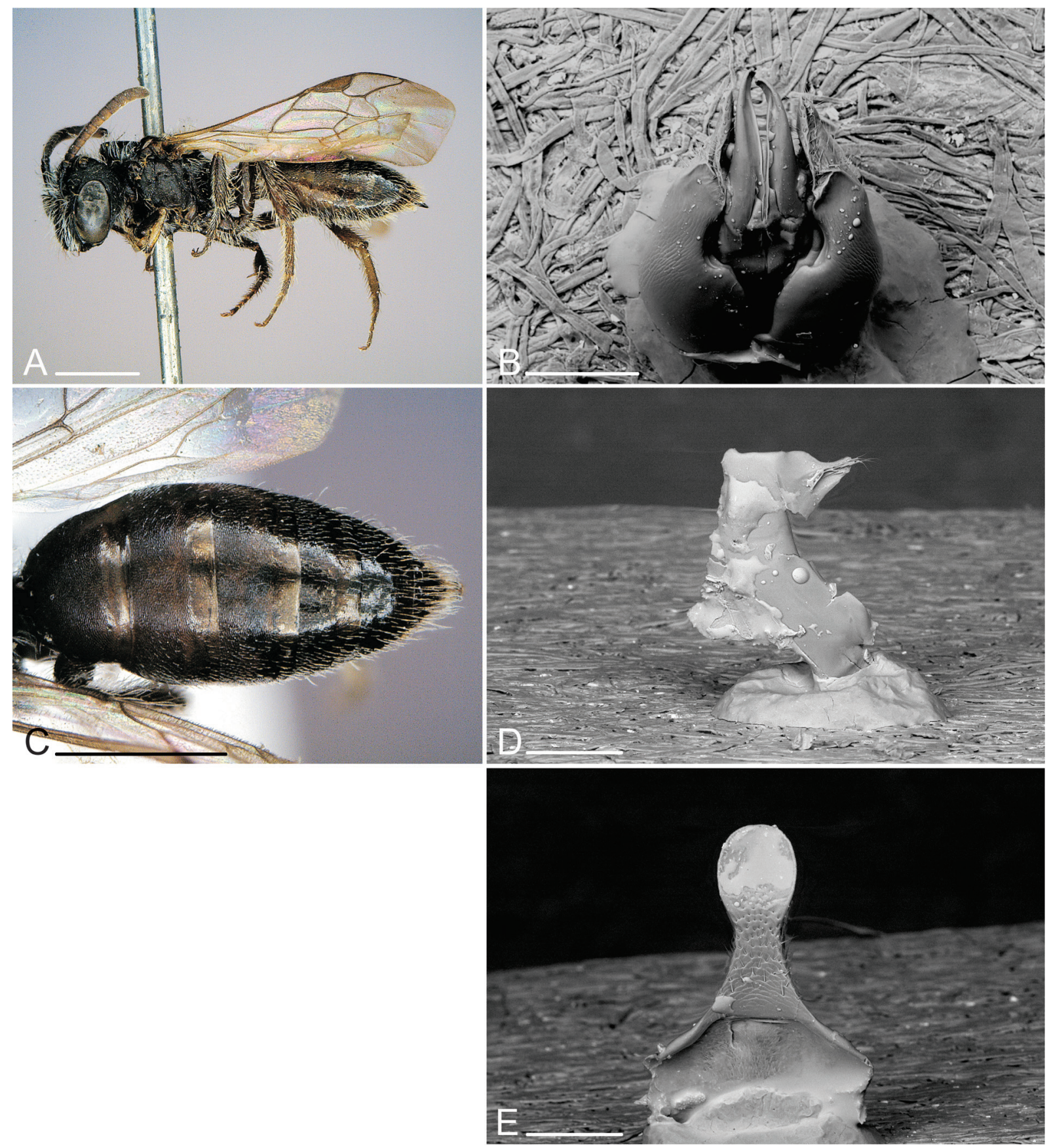

Fig. 20. Scrapter nigritarsis sp. nov., ô. A. Lateral view. B. Genitalia (dorsal view, SEM). C. Metasoma (dorsal view). D. S7 (dorsal view, SEM). E. S8, apical end (SEM). Scale bars: photos: 1 mm, SEM: $0.1 \mathrm{~mm}$. 


\section{Distribution}

The species is known from the type locality around Worcester.

\section{Floral hosts}

Unknown.

\section{Seasonal activity}

September.

$$
\begin{gathered}
\text { Scrapter papkuilsi sp. nov. } \\
\text { urn:1sid:zoobank.org:act:08F5003E-4ECD-4C7D-9756-010E4D626720 }
\end{gathered}
$$

Figs 21-22

\section{Diagnosis}

The female of S. papkuilsi sp. nov. can be separated from other species of this group by the combination of the following characters: head about as long as broad, supraclypeal area and clypeus densely and distinctly punctate, only partly superficially sculptured and matt (Fig. 21B), scutum densely but relatively finely punctate, metanotum apicaly with carinate depression (Fig. 21C-F), stigma brown, apical margins of metasomal terga black, terga densely and coarsely punctate (Fig. $21 \mathrm{G}-\mathrm{H}$ ). The male is characterized by an unmodified antenna, hind tibia apically broadened inside and pointed (Fig. 22E), relatively finely but densely punctate scutum and metasomal terga (Fig. 22C) and the form of S7 (Fig. 22D).

\section{Etymology}

Named after Farm Papkuilsfontein south of the town of Nieuwoudtville, where most of the specimens were collected.

Type material (107 specimens examined)

\section{Holotype}

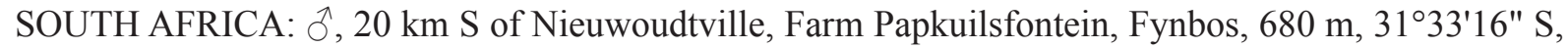
1908'31" E, 27 Aug. 2012, 27 Aug. 2012, M. Kuhlmann (SANC).

\section{Paratypes}

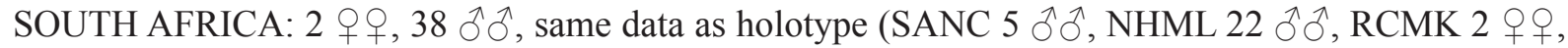

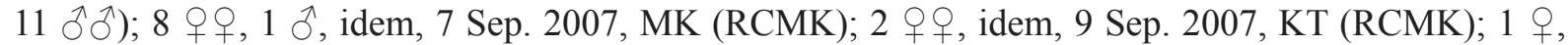

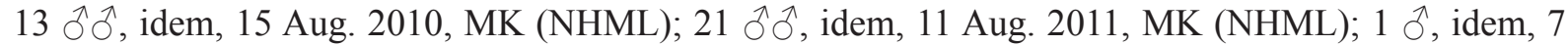
Sep. 2007, MK (EMUS); 1 ㅇ, idem, 9 Sep. 2007, KT (EMUS); 4 우, N. Cape, Fynbos, 15 km NW of Nieuwoudtville, Farm Engelsepunt, 830 m, 31ำ14'31" S, 1859'08" E, 24 Sep. 2003, KT (RCMK); 1 q, idem, 6 Oct. 2003, KT (RCMK); 1 q, 12 km NW of Nieuwoudtville, Farm Avontuur, Fynbos, 770 m, $31^{\circ} 16^{\prime} 18^{\prime \prime}$ S, 1902'55" E, 25 Aug. 2010, MK (RCMK); 1 Oे, Ouberg Pass, 27 km SE of Vanrhynsdorp, Fynbos, 380 m, 31 ${ }^{\circ} 48^{\prime} 07^{\prime \prime} \mathrm{S}, 18^{\circ} 55^{\prime} 00^{\prime \prime} \mathrm{E}, 9$ Aug. 2011, MK (RCMK); 2 + 9 , idem, 8 Aug. 2012, MK

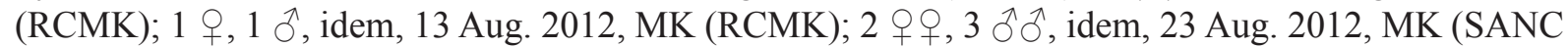

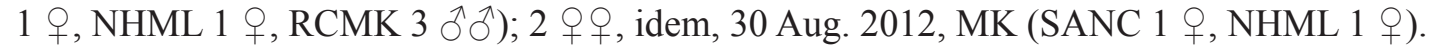

\section{Description}

Female

Body LeNGTH. 4.5-5.1 mm.

HeAD. Head about as wide as long. Integument black, except part of mandibles dark reddish-brown. Face sparsely covered with long, greyish, erect hair (Fig. 21A). Clypeus slightly convex with coarse 


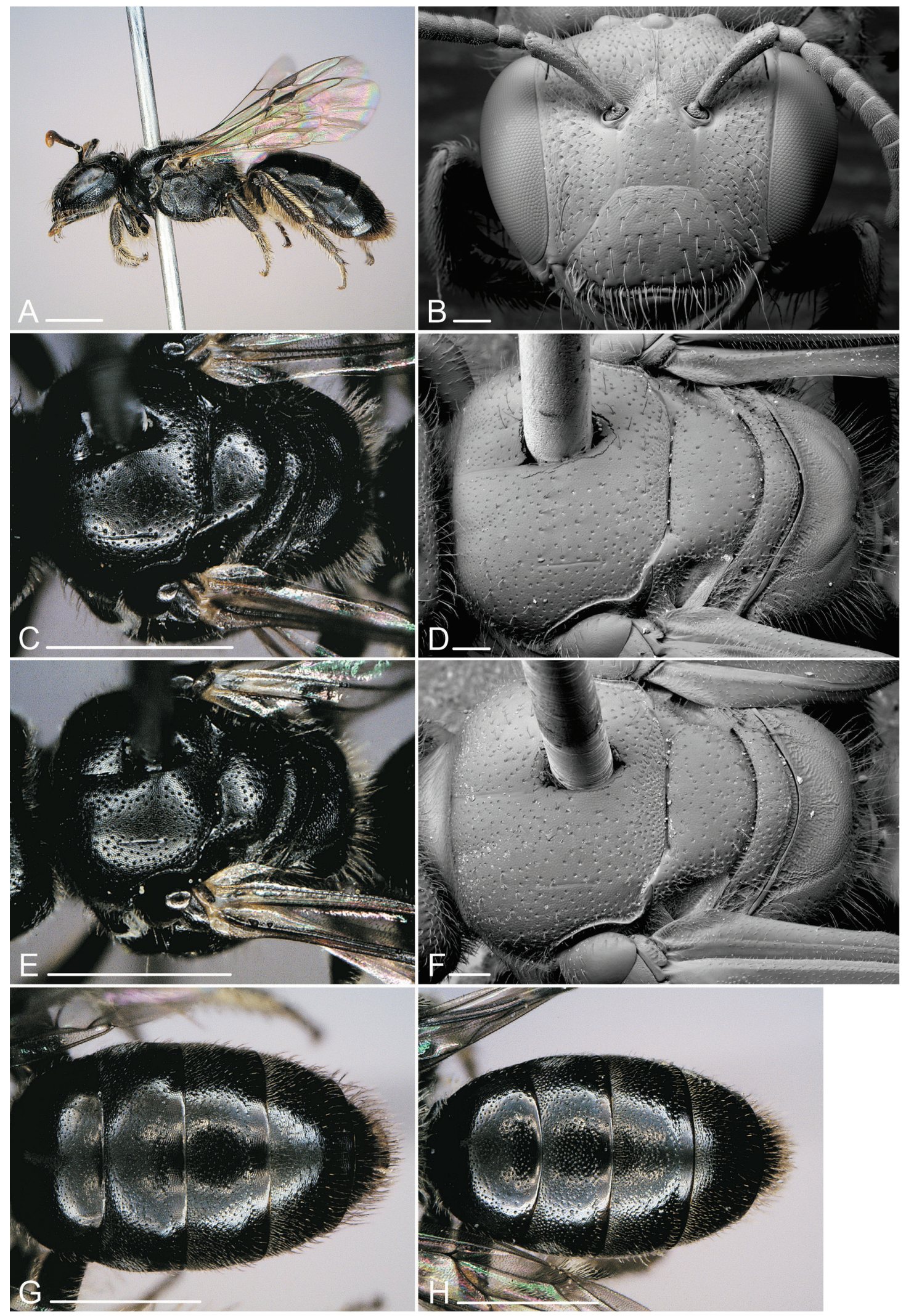

Fig. 21. Scrapter papkuilsi sp. nov., +. A. Lateral view. B. Head (SEM). C. Thorax (dorsal view). D. Thorax (dorsal view, SEM). E. Thorax (dorsal view). F. Thorax (dorsal view, SEM). G. Metasoma (dorsal view). H. Metasoma (dorsal view). Scale bars: photos: $1 \mathrm{~mm}$, SEM: $0.1 \mathrm{~mm}$. 
and dense punctation ( $i=1-2 \mathrm{~d}$ ); surface between punctures apically superficially sculptured and shiny, basally densely sculptured and matt (Fig. 21B). Malar area medially narrow, almost linear. Antenna dorsally blackish-brown, ventrally yellowish-brown.

Mesosoma. Integument black. Mesoscutal disc between punctures to a variable degree but densely reticulate, mostly matt; disc densely $(i=0.5-2.0 \mathrm{~d})$ and finely punctate (Fig. 21C-F). Metanotum slightly shorter than basal area of propodeum, apically with narrow carinate depression (Fig. 21D, F). Propodeum basally shallowly but broadly carinate (Fig. 21D, F). Mesoscutum, scutellum, metanotum, mesepisternum and propodeum sparsely covered with short greyish to brownish, erect hair (Fig. 21A).

WINGS. Slightly yellowish-brown; wing venation and stigma brown.

LEGS. Integument black to dark reddish-brown; fore tibia basally with yellowish spot of variable size. Vestiture greyish to brownish, scopa greyish-brown.

Metasoma. Integument black, apical margins of terga partly narrowly translucent dark reddish-brown (Fig. 21G-H). Disc of T1 without hair; following terga with sparse and very short but increasingly more and longer hair; apical tergal hair bands missing on all terga (Fig. 21G-H). Prepygidial and pygidial fimbriae blackish-brown. T1 to a variable extend densely ( $i=0.5-1.0 \mathrm{~d})$ and very finely punctate, between punctures superficially sculptured but shiny; T2-T4 superficially sculptured, shiny, with dense, very fine to fine, superficial to distinct punctation; T2-T4 with superficially sculptured, broad apical tergal depression (Fig. 21G-H).

\section{Male}

Body LENGTH. 4.6-5.0 mm.

HEAD. Head slightly wider than long. Integument black, except mandible partly dark reddish-brown. Face densely covered with long, greyish-white, erect hair. Malar area medially narrow, almost linear. Antenna dorsally dark brown, ventrally yellowish-brown (Fig. 22A).

Mesosoma. Integument black. Mesoscutal disc between punctures superficially reticulate, slightly matt; disc densely ( $\mathrm{i}=1-2 \mathrm{~d})$ and finely punctate. Mesoscutum, scutellum, metanotum, mesepisternum and propodeum covered with long, greyish, erect hair (Fig. 22A).

WINGS. Slightly yellowish-brown; wing venation and stigma brown.

LEGS. Integument black, fore tibia anteriorly yellow, base of mid tibia with small yellow spot (Fig. 22A). Hind tibia inside apically broadened, rectangular or with a short spine (Fig. 22E). Vestiture greyishwhite.

Metasoma. Integument black (Fig. 22C). Discs of T1-T2 without hair; following terga with sparse and very short but increasingly more and longer hair; T3 and sometimes T2 and T4 basally with a medially very narrow, laterally wider, sparse band of very fine, short, erect silvery hair; apical tergal hair bands missing on all terga (Fig. 22C). T1 and following terga densely ( $\mathrm{i}<0.5-1 \mathrm{~d}$ ), very finely and irregularly punctate, between punctures sculptured and matt; terga with narrow, superficially sculptured but shiny apical tergal depression (Fig. 22C). S3 and particularly S4-S5 with sparse, long apical hair fringes.

Terminalia. Genitalia (Fig. 22B), S7 (Fig. 22D) and terminal plate of S8 (Fig. 22F) as illustrated.

\section{Distribution}

The species has only been found on sandy soils in Fynbos of the wider Nieuwoudtvulle area. 


\section{Floral hosts}

Brassicaceae: white and blue Heliophila sp.

\section{Seasonal activity}

August-October.
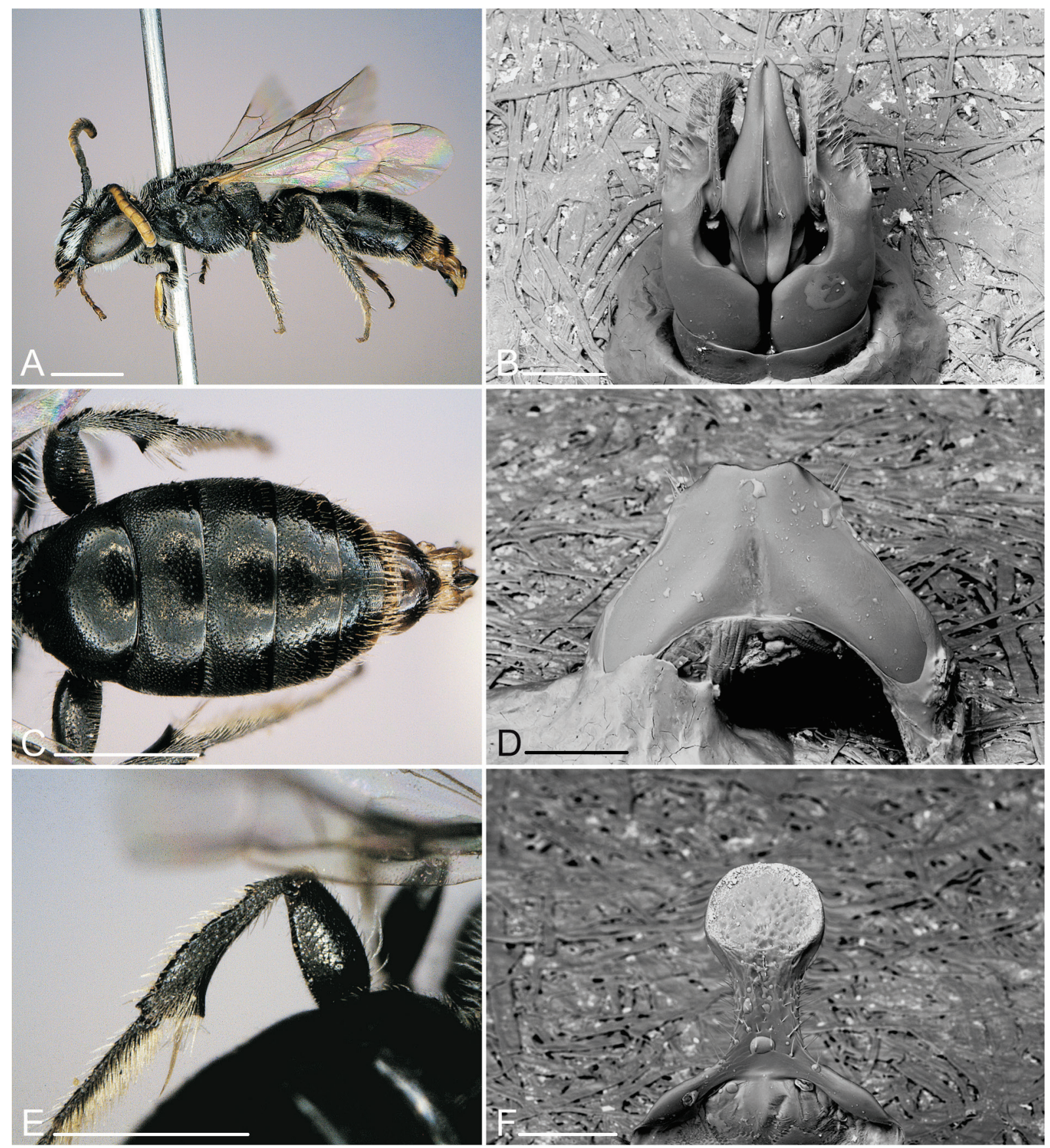

Fig. 22. Scrapter papkuilsi sp. nov., Ô. A. Lateral view. B. Genitalia (dorsal view, SEM). C. Metasoma (dorsal view). D. S7 (dorsal view, SEM). E. Hind tibia. F. S8, apical end (SEM). Scale bars: photos: 1 mm, SEM: $0.1 \mathrm{~mm}$. 


\section{Scrapter punctatus sp. nov. urn:1sid:zoobank.org:act:4C655519-A4FA-450E-8F66-940B66C9B5BA}

Figs 23-24

\section{Diagnosis}

The female of S. punctatus sp. nov. can be separated from other species of this group by the combination of the following characters: supraclypeal area and clypeus densely and distinctly punctate, shiny, only partly superficially sculptured (Fig. 23B), scutum densely and coarsely punctate, basal area of propodeum medially only slightly longer than metanotum (Fig. 23C-D), stigma brown, apical margins of metasomal terga partly and narrowly brownish translucent, terga densely and coarsely punctate (Fig. $23 \mathrm{E}$ ). The male can be separated from all other species of this group by its very long antenna with the last flagellar segment being about as twice as long as wide (Fig. 24E).

\section{Etymology}

Named for the distinct punctation of the scutum and metasomal terga of the species.

Type material ( 7 specimens examined)

\section{Holotype}

SOUTH AFRICA: + , Witwater, slope, yellow + white, $30.23050^{\circ}$ S, $18.13458^{\circ}$ E, 23 Sep. 2003, C. Mayer (SANC).

\section{Paratypes}

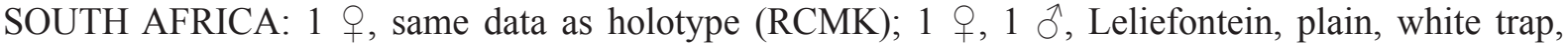
$30.23169^{\circ}$ S, $18.16260^{\circ}$ E, 31 Aug. 2003, C. Mayer (RCMK); 1 ㅇ, Leliefontein, slope, white trap, $30.23288^{\circ} \mathrm{S}, 18.16458^{\circ}$ E, 7 Sep. 2003, C. Mayer (RCMK); $1 \hat{\jmath}^{\hat{\prime}}$, Leliefontein, plain, white trap, $30.23391^{\circ} \mathrm{S}, 18.16476^{\circ}$ E, 7 Sep. 2003, C. Mayer (RCMK); 1 ㅇ, Remhoogte, plain, white trap, $30.23431^{\circ} \mathrm{S}, 18.16491^{\circ} \mathrm{E}, 7$ Oct. 2002, C. Mayer (RCMK).

\section{Description}

\section{Female}

BODY LENGTH. 5.0-5.6 mm.

HEAD. Head wider than long. Integument black, except part of mandibles dark reddish-brown. Face sparsely covered with long, greyish, erect hair (Fig. 23A). Clypeus strongly convex with coarse and dense punctation ( $\mathrm{i}=1-2 \mathrm{~d}$ ); surface between punctures apically smooth and shiny, basally superficially shagreened but shiny (Fig. 23B). Malar area medially narrow, almost linear. Antenna dorsally blackishbrown, ventrally yellowish-brown.

Mesosoma. Integument black. Mesoscutal disc between punctures superficially reticulate, shiny; disc densely ( $\mathrm{i}=1-2 \mathrm{~d}$ ) and coarsely punctate (Fig. 23C-D). Metanotum about as long as basal area of propodeum, apically with narrow, indistinct carinate depression (Fig. 23D). Propodeum basally shallowly but broadly carinate (Fig. 23D). Mesoscutum, scutellum, metanotum, mesepisternum and propodeum sparsely covered with short, greyish, erect hair (Fig. 23A).

WINGs. Slightly yellowish-brown; wing venation and stigma yellowish-brown.

LEGS. Integument black to dark reddish-brown; fore and mid tibia basally sometimes with small yellowish spot. Vestiture greyish-white, scopa greyish-white, dorsally blackish-brown. 
Metasoma. Integument black, apical margins of terga broadly translucent yellowish to reddish-brown (Fig. 23E). Discs of T1 and T2 without hair; following terga with sparse and very short but increasingly more and longer hair; T2 (and sometimes T3) basally with a medially very narrow, laterally much broader band of very fine, short and erect silverish hair; apical tergal hair bands missing on all terga (Fig. 23E). Prepygidial and pygidial fimbriae greyish-brown. T1 densely $(i=0.5-1 \mathrm{~d})$ and finely to indistinctly punctate, between punctures polished to superficially sculptured and shiny; T2-T4 smoorh or superficially sculptured, shiny, with dense, fine, indistinct to fine punctation; T2-T4 with polished or superficially sculptured, broad and shiny apical tergal depression (Fig. 23E).
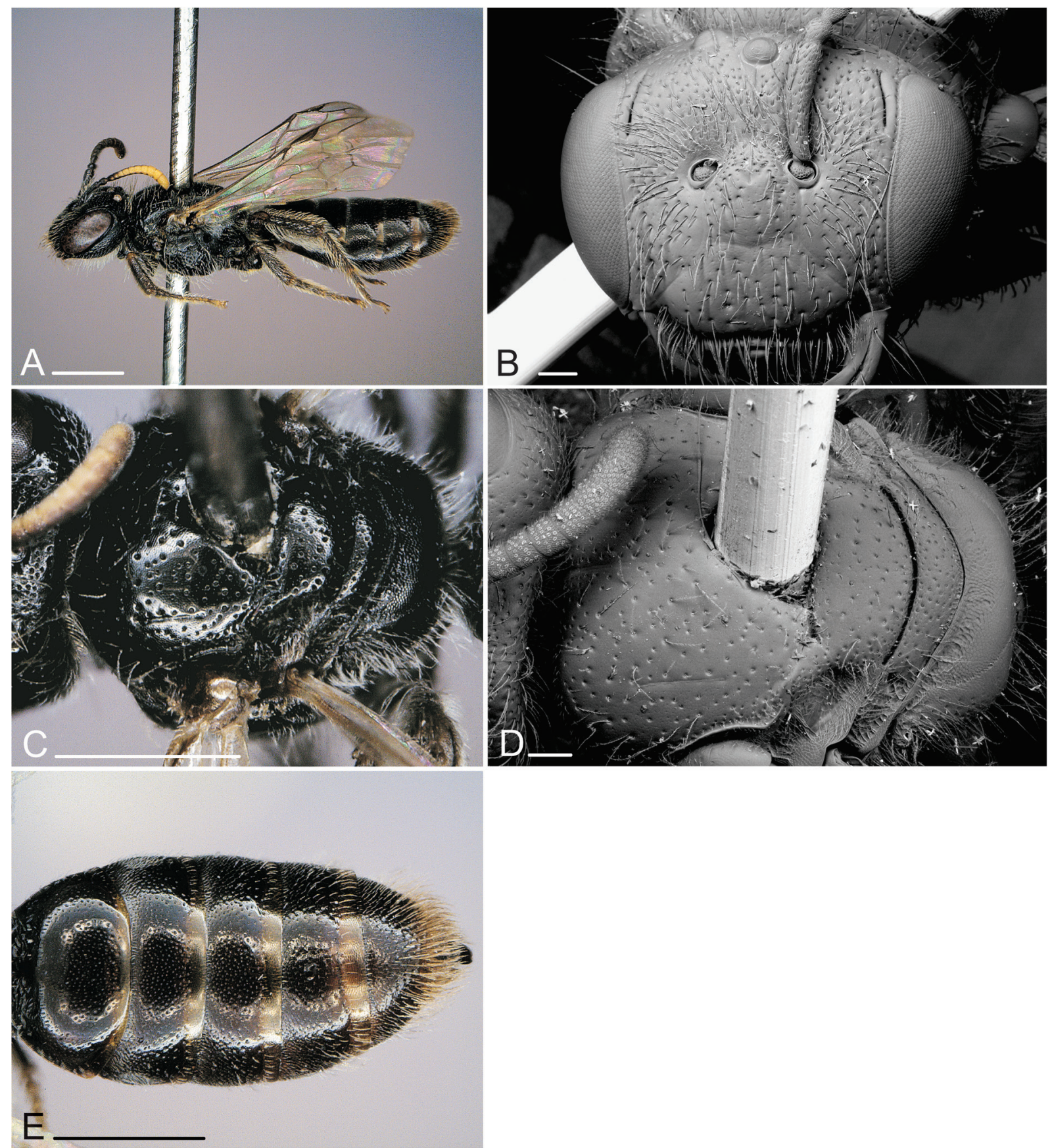

Fig. 23. Scrapter punctatus sp. nov., + . A. Lateral view. B. Head (SEM). C. Thorax (dorsal view). D. Thorax (dorsal view, SEM). E. Metasoma (dorsal view). Scale bars: photos: $1 \mathrm{~mm}$, SEM: $0.1 \mathrm{~mm}$. 


\section{Male}

BODY LENGTH. 5.0-5.4 mm.

HEAD. Head slightly wider than long. Integument black, except mandible partly dark reddish-brown. Face densely covered with long, greyish-white, erect hair. Malar area medially narrow, almost linear. Antenna elongate, last flagellar segment about twice as long as broad, dorsally dark brown, ventrally bright yellowish-brown (Fig. 24E).
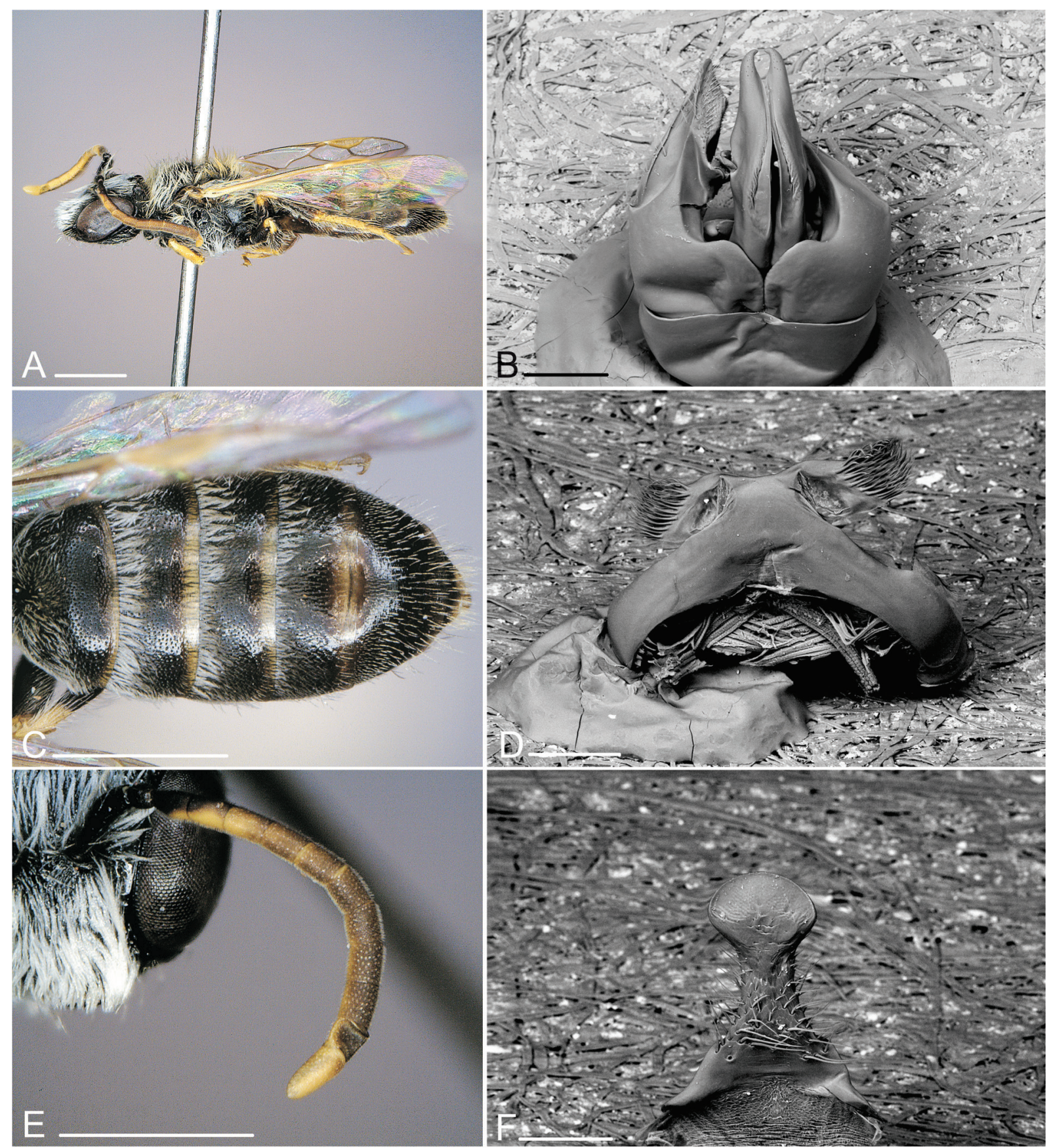

Fig. 24. Scrapter punctatus sp. nov., Ô. A. Lateral view. B. Genitalia (dorsal view, SEM). C. Metasoma (dorsal view). D. S7 (dorsal view, SEM). E. Antenna. F. S8, apical end (SEM). Scale bars: photos: 1 mm, SEM: $0.1 \mathrm{~mm}$. 
Mesosoma. Integument black. Mesoscutal disc between punctures smooth and shiny; disc very densely $(\mathrm{i}<0.5-1.0 \mathrm{~d})$ and finely punctate. Mesoscutum, scutellum, metanotum, mesepisternum and propodeum covered with long, greyish to yellowish-white, erect hair (Fig. 24A).

WINGS. Slightly yellowish-brown; wing venation and stigma yellowish-brown.

LEGS. Integument black, fore tarsi and fore tibia anteriorly yellow (posteriorly with large brown spot), mid and hind tibia basally and apically and femora apically with small yellow spot (Fig. 24A). Hind tibia unmodified. Vestiture greyish-white.

Metasoma. Integument black, apical margins of terga broadly translucent yellowish to reddish-brown (Fig. 24C). T1-T4 anteriorly densely covered with dense long, erect, white to silverish hair, apically with very sparse pilosity; apical tergal hair bands missing on all terga (Fig. 24C). T1 and following terga densely ( $\mathrm{i}<0.5-1 \mathrm{~d}$ ) and finely punctate, between punctures smooth and shiny; terga with broad, smooth and shiny apical tergal depression (Fig. 24C). S3 and particularly S4-S5 with sparse long apical hair fringes.

Terminalia. Genitalia (Fig. 24B), S7 (Fig. 24D) and terminal plate of S8 (Fig. 24F) as illustrated.

\section{Distribution}

The species is only known from the Kamiesberg Mountains.

\section{Floral hosts}

Unknown.

\section{Seasonal activity}

August-October.

Scrapter pygmaeus sp. nov. urn:lsid:zoobank.org:act:9327C6C8-CEB2-4BEA-A958-2EE02563FFA8 Fig. 25

\section{Diagnosis}

The female of S. pygmaeus sp. nov. can be separated from other species of this group by the combination of the following characters: supraclypeal area and clypeus sparsely but distinctly punctate, mostly finely sculptured and slightly matt (Fig. 25B), scutum reticulate, sparsely and shallowly punctate, basal area of propodeum basally indistinctly carinate (Fig. 25C-D), stigma brown, apical margins of metasomal terga black, terga impunctate (Fig. 25E). The male is unknown.

\section{Etymology}

Named for the small body size of the species.

Type material (35 specimens examined)

\section{Holotype}

SOUTH AFRICA: + , Nieuwoudtville, pad to Farm Glen Lyon, slope, 737 m, 31 $233^{\prime 2} 25^{\prime \prime}$ S, $19^{\circ} 08^{\prime} 28^{\prime \prime}$ E, 3 Sep. 2007, K. Timmermann (SANC).

\section{Paratypes}

SOUTH AFRICA: 5 q $q$, same data as holotype (RCMK); 6 우, idem, 2 Sep. 2007, KT (SANC 1 , RCMK 5 우우); 1 우, Nieuwoudtville, garden, 700 m, 312'ㄴ S, 1907' E, 18-19 Aug. 2007, KT (RCMK); 
1 q, Nieuwoudtville, Pad Glen Lyon to R27, 740 m, 31²3'24" S, 1909'06" E, 7 Sep. 2007, KT, on Ruschia sp. (RCMK); 1 ㅇ, idem, 17 Sep. 2007, KT (SANC); 1 +, idem, 20 Sep. 2007, KT (RCMK); 1 ㅇ, N. Cape, Nieuwoudtville, Flower Reserve, 770 m, 31²2'10" S, 1908'50" E, 27 Aug. 2006, KT (RCMK); 1 ㅇ, idem, 1 Sep. 2006, KT (SANC); 3 우, idem, 2 Sep. 2006, KT (NHML 1 ㅇ, RCMK 2 우우); 2 우어, idem, 10 Sep. 2006, KT (NHML, RCMK); 3 우아, idem, 18 Sep. 2006, KT (NHML 1 의, RCMK 2 우); 4 우, idem, 16 Aug. 2007, KT (NHML 1 ㅇ, RCMK 3 우); 1 q, idem, 19 Aug. 2007, KT (SANC); 2 우, idem, 21 Aug. 2007, KT (RCMK); 2 우, idem, 6 Sep. 2007, KT (RCMK).
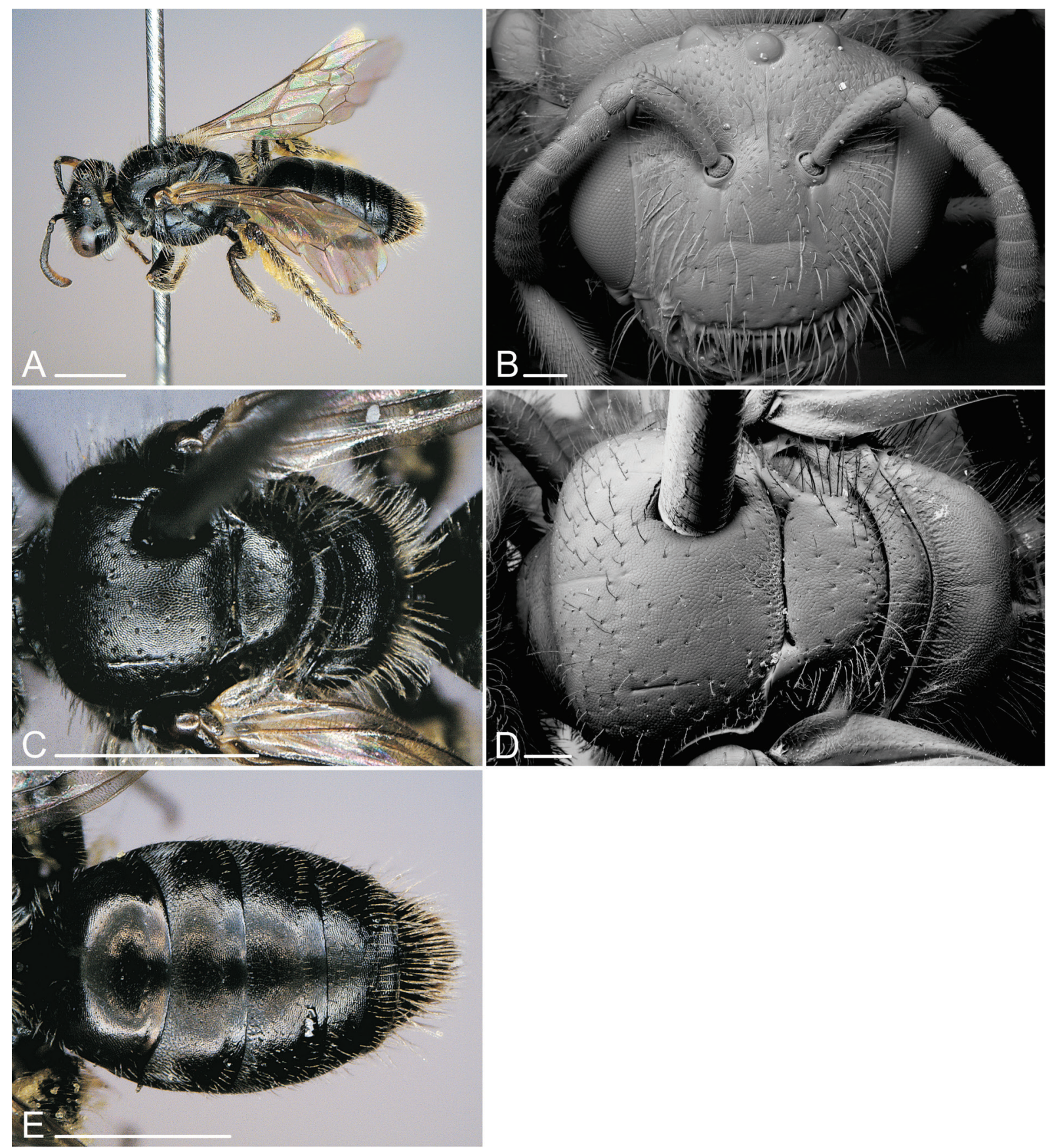

Fig. 25. Scrapter pygmaeus sp. nov., . A. Lateral view. B. Head (SEM). C. Thorax (dorsal view). D. Thorax (dorsal view, SEM). E. Metasoma (dorsal view). Scale bars: photos: $1 \mathrm{~mm}, \mathrm{SEM}$ : $0.1 \mathrm{~mm}$. 


\section{Description}

Female

Body LENGTH. 4.6-5.0 mm.

HEAD. Head slightly wider than long. Integument black, except part of mandibles dark reddish-brown. Face sparsely covered with long, greyish, erect hair (Fig. 25A). Clypeus almost flat, with dispersed large, shallow punctation ( $i=1-2 \mathrm{~d}$ ); surface between punctures apically smooth or only superficially sculptured, shiny, basally more heavily sculptured and matt (Fig. 25B). Malar area medially narrow, almost linear. Antenna dorsally blackish-brown, ventrally yellowish-brown.

Mesosoma. Integument black. Mesoscutal disc between punctures strongly reticulate, matt; disc sparsely $(\mathrm{i}=2-3 \mathrm{~d}$ ), finely and shallowly punctate (Fig. 25C-D). Metanotum about half as long as basal area of propodeum, apically with indistinct narrow carinate depression (Fig. 25D). Propodeum with shallow carination covering about half of the basal area (Fig. 25D). Mesoscutum, scutellum, metanotum, mesepisternum and propodeum sparsely covered with short, greyish, erect hair (Fig. 25A).

Wings. Yellowish-brown; wing venation and stigma brown.

LEGS. Integument black to dark reddish-brown; fore tibia basally with small yellow spot. Vestiture greyish-white, scopa greyish-white, dorsally blackish-brown.

Metasoma. Integument black, apical margins of terga sometimes narrowly translucent yellowish to dark reddish-brown (Fig. 25E). Disc of T1 without hair; following terga with sparse and short but increasingly more and longer hair; T2 and T3 basally with a medially very narrow, laterally much broader band of very fine, short and erect, silverish hair; apical tergal hair bands missing on all terga (Fig. 25E). Prepygidial and pygidial fimbriae yellowish-brown. Terga impunctate, superficially and \pm densely sculptured, mostly shiny; T2-T4 with finely sculptured, broad apical tergal depression (Fig. 25E).

Male

Unknown.

\section{Distribution}

The species is only known from the vicinity of Nieuwoudtville.

\section{Floral hosts}

Aizoaceae: Ruschia sp.

\section{Seasonal activity}

August-September.

\section{Scrapter roggeveldi $\mathrm{sp}$. nov. urn:Isid:zoobank.org:act:A27CB4A6-3323-440A-A4A1-C5C8F545A389}

Figs 26-27

\section{Diagnosis}

The female of $S$. roggeveldi sp. nov. can be separated from other species of this group by the combination of the following characters: supraclypeal area and clypeus densely and distinctly punctate, partly superficially sculptured and matt (Fig. 26B), scutum densely but relatively finely punctate (Fig. 26C-D), stigma brown, apical margins of metasomal terga black, terga minutely punctate (Fig. 26E). The male 
is characterized by an unmodified antenna, hind tibia apically broadened inside, forming a \pm right angle (Fig. 27G), S4-S5 with long apical hair fringes (Fig. 27E) and the form of S7 (Fig. 27D).

Only one male of this species was collected, near Sutherland, but a single specimen from the Hantam Plateau about $130 \mathrm{~km}$ further NW probably represents the female of this species. This female is diagnosed and described here, but because of the uncertainty it is not included in the type series.

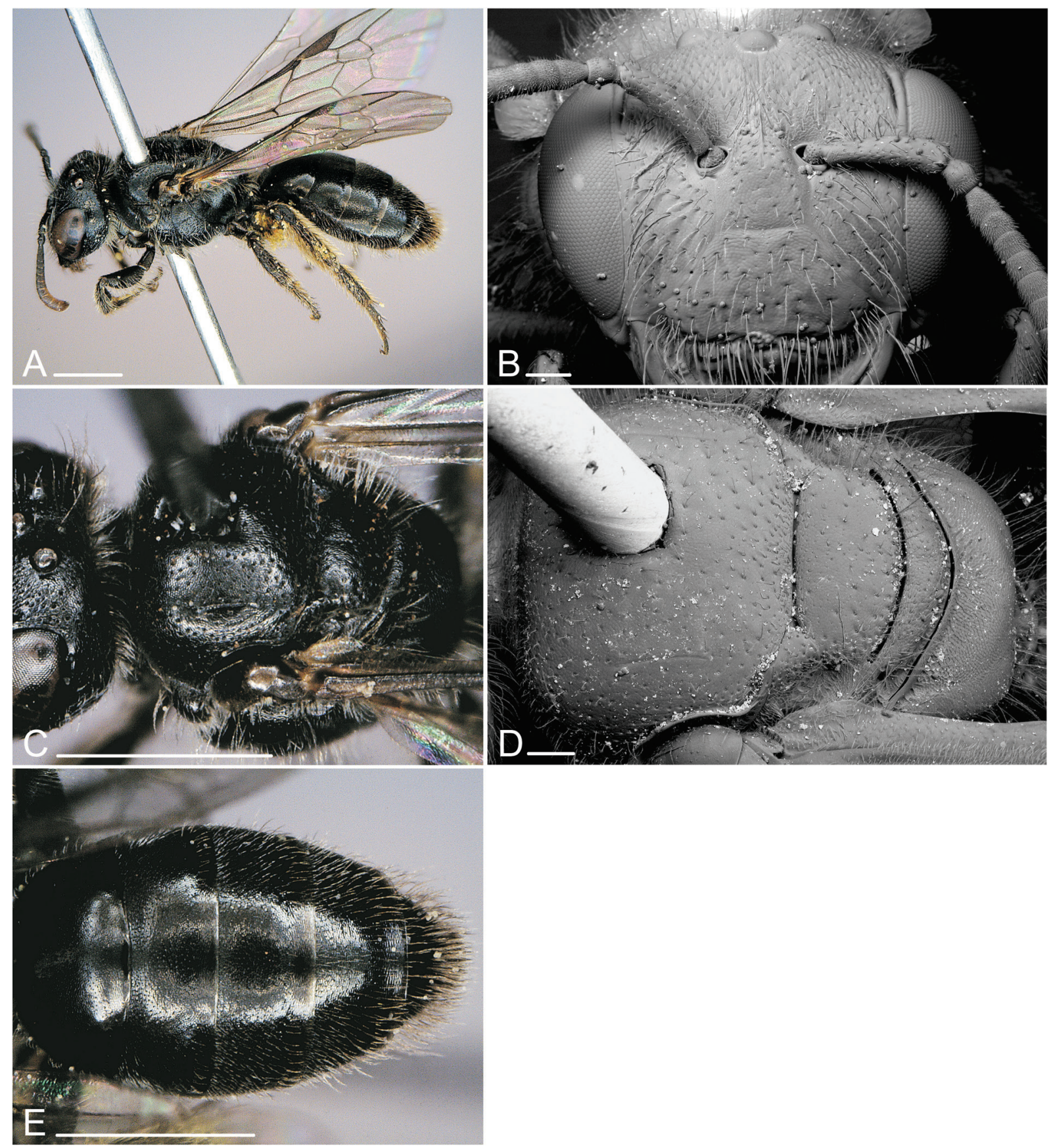

Fig. 26. Scrapter roggeveldi sp. nov., +. A. Lateral view. B. Head (SEM). C. Thorax (dorsal view). D. Thorax (dorsal view, SEM). E. Metasoma (dorsal view). Scale bars: photos: $1 \mathrm{~mm}$, SEM: $0.1 \mathrm{~mm}$. 


\section{Etymology}

Named after the Roggeveld Mountains between Calvinia and Sutherland where this species was found.

Type material ( 1 specimen examined)

\section{Holotype}

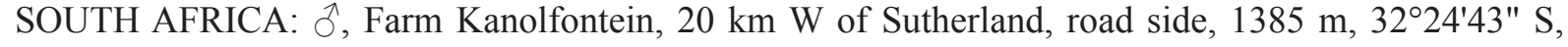
20²7'28" E, 7 Sep. 2012, M. Kuhlmann (RCMK).

\section{Additional material examined}

SOUTH AFRICA: 1 \%, Plateau Hantam Mts., weather stn., $12 \mathrm{~km} \mathrm{~N}$ of Calvinia, $1580 \mathrm{~m}, 31^{\circ} 21^{\prime} 13^{\prime \prime} \mathrm{S}$, 1947'53" E, 11 Sep. 2010, MK (RCMK).

\section{Description}

\section{Female}

Body LENGTH. $4.8 \mathrm{~mm}$.

HEAD. Head wider than long. Integument black, except part of mandibles dark reddish-brown. Face sparsely covered with long, greyish, erect hair (Fig. 26B). Clypeus almost flat with coarse, shallow and sparse punctation ( $\mathrm{i}=1-2 \mathrm{~d}$ ); surface between punctures apically smooth and shiny, basally superficially shagreened and slightly matt (Fig. 26B). Malar area medially narrow, almost linear. Antenna dorsally blackish-brown, ventrally yellowish-brown.

Mesosoma. Integument black. Mesoscutal disc between punctures superficially reticulate but shiny; disc densely ( $i=1-2 \mathrm{~d}$ ), shallowly and finely punctate (Fig. 26C-D). Metanotum slightly shorter than basal area of propodeum, apically with narrow carinate depression (Fig. 26D). Propodeum basally shallowly carinate (Fig. 26D). Mesoscutum, scutellum, metanotum, mesepisternum and propodeum sparsely covered with short, greyish, erect hair (Fig. 26A).

WINGS. Slightly yellowish-brown; wing venation and stigma brown.

LEGS. Integument completely black to dark reddish-brown. Vestiture greyish-white, scopa greyish-white, dorsally blackish (Fig. 26A).

METASOMA. Integument black, apical margins of terga partly and narrowly translucent reddish-brown (Fig. 26E). Disc of T1 without hair; following terga with very short but increasingly more and longer hair; T3 basally with a narrow and very sparse band of very fine, short, erect hair; apical tergal hair bands missing on all terga (Fig. 26E). Prepygidial and pygidial fimbriae greyish-brown. T1 very finely, superficially and sparsely $(\mathrm{i}=2-3 \mathrm{~d}$ ) punctate, between punctures superficially sculptured but shiny; T2-T4 shiny, with dense, fine, superficial punctation; T2-T4 with superficially sculptured, broad apical tergal depression (Fig. 26E).

\section{Male}

BODY LENGTH. $5.0 \mathrm{~mm}$.

HeAD. Head slightly wider than long. Integument black, except mandible partly dark reddish-brown. Face densely covered with long, greyish-white, erect hair. Malar area medially narrow, almost linear. Antenna dorsally dark brown, ventrally yellowish-brown except last three flagellar segments almost completely dark brown (Fig. 27A). 

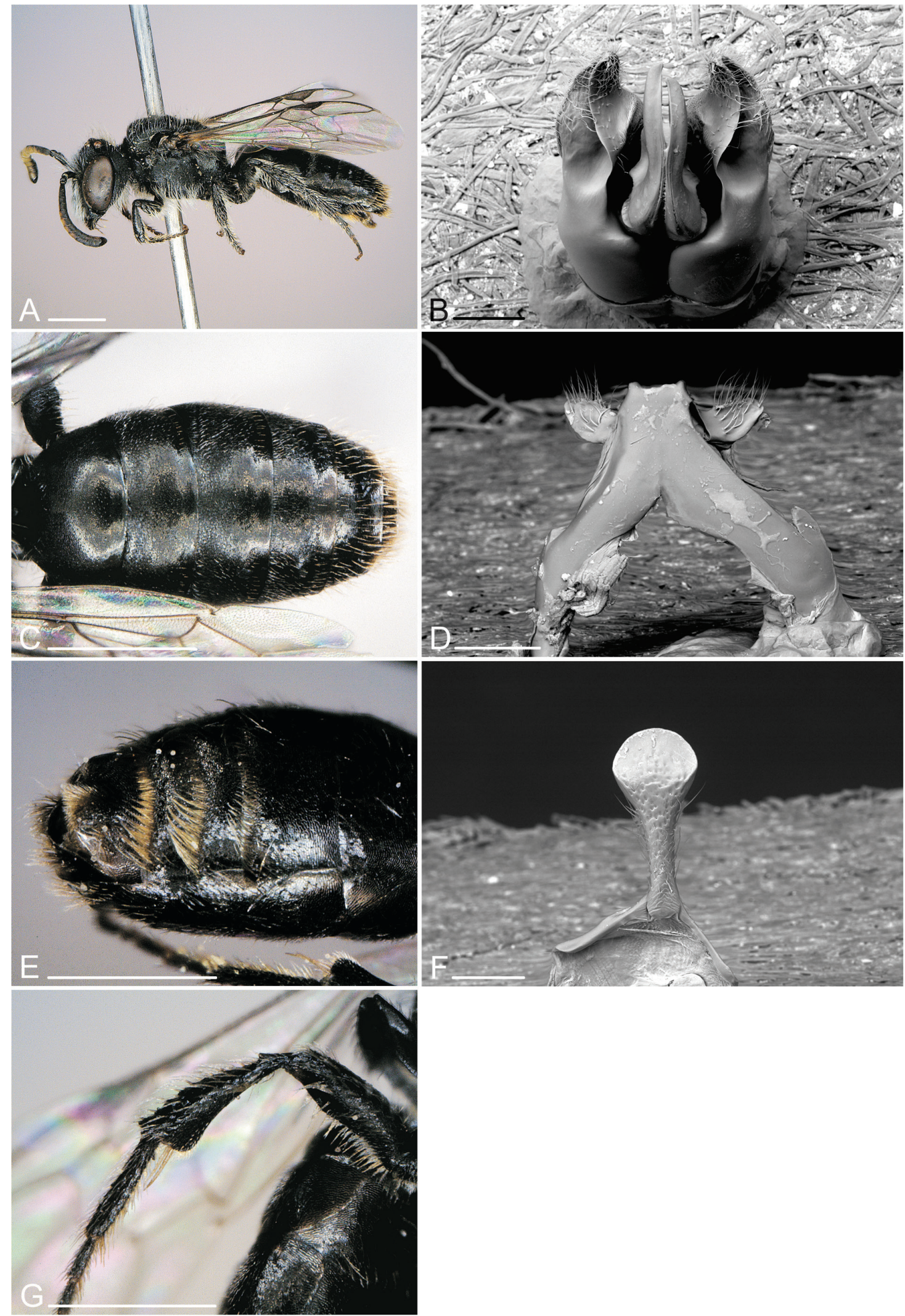

Fig. 27. Scrapter roggeveldi sp. nov., Ô. A. Lateral view. B. Genitalia (dorsal view, SEM). C. Metasoma (dorsal view). D. S7 (dorsal view, SEM). E. Metasoma (ventral view). F. S8, apical end (SEM). G. Hind tibia. Scale bars: photos: $1 \mathrm{~mm}$, SEM: $0.1 \mathrm{~mm}$. 
Mesosoma. Integument black. Mesoscutal disc between punctures strongly reticulate and matt; disc finely, very shallowly and almost invisibly, sparsely punctate $(i=2-3 \mathrm{~d})$. Mesoscutum, scutellum, metanotum, mesepisternum and propodeum covered with long, greyish, erect hair (Fig. 27A).

Wings. Slightly yellowish-brown; wing venation and stigma brown.

LEGS. Integument black or dark reddish-brown (Fig. 27A). Hind tibia inside apically broadened, with an almost rectangular edge (Fig. 27G). Vestiture greyish-white.

Metasoma. Integument black, apical margins of terga partly narrowly translucent dark reddish-brown (Fig. 27C). Discs of T1-T3 without hair, laterally sparsely covered with short, erect greyish-white hair; following terga with sparse and very short but increasingly more and longer hair; apical tergal hair bands missing on all terga (Fig. 27C). T1 and following terga sparsely ( $i=2-3 \mathrm{~d}$ ) and almost invisibly very finely and superficially punctate, between punctures superficially sculptured and shiny; terga with broad, superficially sculptured but shiny apical tergal depression (Fig. 27C). S3 and particularly S4-S5 with long apical hair fringes (Fig. 27E).

Terminalia. Genitalia (Fig. 27B), S7 (Fig. 27D) and terminal plate of S8 (Fig. 27F) as illustrated.

\section{Distribution}

The species is known from higher altitudes at the extreme northern and southern ends of the Roggeveld Mountains.

\section{Floral hosts}

Aizoaceae: Galenia sarcophylla.

\section{Seasonal activity}

September.

Scrapter sittybon Davies, 2005

Figs 28-29

Scrapter sittybon Davies, 2005: 171-173, figs 36-39, holotype § (type locality: Farm Kalkgat, 40 km north-east of Vanrhynsdorp, South Africa) (SANC).

\section{Diagnosis}

The female of $S$. sittybon is here described for the first time. It can be separated from other species of this group by the combination of the following characters: fore tibia entirely or dominantly yellowish to reddish brown, stigma brown, apical margins of metasomal terga broadly brownish translucent (Fig. 28B). The male is characterized by an unmodified antenna, scutum between punctures smooth and shiny, the form of S7 (Fig. 29D), hind basitarsus blackish and hind tibia apically slightly swollen and curved (Fig. 29E).

Material examined (2 specimens)

SOUTH AFRICA: 1 , , W. Cape, Knersvlakte, Sukkulent Karoo, 40 km N of Vanrhynsdorp, Farm

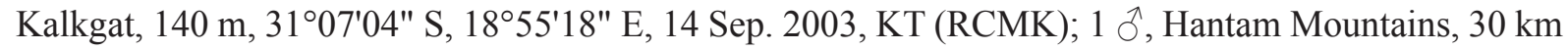
N of Calvinia, 880 m, 31 $12^{\circ} 09^{\prime \prime} \mathrm{S}, 19^{\circ} 50^{\prime} 04^{\prime \prime} \mathrm{E}, 16$ Sep. 2007, KT (RCMK). 


\section{Description}

\section{Female}

Body LeNGTH. 4.9-5.1 mm.

HEAD. Head wider than long. Integument black, except part of mandibles dark reddish-brown. Face sparsely covered with long, greyish, erect hair (Fig. 28C). Clypeus slightly convex with coarse punctation, apically coarser and sparser $(i=1-2 \mathrm{~d})$, basally much finer and denser $(\mathrm{i}<0.5 \mathrm{~d})$; surface between punctures apically smooth and shiny, basally superficially sculptured and slightly matt (Fig.
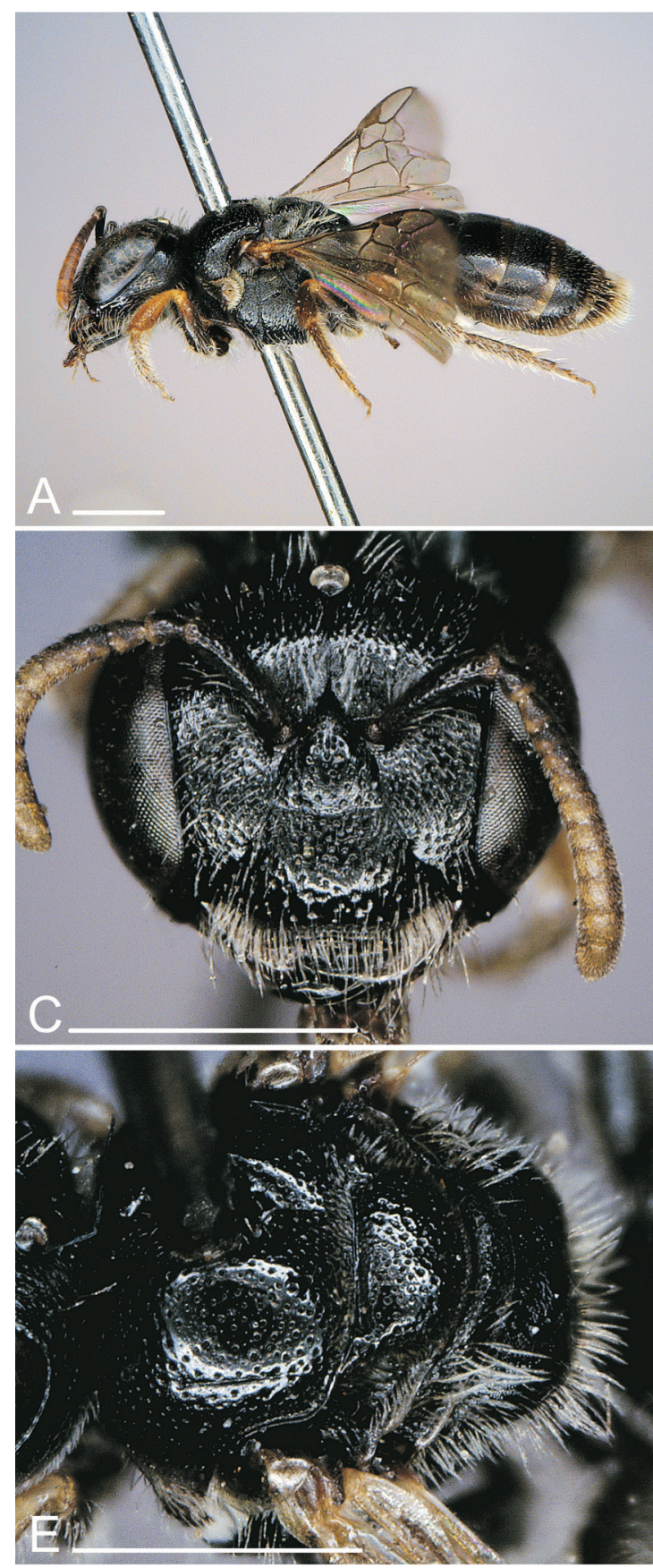
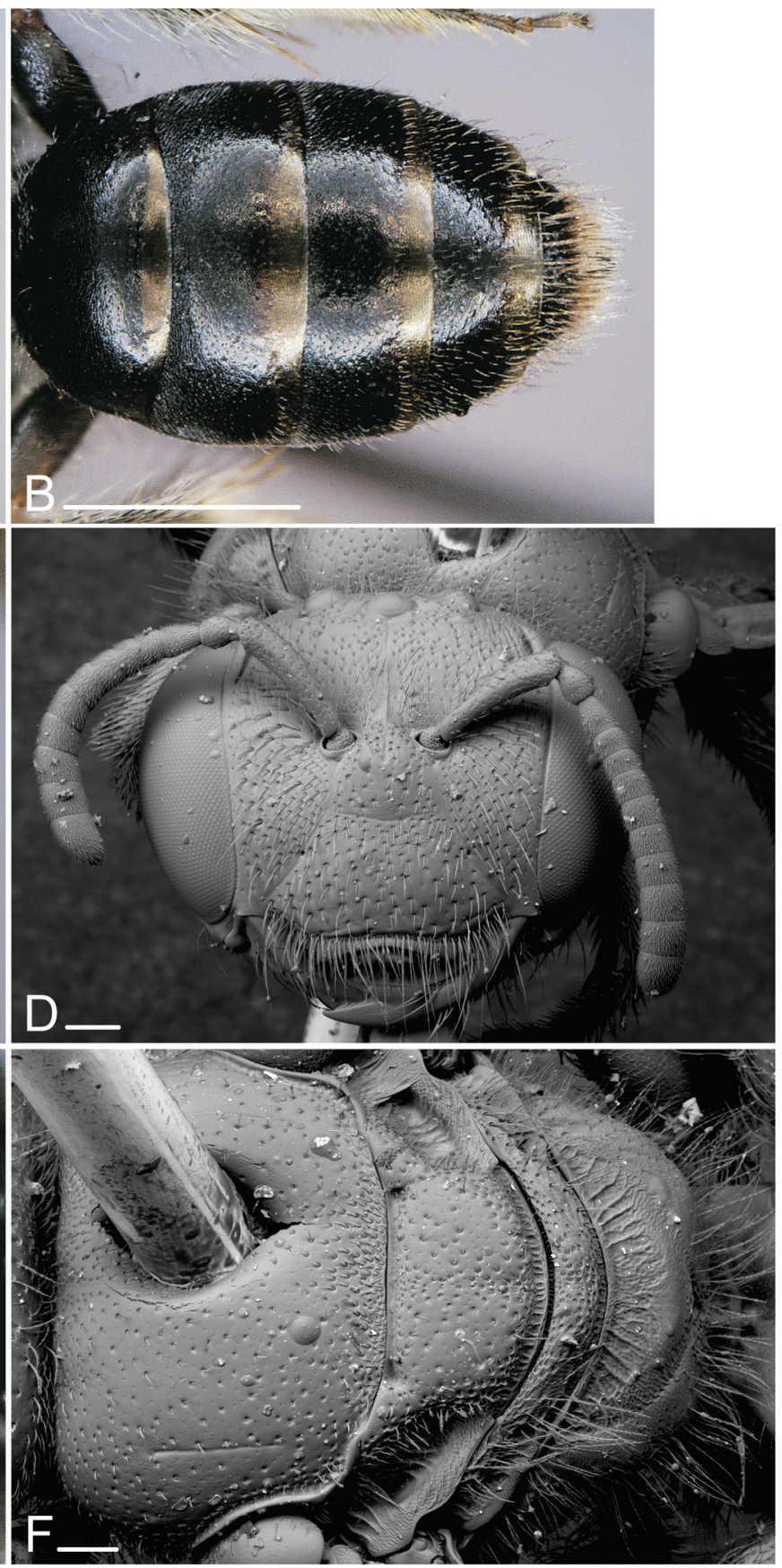

Fig. 28. Scrapter sittybon Davies, 2005, o. A. Lateral view. B. Metasoma (dorsal view). C. Head. D. Head (SEM). E. Thorax (dorsal view). F. Thorax (dorsal view, SEM). Scale bars: photos: $1 \mathrm{~mm}$, SEM: $0.1 \mathrm{~mm}$. 
28C-D). Malar area medially narrow, almost linear. Antenna dorsally darker orange-brown, ventrally more yellowish-brown (Fig. 28C).

Mesosoma. Integument black, except pronotal lobe and tegula yellowish to reddish-brown (Fig. 28A). Mesoscutal disc between punctures polished and shiny; disc densely ( $\mathrm{i}=1-2 \mathrm{~d}$ ) and coarsely punctate, punctures of variable size (Fig. 28E-F). Metanotum about $2 / 3$ as long as basal area of propodeum, apically with distinct carinate depression (Fig. 28F). Propodeum basally coarsely and broadly carinate (Fig. 28F). Mesoscutum, scutellum, metanotum, mesepisternum and propodeum sparsely covered with short, greyish, erect hair (Fig. 28A).

WINGS. Slightly yellowish-brown; wing venation and stigma brown.

LEGS. Integument mostly dark reddish-brown, partly blackish; fore tibia and tarsi almost completely, mid tibia anteriorly and hind tibia basally yellowish-brown (Fig. 28A). Vestiture greyish-white, scopa greyish-white.

Metasoma. Integument black, apical margins of terga broadly translucent yellowish to reddish-brown (Fig. 28B). Discs of T1 and T2 without hair; following terga with very sparse and short but increasingly more and longer hair; apical tergal hair bands missing on all terga (Fig. 28B). Prepygidial and pygidial fimbriae greyish-brown. $\mathrm{T} 1$ and following terga densely $(i=1 \mathrm{~d})$ but almost invisibly very finely and irregularly punctate, between punctures sculptured and slightly matt; T2-T4 with superficially sculptured but shiny, broad apical tergal depression (Fig. 28B).

\section{Male}

Body LENGTH. 4.8-5.2 mm.

HEAD. Head slightly wider than long. Integument black, except mandible partly dark reddish-brown. Face densely covered with long, greyish-white, erect hair. Malar area medially narrow, almost linear. Antennal flagellum either completely yellowish-brown or sometimes dorsally dark brown, particularly the last 3-4 segments dorsally (Fig. 29A).

Mesosoma. Integument black, tegula yellowish-brown. Mesoscutal disc between punctures smooth and shiny; disc densely ( $\mathrm{i}=0.5-1.0 \mathrm{~d}$ ) and finely punctate. Mesoscutum, scutellum, metanotum, mesepisternum and propodeum covered with long, yellowish-grey, erect hair (Fig. 29A).

WINGs. Slightly yellowish-brown; wing venation and stigma brown.

LEGS. Integument mostly dark yellowish to reddish-black, fore tibia and tarsi, mid tibia (except darker spot posteriorly), base of hind tibia and femora apically yellow to yellowish-brown (Fig. 29A). Hind tibia inside apically slightly broadened and curved (Fig. 29E). Vestiture greyish-white.

Metasoma. Integument black, apical margins of terga broadly translucent yellowish to reddish-brown (Fig. 29C). Discs of T1-T3 without hair; following terga with very short and sparse but increasingly more and longer hair; T2-T4 basally with a broad and dense band of very fine but long, erect, silverish hair; apical tergal hair bands missing on all terga (Fig. 29C). T1 and following terga irregularly densely ( $i<0.5-1 \mathrm{~d}$ ) but almost invisibly very finely punctate, between punctures sculptured and slightly matt; terga with broad, superficially sculptured but shiny apical tergal depression (Fig. 29C). S3-S5 with long, sparse apical hair fringes.

Terminalia. Genitalia (Fig. 29B), S7 (Fig. 29D) and terminal plate of S8 (Fig. 29F) as illustrated. 


\section{Distribution}

The species is only known from the Knersvlakte and the Hantam Mountains.

\section{Floral hosts}

Unknown.

\section{Seasonal activity}

September.

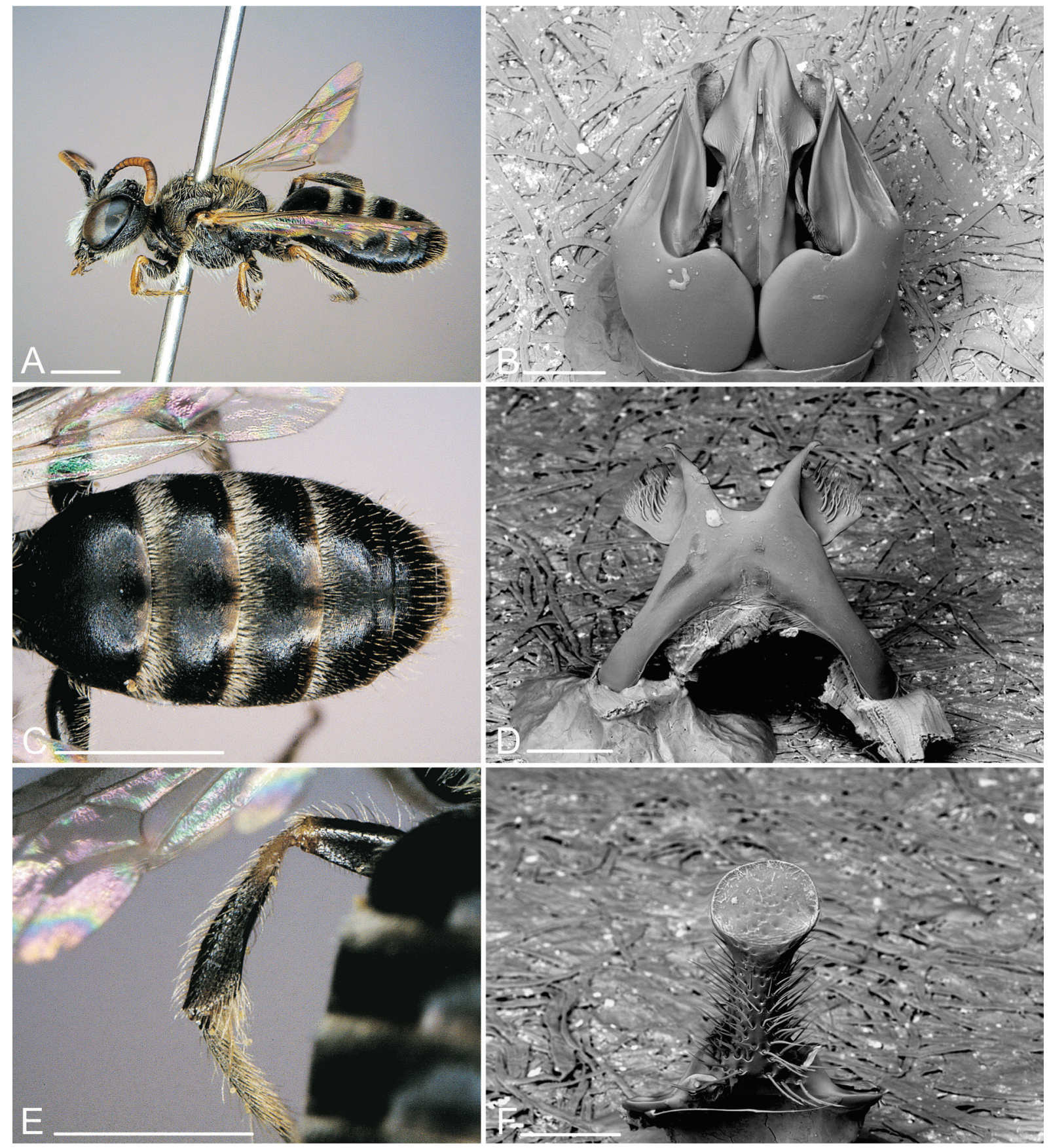

Fig. 29. Scrapter sittybon Davies, 2005, §. A. Lateral view. B. Genitalia (dorsal view, SEM). C. Metasoma (dorsal view). D. S7 (dorsal view, SEM). E. Hind tibia. F. S8, apical end (SEM). Scale bars: photos: $1 \mathrm{~mm}$, SEM: $0.1 \mathrm{~mm}$. 


\section{Scrapter spinipes sp. nov. urn:Isid:zoobank.org:act:33BE1BCA-688F-4E9B-AD5D-5E5AC395B6BF}

Figs $30-31$

\section{Diagnosis}

The female of $S$. spinipes sp. nov. can be separated from other species of this group by the combination of the following characters: supraclypeal area and clypeus densely and distinctly punctate, shiny, only partly superficially sculptured (Fig. 30B), scutum densely and coarsely punctate, basal area of propodeum medially about 1.5 times as long as metanotum (Fig. 30C-D), stigma brown, apical margins of metasomal terga black, terga densely and coarsely punctate (Fig. 30E). The male is characterized by an unmodified antenna, coarsely and densely punctate scutum and metasomal terga (Fig. 31C), hind tibia apically broadened inside, forming a long spine (Fig. 31E), and the form of S7 (Fig. 31D).

\section{Etymology}

Named for the conspicuous apicolateral spine of the male hind tibia.

Type material (63 specimens examined)

\section{Holotype}

SOUTH AFRICA: ${ }^{\Uparrow}, 12 \mathrm{~km}$ NW of Nieuwoudtville, Farm Avontuur, Fynbos, 770 m, 31 ${ }^{\circ} 16^{\prime} 18^{\prime \prime} \mathrm{S}$, 1902'55" E, 18 Aug. 2012, M. Kuhlmann (SANC).

\section{Paratypes}

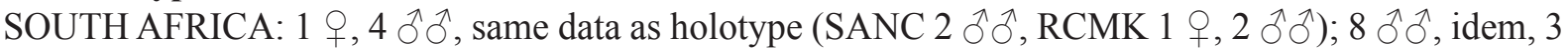
Sep. 2012, MK (RCMK); 1 ㅇ, 1 ○े, Ouberg Pass, 27 km SE of Vanrhynsdorp, Fynbos, 380 m, 31 ${ }^{\circ} 48^{\prime} 07^{\prime \prime}$

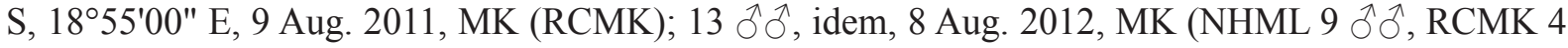

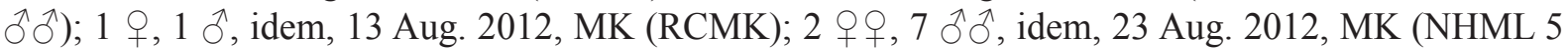

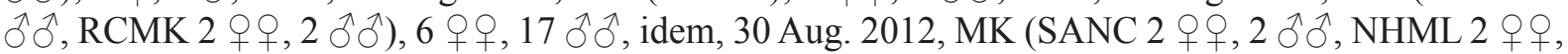

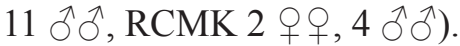

\section{Description}

\section{Female}

BODY LENGTH. 4.8-5.1 mm.

HEAD. Head wider than long. Integument black, except part of mandibles dark reddish-brown. Face sparsely covered with long, greyish, erect hair (Fig. 30B). Clypeus slightly convex with coarse punctation, apically sparse $(i=2-3 \mathrm{~d})$, basally dense $(i=0.5-1 \mathrm{~d})$; surface between punctures apically smooth and shiny, basally superficially shagreened and slightly matt (Fig. 30B). Malar area medially narrow, almost linear. Antenna dorsally blackish-brown, ventrally yellowish-brown.

Mesosoma. Integument black. Mesoscutal disc between punctures superficially reticulate but shiny; disc densely (i $=0.5-1.0 \mathrm{~d}$ ) and coarsely punctate (Fig. 30C-D). Metanotum distinctly shorter than basal area of propodeum, apically with broad carinate depression (Fig. 30D). Propodeum basally distinctly and broadly carinate (Fig. 30D). Mesoscutum, scutellum, metanotum, mesepisternum and propodeum sparsely covered with short, greyish, erect hair (Fig. 30A).

WINGS. Slightly yellowish-brown; wing venation and stigma brown.

LEGS. Integument black to dark reddish-brown; fore tibia basally partly with small yellowish spot. Vestiture greyish-white, scopa greyish-white, dorsally slightly brownish. 
Metasoma. Integument black, apical margins of terga partly narrowly translucent reddish-brown (Fig. $30 \mathrm{E}$ ). Discs of T1 and T2 without hair; following terga with very few and short but increasingly more and longer hair; apical tergal hair bands missing on all terga (Fig. 30E). Prepygidial and pygidial fimbriae dark greyish-brown. T1 densely $(i=1 \mathrm{~d})$ and relatively coarsely but irregularly punctate, between punctures superficially sculptured and shiny; T2-T4 superficially sculptured but shiny, with dense, relatively coarse punctation; T2-T4 with superficially sculptured but shiny, broad apical tergal depression (Fig. 30D).
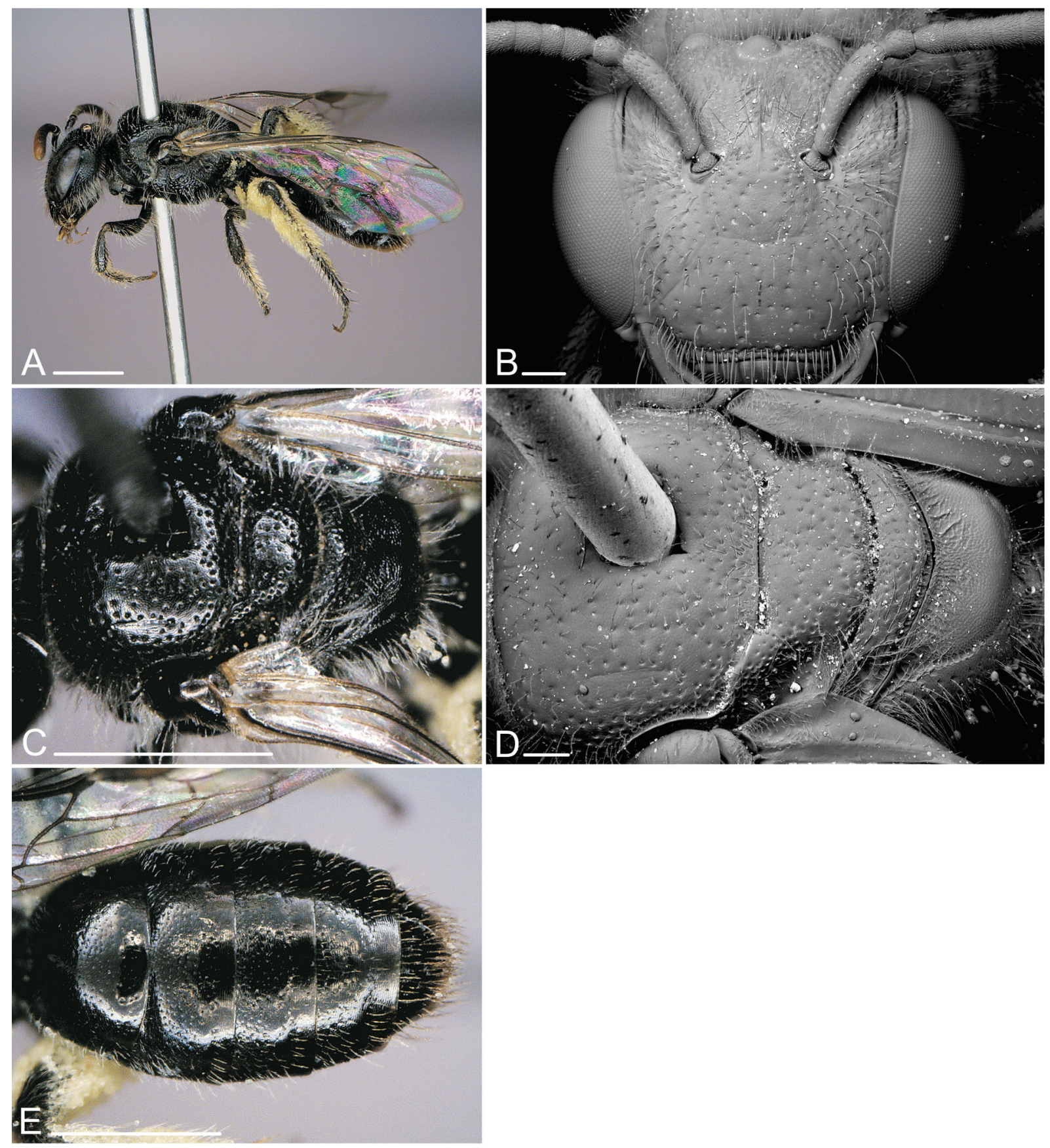

Fig. 30. Scrapter spinipes sp. nov., ․ A. Lateral view. B. Head (SEM). C. Thorax (dorsal view). D. Thorax (dorsal view, SEM). E. Metasoma (dorsal view). Scale bars: photos: $1 \mathrm{~mm}$, SEM: $0.1 \mathrm{~mm}$. 


\section{Male}

Body LeNGTH. 4.8-5.1 mm.

HEAD. Head slightly wider than long. Integument black, except mandible partly dark reddish-brown. Face densely covered with long, greyish-white, erect hair. Malar area medially narrow, almost linear. Antenna dorsally dark brown, ventrally yellowish-brown, sometimes apical flagellar segments completely or largely dark brown (Fig. 31A).

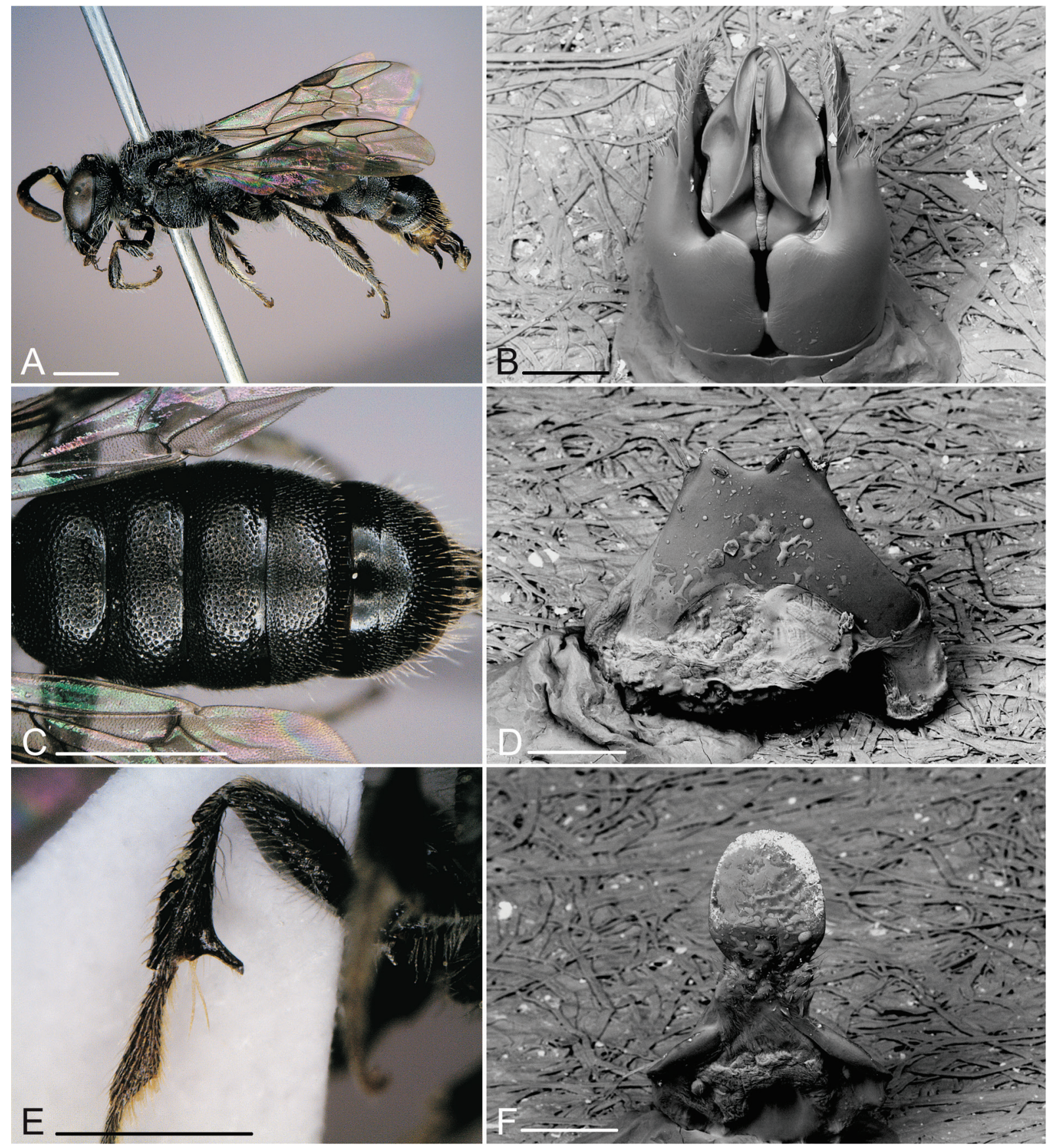

Fig. 31. Scrapter spinipes sp. nov., ふૈ. A. Lateral view. B. Genitalia (dorsal view, SEM). C. Metasoma (dorsal view). D. S7 (dorsal view, SEM). E. Hind tibia. F. S8, apical end (SEM). Scale bars: photos: 1 mm, SEM: $0.1 \mathrm{~mm}$. 
Mesosoma. Integument black. Mesoscutal disc between punctures superficially reticulate and slightly matt; disc densely ( $\mathrm{i}=0.5-1.0 \mathrm{~d}$ ) and very coarsely punctate. Mesoscutum, scutellum, metanotum, mesepisternum and propodeum covered with long, greyish, erect hair (Fig. 31A).

Wings. Slightly yellowish-brown; wing venation and stigma brown.

LEGS. Integument black, fore tibia in the basal half anteriorly yellow (Fig. 31A). Hind tibia inside apically broadened, with a long spine; hind basitarsus subapically broadened (Fig. 31E). Vestiture greyish-white.

METASOMA. Integument black, apical margins of terga partly narrowly translucent reddish-brown (Fig. 31C). Discs of T1-T2 without hair; following terga with very few and short but increasingly more and longer hair; apical tergal hair bands missing on all terga (Fig. 31C). T1 and following terga densely ( $\mathrm{i}<$ $0.5 \mathrm{~d}$ ) and very coarsely punctate, between punctures polished and shiny; terga with narrow, superficially sculptured but shiny apical tergal depression (Fig. 31C). S3 and particularly S4-S5 with long, sparse apical hair fringes.

Terminalia. Genitalia (Fig. 31B), S7 (Fig. 31D) and terminal plate of S8 (Fig. 31F) as illustrated.

\section{Distribution}

The species has only been found on sandy soils in Fynbos of the wider Nieuwoudtville area.

\section{Floral hosts}

Brassicaceae: Heliophila sp., with a strong preference for blue-flowering species.

\section{Seasonal activity}

August-September.

Scrapter ulrikae sp. nov.

urn:1sid:zoobank.org:act:1E428C5C-04E8-4EDC-B815-F6C1BF840F31

Figs $32-33$

\section{Diagnosis}

The female of $S$. ulrikae sp. nov. can be separated from other species of this group by the combination of the following characters: fore tibia dominantly dark blackish-brown, stigma brown, apical margins of metasomal terga broadly brownish translucent, terga between punctures finely sculptured and slightly matt (Fig. 32E). The male is characterized by an unmodified antenna, scutum between punctures smooth and shiny, hind tibia simple, hind basitarsus blackish, T2-T4 basally densely covered with short, erect, silverish hair (Fig. 33C) and the form of S7 (Fig. 33D).

\section{Etymology}

This species is dedicated to my partner Ulrike Gigengack, who enthusiastically collects bees and has accompanied me on many field trips to South Africa.

Type material (33 specimens)

\section{Holotype}

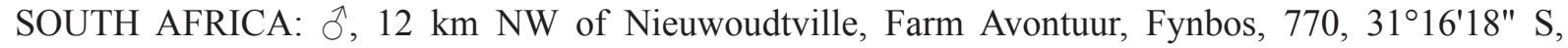
1902'55" E, 18 Aug. 2012, M. Kuhlmann (SANC). 


\section{Paratypes}

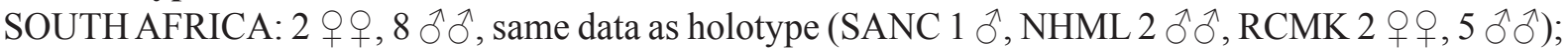
4 웅, idem, 25 Aug. 2010, MK (SANC 3 우, RCMK 1 우); 8 $\widehat{\jmath}$, idem, 16 Aug. 2011, MK (RCMK); 1 , idem, 17 Aug. 2011, H. Erhardt (RCMK); 2 우, idem, 5 Sep. 2012, H. Erhardt (RCMK); 1 , N. Cape, Fynbos, 15 km NW of Nieuwoudtville, Farm Engelsepunt, 830 m, 31¹4'31" S, 1859'08" E, 6 Aug. 2003, KT (NHML); 2 + $ᄋ$, idem, 28 Aug. 2003, KT (NHML); 1 ㅇ, 24 Sep. 2003, KT (NHML); 1 ㅇ, N. Cape, Nieuwoudtville, Glenlyon, Renosterveld, 700 m, 312ㄴ'03" S, 1908'34" E, 10 Sep. 2003,
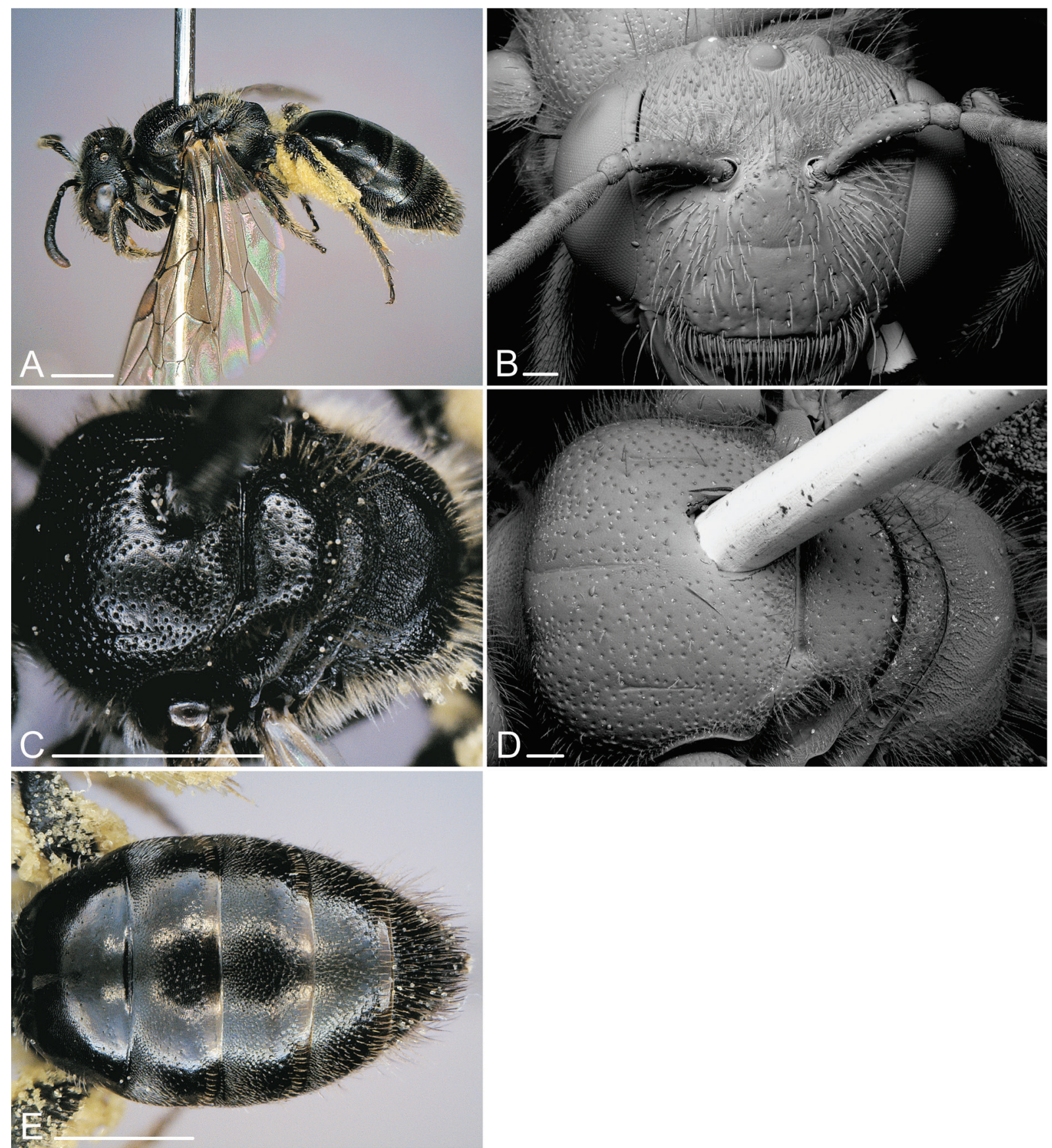

Fig. 32. Scrapter ulrikae sp. nov., ․ A. Lateral view. B. Head (SEM). C. Thorax (dorsal view). D. Thorax (dorsal view, SEM). E. Metasoma (dorsal view). Scale bars: photos: $1 \mathrm{~mm}$, SEM: $0.1 \mathrm{~mm}$. 
MK (RCMK); 2 우, Farm Kanolfontein, $20 \mathrm{~km} \mathrm{~W}$ of Sutherland, road side, 1385 m, 32²4'43" S, $20^{\circ} 27^{\prime} 28^{\prime \prime}$ E, 7 Sep. 2012, MK (RCMK).

\section{Description}

Female

Body LeNGTH. 6.0-6.4 mm.

HEAD. Head wider than long. Integument black, except part of mandibles dark reddish-brown. Face sparsely covered with long, greyish, erect hair (Fig. 32B). Clypeus slightly convex with coarse and dense punctation ( $\mathrm{i}=0.5-2 \mathrm{~d})$; surface between punctures smooth and shiny (Fig. 32B). Malar area medially narrow, almost linear. Antenna dorsally blackish-brown, ventrally yellowish-brown.

Mesosoma. Integument black, tegula dark reddish-brown. Mesoscutal disc between punctures superficially reticulate but shiny; disc densely $(\mathrm{i}=0.5-1.0 \mathrm{~d})$ and coarsely punctate (Fig. 32C-D). Metanotum only about half as long as basal area of propodeum, apically with narrow carinate depression (Fig. 32D). Propodeum basally coarsely and broadly carinate (Fig. 32D). Mesoscutum, scutellum, metanotum, mesepisternum and propodeum sparsely covered with short, yellowish-grey, erect hair (Fig. 32A).

Wings. Slightly yellowish-brown; wing venation and stigma brown.

LEGS. Integument black to dark reddish-brown; fore tibia anteriorly in basal half with small yellowish spot. Vestiture greyish-white, scopa greyish-white, dorsally dark brown (Fig. 32A).

Mеталома. Integument black, apical margins of terga broadly or narrowly translucent reddish-brown, sometimes yellowish (Fig. 32E). Discs of T1 and T2 without hair; following terga with very few and short but increasingly more and longer hair; apical tergal hair bands missing on all terga (Fig. 32E). Prepygidial and pygidial fimbriae blackish-brown. T1 almost impunctate, superficially sculptured and shiny; T2-T3 basally densely sculptured, matt and finely but densely punctate, apically almost polished and shiny, with sparse but larger punctation; T2-T4 with polished broad apical tergal depression (Fig. $32 \mathrm{E})$.

\section{Male}

BODY LENGTH. 5.5-5.8 mm.

HEAD. Head slightly wider than long. Integument black, except mandible partly dark reddish-brown. Face densely covered with long, greyish-white, erect hair. Malar area medially narrow, almost linear. Antenna dorsally dark brown, ventrally yellowish-brown (Fig. 33A).

Mesosoma. Integument black. Mesoscutal disc between impunctate and densely sculptured, completely matt. Mesoscutum, scutellum, metanotum, mesepisternum and propodeum covered with long, greyish, erect hair (Fig. 33A).

WINGS. Slightly yellowish-brown; wing venation and stigma brown.

LEGS. Integument black, fore tibia anteriorly yellow, base of mid and hind tibia with small yellow spot (Fig. 33A). Hind tibia unmodified. Vestiture greyish-white.

METASOMA. Integument black, apical margins of terga partly narrowly translucent yellowish to reddishbrown (Fig. 33C). Disc of T1 and basal half of T2-T4 densely covered with band of very fine, short, erect, silverish hair; apical tergal hair bands missing on all terga (Fig. 33C). T1 almost impunctate, sculptured and matt, following terga densely $(i<0.5-1 \mathrm{~d})$ and finely punctate, between punctures polished or 
superficially sculptured, shiny to slightly matt; terga with narrow, polished to superficially sculptured but shiny apical tergal depression (Fig. 33C). Sterna without conspicuous long apical hair fringes.

Terminalia. Genitalia (Fig. 33B), S7 (Fig. 33D) and terminal plate of S8 (Fig. 33F) as illustrated.

\section{Distribution}

The species is known from sandstone Fynbos around Nieuwoudtville to the vicinity of Sutherland.
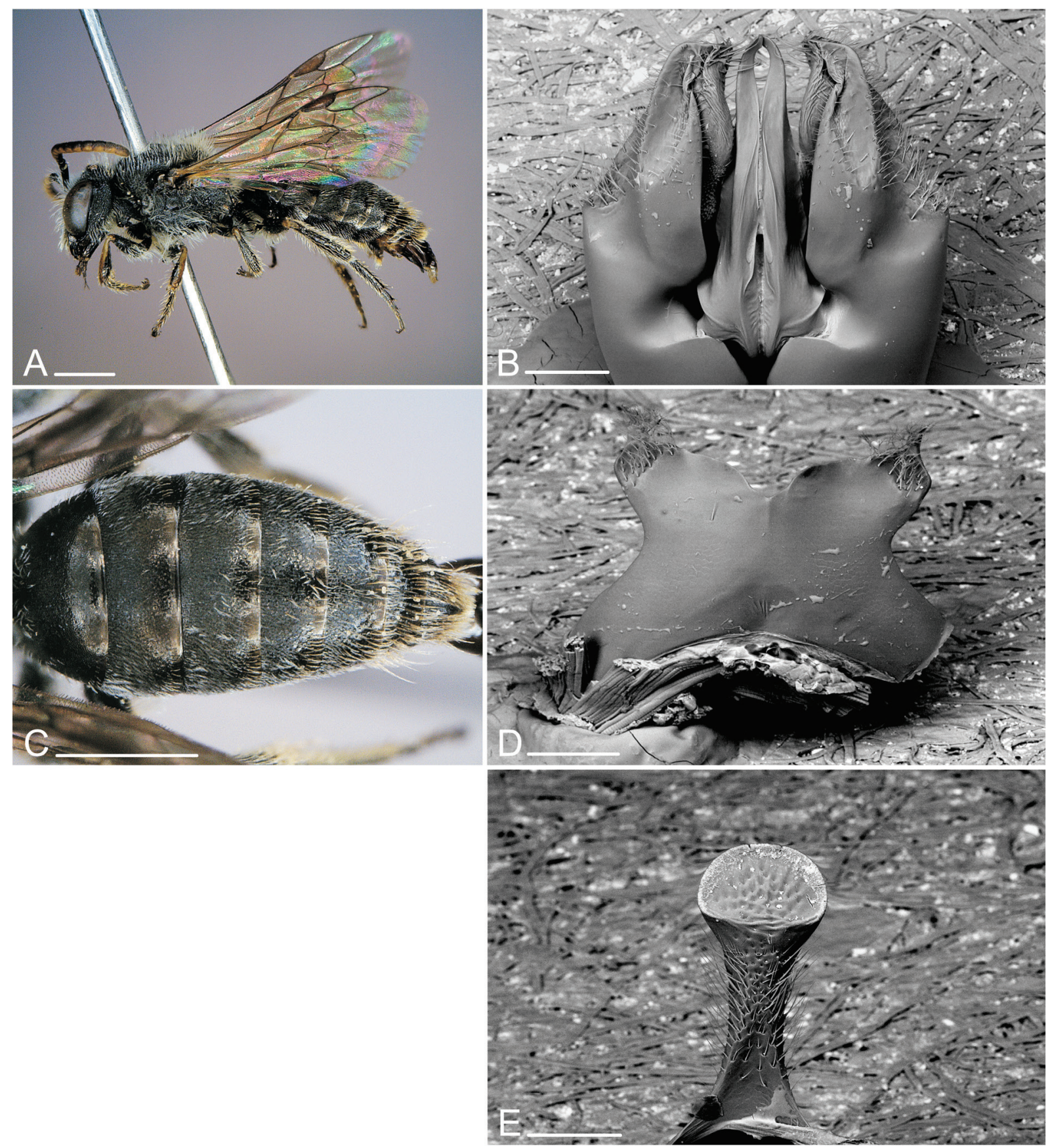

Fig. 33. Scrapter ulrikae sp. nov., ô. A. Lateral view. B. Genitalia (dorsal view, SEM). C. Metasoma (dorsal view). D. S7 (dorsal view, SEM). E. S8, apical end (SEM). Scale bars: photos: $1 \mathrm{~mm}$, SEM: 0.1 $\mathrm{mm}$. 


\section{Floral hosts}

Brassicaceae: white and blue Heliophila sp.

\section{Seasonal activity}

August-September.

\section{Key to species of "euryglossiform" Scrapter}

Due to their small size, the similarity of many species and the subtle, often gradual differences between some of them, identification can be very difficult, particularly in females. For males it is generally recommended to dissect genitalia and hidden sterna S7 and S8.

\section{Females}

The females of $S$. glareus and S. minutissimus sp. nov. are unknown.

1 Stigma bright yellow (Fig. 11A) .................................... luteistigma sp. nov.

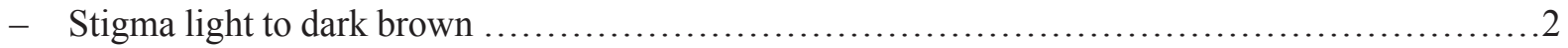

2 Apical tergal margins broadly brownish to yellowish translucent (Figs 1B, 28B, 32E); larger

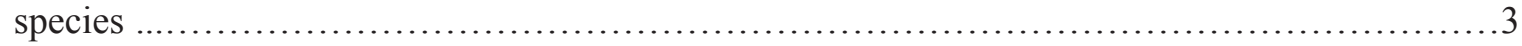

- Apical tergal margins black or very narrowly brownish translucent; smaller species .............5

3 Punctation on basal part of clypeus much finer than apically (Fig. 28C-D); foretibia entirely or predominantly yellowish to reddish brown (Fig. 28A) .........................S. sittybon Davies

- Punctation on clypeus more evenly sized (Figs 1C-D, 32B); foretibia dominantly dark blackishbrown (Figs 1A, 32A) ...................................................................

4 Metasomal terga between punctures smooth and shiny (Fig. 1B); clypeus distinctly convex (Fig.

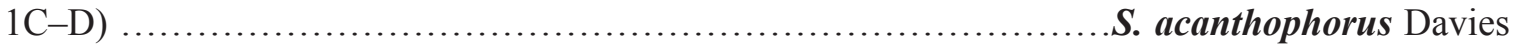

- Metasomal terga between punctures finely sculptured, slightly matt (Fig. 32E); clypeus more flat (Fig. 32B)

S. ulrikae sp. nov.

5 Scutum sparsely and finely punctured, looking almost impunctate and shiny (Figs 6E-F, 8E-F) .....6

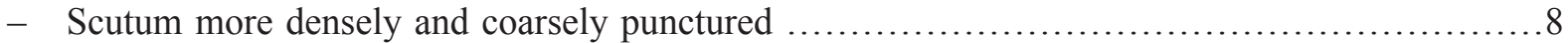

6 Supraclypeal area, clypeus (Fig. 6C-D) and mesepisternum only partially and superficially

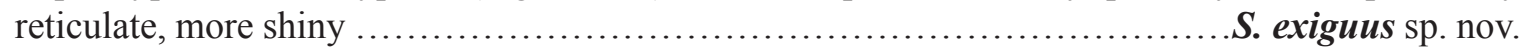

- Supraclypeal area apically, clypeus basally (Fig. 8C-D) and mesepisternum extensively and strongly

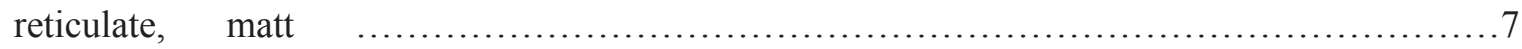

7 Facial fovea slightly shorter than in S. gessorum sp. nov. (Fig. 4A-B); a variable species with respect to surface sculture and punctation (Figs 3C-F, 4A-D) ...........S. albitarsis (Friese)

- Facial fovea slightly longer than in S. albitarsis (Fig. 8D) ................ gessorum sp. nov.

8 Clypeus and supraclypeal area matt, strongly reticulate, very sparsely, finely and shallowly punctate

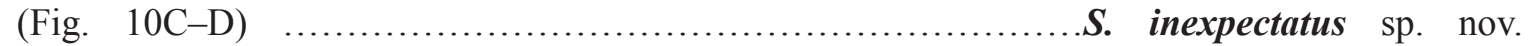

- Clypeus and supraclypeal area more shiny, only partly or superficially sculptured, punctation

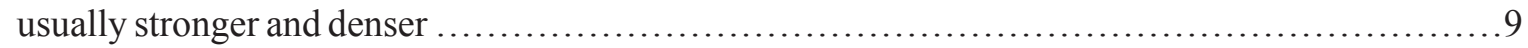

9 Metasomal terga finely and densely punctate, between punctures completely smooth and shiny (Fig. 18B) S. nigerrimus sp. nov. 
- Metasomal terga either impunctate or with more dispersed/coarser punctation; if punctation is similar (some specimens of $S$. punctatus sp. nov.) then terga at least basally with superficial sculpture and slightly matt

10 Metasomal terga impunctate (Figs 19E, 25E); scutum distinctly reticulate and shallowly punctate (Figs 19B, 25C-D)

- Metasomal terga punctate, sometimes punctures minute (Fig. 26E); scutum either without reticulation or only very weakly reticulate

11 Basal area of propodeum distinctly and largely carinate (Fig. 19B) .....S. nigritarsis sp. nov.

- Basal area of propodeum along anterior margin indistinctly carinate (Fig. 25C-D)

S. pygmaeus sp. nov.

12 Scutum covered with large punctures (Figs 23C-D, 30C-D) ............................

- Scutum covered with smaller punctures (Figs 14E-F, 15C-D, 16E-F, 21C-F, 26C-D) .......14

13 Basal area of propodeum shorter, medially only slightly longer than metanotum; few, short and indistinct carinae (Fig. 23C-D)

S. punctatus sp. nov.

- Basal area of propodeum longer, medially about 1.5 times as long as metanotum; carinae longer and more distinct than in S. punctatus (Fig. 30C-D) S. spinipes sp. nov.

14 Punctation of metasomal terga minute, almost invisible (Fig. 26E)

S. roggeveldi $\mathrm{sp}$. nov.

- Punctation of metasomal terga much coarser and clearly visible (Figs 14B, 15E, 16B, 21G-H) ...15

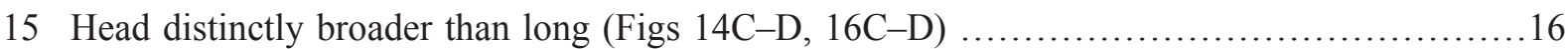

- Head about as long as broad (Figs 15B, 21B) ............................................

16 Clypeus, supraclypeal area and T1 mostly polished and shiny, only partially very finely and superficially sculptured, slightly matt (Fig. 14B-D) ................... minutuloides sp. nov.

- Clypeus, supraclypeal area and T1 (particularly anteriorly) mostly finely sculptured and matt

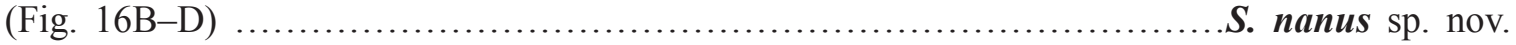

17 Metanotum apically more evenly rounded, without distinct carinate depression (Fig. 15D); fore tibia anteriorly largely yellowish-brown ....................... minutus sp. nov.

- Metanotum apically with a carinate depression (Fig. 21D, F); fore tibia anteriorly blackish, only at the base with a small yellowish spot

S. papkuilsi sp. nov.

\section{Males}

The males of $S$. gessorum sp. nov., S. inexpectatus sp. nov., S. minutuloides sp. nov., S. minutus sp. nov., S. nigerrimus sp. nov. and $S$. pygmaeus sp. nov. are unknown.

1 Antennal flagellum medially broadened, entirely orange (Fig. 12B); stigma bright yellow (Fig. 12A); S7 and S8 as in Fig. 12D, F .

S. luteistigma sp. nov.

- Antennal flagellum not broadened, only partly yellowish; stigma darker $\ldots \ldots \ldots \ldots \ldots \ldots \ldots \ldots \ldots . .2$

2 Antenna long, last flagellar segment about twice as long as wide (Fig. 24E); S7 and S8 as in Fig. $24 \mathrm{D}, \mathrm{F}$ S. punctatus sp. nov.

- Antenna shorter, last flagellar segment at most 1.5 times as long as wide ....

3 Hind tibia inside apically broadened, pointed (Fig. 22E) or forming either a spine (Figs 2E, 31E) or a \pm right angle (Fig. $27 \mathrm{G}$ ) 
- Hind tibia unmodified, if apically broadened then without spine or \pm sharp edge

4 Hind tibia inside apically forming a \pm right angle (Fig. 27G); S4-S5 with conspicuously long apical hair fringes (Fig. 27E); S7 and S8 as in Fig. 27D, F .......S. roggeveldi sp. nov.

- Hind tibia inside apically pointed (Fig. 22E) or forming a spine (Figs 2E, 31E) ................

5 Hind tibia inside apically pointed (Fig. 22E); scutum and metasomal terga finely punctate (Fig. 22C); S7 and S8 as in Fig. 22D, F .................................... papkuilsi sp. nov.

- Hind tibia inside apically with spine (Figs 2E, 31E); scutum and metasomal terga coarsely punctate (Figs 2C, 31C)

6 Hind tibia apically with longer spine (Fig. 31E); metasomal terga densely punctate (Fig. 31C); S7 and S8 as in Fig. 31D, F ......................................... spinipes sp. nov.

- Hind tibia apically with shorter spine (Fig. 2E); metasomal terga sparsely punctate (Fig. 2C); S7

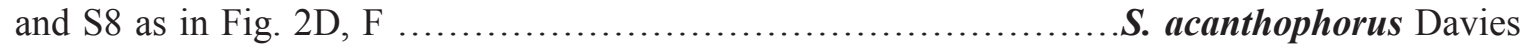

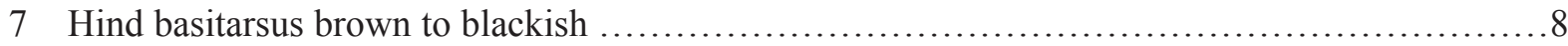

- Hind basitarsus yellowish ............................................................. 11

8 Hind tibia apically slightly swollen and curved (Fig. 29E); scutum between punctures smooth and shiny; S7 and S8 as in Fig. 29D, F .................................. sittybon Davies

- Hind tibia unmodified; scutum between punctures sculptured and matt ........................

9 Basal half of T2-T4 densely covered with short, erect, silverish hair (Fig 33C); S7 and S8 as in Fig. 33D-E ................................................................. ulrikae sp. nov.

- Basal half of T2-T4 almost hairless (Figs 17C, E, 20C) ................................... 10

10 Discs of metasomal terga impunctate, very finely and regularly sculptured (Fig. 20C); S7 and S8

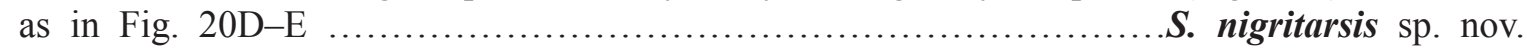

- Discs of metasomal terga partly punctate, strongly to heavily and irregularly sculptured (Fig. 17C, E); S7 and S8 as in Fig. 17D, F .................................... nanus sp. nov.

11 Hind tibia yellow with a brown spot on the back side (Fig. 9A, C); S7 and S8 as in Fig. 9D-E

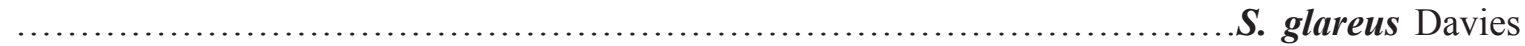

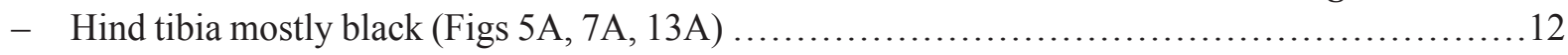

The males of the following three species are very similar and can be best separated by S7 and S8.

12 S7 without membraneous apicolateral lobes (Fig. 13D); S8 as in Fig. 13E ...S. minutissimus sp. nov.

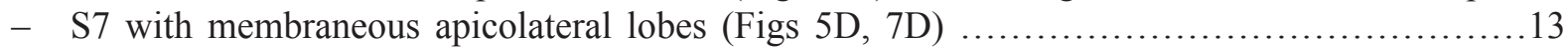

13 S7 apically with emargination slightly broader and shallower (Fig. 5D) .....S. albitarsis (Friese)

- S7 apically with emargination slightly narrower and deeper (Fig. 7D) .......S. exiguus sp. nov.

\section{Discussion}

The present study includes the description of 16 new species of the bee genus Scrapter, quadrupling the number of taxa known from this species-group. Almost all descriptions are based on specimens collected over the last ten years in western South Africa, highlighting the importance of additional fieldwork even in relatively well sampled regions. The description of the "euryglossiform" Scrapter species-group and discovery of additional species might also allow for a better future understanding of the phylogenetic relationships of the Scraptrinae. "Euryglossiform" Scrapter resemble some Australian 
Euryglossinae, potentially reflecting a sister-group relationship of both subfamilies as suggested by Almeida \& Danforth (2009). However, a more comprehensive taxonomic and phylogenetic study of Scrapter is required, including the full extent of the (undescribed) diversity in other species-groups, to understand intrageneric and sister-group relationships.

\section{Acknowledgements}

I am very much indebted to the following colleagues (in alphabetical order of collection acronyms) who made specimens under their curation available for this study: S.K. Gess and †F.W. Gess (AMGS), B.N. Danforth (CUIC), T. Griswold (EMUS), L. Packer (PCYU), C.D. Eardley (SANC) and F. Koch (ZMHB). Northern Cape Nature Conservation Service and the Western Cape Nature Conservation Board (CapeNature) are gratefully acknowledged for giving their permission to collect bees. The following land owners/managers very much facilitated research by kindly giving access to their properties and granting permission for bee collecting: O. Huyser, Manager of the Table Mountain Fund, and N. Oettle, Managing Director of Avontuur Sustainable Agriculture (Farm Avontuur), E. Marinus, Curator of the Hantam National Botanical Garden, W. van Wyk (Farm Papkuilsfontein), H. Nel (Farm Engelsepunt), B. Nel (Farm Vanrhyn's Hoek). Ulrike Gigengack, Münster (Germany) and H. Erhardt, Edewecht (Germany), actively and enthusiastically supported fieldwork and added many valuable specimens to the collection. The insightful comments of two anonymous reviewers helped to improve the paper.

\section{References}

Almeida E.A.B. \& Danforth B.N. 2009. Phylogeny of colletid bees (Hymenoptera: Colletidae) inferred from four nuclear genes. Molecular Phylogenetics and Evolution 50: 290-309.

Ascher J.S. \& Engel M.S. 2006. On the availability of family-group names based on Scrapter (Hymenoptera: Colletidae). Entomological News 117: 117-119.

Brauns H. 1929. Neue und auffallende Apiden aus Süd-Afrika. Zeitschrift für Wissenschaftliche Insektenbiologie 24: 130-143.

Cockerell T.D.A. 1916. Descriptions and records of bees-LXXII. Annals and Magazine of Natural History (8)17: 428-435. http://www.biodiversitylibrary.org/item/61721\#page/440/mode/1up

Cockerell T.D.A. 1921. Descriptions and records of bees-XC. Annals and Magazine of Natural History (9)7: 201-212. http://www.biodiversitylibrary.org/item/53357\#page/227/mode/1up

Davies G.B.P. \& Brothers D.J. 2006. Morphology of Scrapter (Hymenoptera: Anthophila: Colletidae), with description of three new species and taxonomic status of five Cockerell taxa. African Invertebrates 47: $135-183$.

Davies G.B.P., Eardley C.D. \& Brothers D.J. 2005. Eight new species of Scrapter (Hymenoptera: Apoidea: Colletidae), with descriptions of $S$. albifumus and S. amplispinatus females and a major range extension of the genus. African Invertebrates 46: 141-179.

Eardley C.D. 1996. The genus Scrapter Lepeletier \& Serville (Hymenoptera: Colletidae). African Entomology 4: 37-92.

Eardley C.D. \& Urban R. 2010. Catalogue of Afrotropical bees (Hymenoptera: Apoidea: Apiformes). Zootaxa 2455: 1-548.

Engel, M.S. 2005. Family-group names for bees (Hymenoptera: Apoidea). American Museum Novitates 3476: 1-33.

Friese H. 1909. Die Bienen Afrikas nach dem Stande unserer heutigen Kenntnisse. In: Schultze L. (ed.) Zoologische und Anthropologische Ergebnisse einer Forschungsreise im westlichen und 
zentralen Südafrika ausgeführt in den Jahren 1903-1905, Band 2. Denkschriften der Medizinischnaturwissenschaftlichen Gesellschaft zu Jena 14: 83-476, pls. IX-X.

Friese H. 1912. Neue und wenig bekannte Bienen Süd-Afrikas. Archiv für Naturgeschichte, Abt. A 78(5): 181-189.

Germishuizen G. \& Meyer N.L. (eds) 2003. Plants of Southern Africa: an Annotated Checklist. Strelitzia, 14, National Botanical Institute, Pretoria.

Harris R.A. 1979. A glossary of surface sculpturing. Occasional Papers in Entomology 28: 1-31.

Kuhlmann M. 2009. Patterns of diversity, endemism and distribution of bees (Insecta: Hymenoptera: Anthophila) in southern Africa. South African Journal of Botany 75: 726-738.

Kuhlmann M. \& Eardley C.D. 2012. Pollen resources of non-Apis bees in southern Africa. In: Patiny S. (ed.) Evolution of Plant-Pollinator Relationships: 439-456. Cambridge University Press, Cambridge.

Lepeletier de Saint-Fargeau A.L.M. 1841. Histoire Naturelle des Insectes-Hymenopteres. Vol. 2, Roret, Paris.

Lepeletier de Saint-Fargeau A.L.M. \& Serville A. 1828. In: M. Diderot et al. (eds) Encyclopedie Méthodique, Histoire Naturelle. Insectes, Vol. 10: 345-832. Paris.

Melo G.A.R. \& Gonçalves R.B. 2005. Higher level bee classifications. Revista Brasileira de Zoologia 22: $153-159$.

Michener C.D. 1997. Genus-group names of bees and supplemental family group names. Scientific Papers, Natural History Museum, University of Kansas 1: 1-81.

Michener C.D. 2007. The Bees of the World. $2^{\text {nd }}$ edition, Johns Hopkins University Press, Baltimore, Maryland.

Munyuli M.B.T. 2013. Climatic, regional land-use intensity, landscape, and local variables predicting best the occurrence and distribution of bee community diversity in various farmland habitats in Uganda. Psyche volume 2013, Article ID 564528: 1-38. http://dx.doi.org/10.1155/2013/564528

Sandhouse G.A. 1943. The type species of the genera and subgenera of bees. Proceedings of the United States National Museum 92: 519-619. http://www.biodiversitylibrary.org/item/53694\#page/585/ $\underline{\text { mode/1up }}$

Vachal, J. 1897. Eclaircissements sur de genre Scrapter et description d'une espèce nouvelle de Dufourea. Bulletin de la Société Entomologique de France 1897: 61-64.

Manuscript received: 1 May 2014

Manuscript accepted: 1 July 2014

Published on: 5 September 2014

Topic editor: Koen Martens

Desk editor: Kristiaan Hoedemakers

Printed versions of all papers are also deposited in the libraries of the institutes that are members of the EJT consortium: Muséum National d'Histoire Naturelle, Paris, France; Botanic Garden Meise, Belgium; Royal Museum for Central Africa, Tervuren, Belgium; Natural History Museum, London, United Kingdom; Royal Belgian Institute of Natural Sciences, Brussels, Belgium; Natural History Museum of Denmark, Copenhagen, Denmark. 